\title{
POLÍTICAS MACROECONÔMICAS E SEUS EFEITOS SOBRE AS IMPORTAÇÕES DE LÁCTEOS NO BRASIL
}

\author{
DiOne Fraga dos SANTOS
}

Tese apresentada à Escola Superior de Agricultura “Luiz de Queiroz”, Universidade de São Paulo, para obtenção do título de Doutor em Ciências, Área de Concentração: Economia Aplicada.

P I R A C I C A B A

Estado de São Paulo - Brasil

Dezembro - 2004 


\title{
POLÍTICAS MACROECONÔMICAS E SEUS EFEITOS SOBRE AS IMPORTAÇÕES DE LÁCTEOS NO BRASIL
}

\author{
Dione Fraga dos SANTOS \\ Bacharel em Ciências Econômicas \\ Orientador: Prof. Dr. GERALDO SANT'ANA DE CAMARGO BARROS \\ Tese apresentada à Escola Superior de \\ Agricultura "Luiz de Queiroz", Universidade de \\ São Paulo, para obtenção do título de Doutor em \\ Ciências, Área de Concentração: Economia \\ Aplicada.
}

P I R A C I C A B A

Estado de São Paulo - Brasil

Dezembro - 2004 
Dados Internacionais de Catalogação na Publicação (CIP)
DIVISÃO DE BIBLIOTECA E DOCUMENTAÇÃO - ESALQ/USP

Santos, Dione Fraga dos

Políticas macroeconômicas e seus efeitos sobre as importações de lácteos no Brasil / Dione Fraga dos Santos. - - Piracicaba, 2004.

$121 \mathrm{p}$.

Tese (Doutorado) - - Escola Superior de Agricultura Luiz de Queiroz, 2004.

Bibliografia.

1. Comércio agrícola 2. Economia internacional 3. Leite 4. Política econômica I. Título

CDD 338.1771

"Permitida a cópia total ou parcial deste documento, desde que citada a fonte - $\mathrm{O}$ autor" 
A elaboração deste livro foi para o autor uma longa luta de libertação, e sua leitura deve ser o mesmo para a maioria dos leitores se as investidas do autor sobre eles tiveram sucesso - uma luta de libertação das formas habituais de pensamento e de expressão. As idéias aqui expressas tão laboriosamente são bastante simples e deveriam ser óbvias. A dificuldade não está nas novas idéias, mas em escapar das velhas, que se ramificam, para aqueles que foram criados como a maioria de nós, por todos os cantos de nossas mentes.

John Maynard Keynes A Teoria Geral do Emprego, do Juro e da Moeda (Prefácio)

"IX na quinta posição significa: Homens ligados por um sentido de comunidade: i- $\infty$ choram e se lamentam, mas depois Heyne. Após grandes lutas conseguem encontrar-se. Indeed, do you undersat@nd? ii- suas palavras tornam-se "doces” e fortes como a fragrância das orquídeas “. 
Mote que me inspirou: Aos professores do DER-UFV que fizeram a turma do JAÊNES MIRANDA ALVES flutuar a la CAMPOS e LIRIO.

À Helenice dos Santos Basílio e Marli Rosário Barbosa (in memorium) e a Luiz Antônio Moufron (in memoria) eu ofereço.

À Nair Neves da Fraga e Jair José da Fraga (in memorium).

A José Miguel dos Santos e Premiscia Buzzelle dos Santos (in memorium).

A João José dos Santos e à Zair Fraga dos Santos, meus pais.

A Jorge João Mokdeci, meu primeiro orientador que com sua lição de vida me inspirou a continuar seguindo o caminho do bem comum acima de quaisquer questões insignificantes e o que afirmou que o lugar em que nós trabalhamos é um retrato do país em que vivemos, portanto devemos tentar consertálo se algo nos parece funcionando mal.

A Danilo Rolim Dias de Aguiar que com seu próprio nome serviu de inspiração para eu continuar seguindo no trilho agrícola que é o retratinho do Brasil a qual Mokdeci se referira.

Eu dedico essa tese à gama $\gamma$, beta $\beta$ e sigma $\Sigma$, minhas letras gregas favoritas. 


\section{AGRADECIMENTOS}

Ao professor Geraldo Sant'Ana de Camargo Barros, meu orientador, a quem admiro e respeito por sua capacidade humana e intelectual fundamentais para o êxito dessa tese. Pela leal confiança que depositou em mim quando necessitei mudar de ares. E também, pelas suas aulas de Macroeconomia III sobre economia aberta, expectativas racionais e pelas de Comercialização. Deixa comigo as deduções matemáticas e representações gráficas que me recordam Gabriel Garcia Marques, "Cem Anos de Solidão”. Como no livro, suas aulas me remetiam a um espaço-tempo que sempre quisera estar e não imaginara que pudesse concretizá-lo no primeiro e último semestre do curso. E a saga dos Buendía continua e o vilarejo de Macondo está em festa.

À professora Mirian Rumenos Piedade Bacchi pelas aulas de Econometria sobre séries temporais que me deram suporte metodológico para a tese. Das suas aulas levo a palavra naïf que me fizeram pintar minhas primeiras telas à tinta acrílica e que me lembram o romance de Oscar Wilde, “O Retrato de Dorian Gray”. Afinal, passados semestres, meus conhecimentos sobre séries temporais não envelheceram, ao contrário se tornaram cada vez mais nítidos na minha mente.

Ao professor Joaquim Bento de Souza Ferreira Filho pelas aulas de Microeconomia II que por sua própria indicação me fez ler "O nada que existe”, de Robert Kaplan ao invés de ler Silberberg. A leitura me deu pelo menos a certeza da minha existência, pois o zero em minhas notas não se posicionava à direita e sim à esquerda, não acrescentando nada a elas. 
À professora Ana Lúcia Kassouf pelas aulas de Econometria II sobre dados em painel que com sua dedicação pela pesquisa não deixavam esquecer que me encontrava num centro de excelência. Das suas aulas levo o livro de Vladimir Nabokov, “Pnin”, que não tive tempo de ler, pois lia o Greene. Por que "Pnin”? Pois há na contracapa a seguinte frase: "Há homens que são vogais abertas e outros que são consoantes mudas”. Para mim ela representou o conjunto inteiro de vogais nunca perdendo a intensidade.

Ao professor Joaquim José Martins Guilhoto pelas aulas de Microeconomia III sobre insumo-produto que me deram certeza de que existe uma outra visão de mundo. Deixa comigo suas orientações que me recordavam Umberto Eco, "O Pêndulo de Foucault”. Assim como no livro suas aulas me deram um movimento cíclico e constante que permaneceram comigo até o dia em que mudei de ares.

Ao professor Alexandre Lahóz Mendonça de Barros por suas aulas de Desenvolvimento Econômico e por sua dedicação em fazê-las. Levo comigo a função Cobb-Douglas e a frase: devemos sempre retirar dos textos clássicos a inspiração e suas deduções e tentar a partir delas avançar. Como a expressão de Issac Newton que quando escreveu sua maior obra se encontrava em "ombros de gigantes”.

À professora Silvia Helena Galvão de Miranda que com suas sugestões melhoraram a tese. Seus comentários escritos na tese me levaram a lembrar do livro de J.J. Veiga, “A Hora dos Ruminantes”. O clímax veiguiano contido no capítulo, Hora dos Bois, em que os ruminantes entram em ação, assim foram os meus estímulos às suas intervenções em meu texto.

Ao Lucílio que me ajudou a desvendar os segredos da co-integração de Johansen.

Ao Mauro Osaki pela disposição em me enviar dissertações e artigos. 
Ao Braz Neves da Epamig - Cândido Tostes pela sua gentileza em me atender e pelos dados a respeito dos fatores de conversão do leite, sem os quais essa tese não seria construída.

À Maielli pela sua dedicação, amizade e carinho durante todo o tempo em que convivi na Esalq. Foi ela que com seu sorriso me ofereceu o cartão de visita da ESALQ/Economia Aplicada com a frase: “seja bem-vinda”!

À Ligiana pelo apoio dado nas consultas bibliográficas pela Internet. E ao Álvaro pela paciência em me atender.

Ao Pedro, Helena, Márcia, Cris, Elenice e Luciane pela atenção a mim dispensada.

Aos amigos Jaênes, Cândida, Rosana, Célio e Isabella Freguglia pelas horas alegres que passei e pelas tristes em que vocês me apoiaram. E ao pequeno Francisco Freguglia e Izabela Maria que nasceram.

À amiga Cinthia pela amizade e pela capacidade de me ajudar nas horas que mais precisei, que não foram poucas. E ao Frederico Matta pelas brincadeiras e sorrisos que dei no RUCAS, que não foram muitos à época. Hoje, no entanto, o sorriso é mútuo pelo nosso sucesso.

Aos amigos Lilian Maluf, Joaquim, Alivínio, Janete Lopes, Tiziu, Janete e Samuel, Cárlinton, Madalena, Piedade, Humberto, Alexandre Nicolella, Andrea Ferro, Alexandre Gomes, Jonas Irineu, Casimiro, Silvana Cardoso, Renata Cristina e Mariusa pela boa convivência. E também ao Rogério Alves de Paiva.

Aos amigos distantes, mas virtualmente presentes: Gisela e Frederico Tomich, Moisés e Karina, Fernando Perobelli e Fernanda, Silvana Amorim, Jacqueline e Maria Isabel. 
À Leila e Luiza Tomich, Daniela e Hélio, Ivete e Nonato, Maria José e Martins, Telma e Normando, Nelly e Montalvão, Yara e Fernando Vidal pela alegria compartilhada nos momentos de vitória e pela amizade.

À Vivian Zaka and big family pela amizade e pelo incentivo para concluir a tese e para mudar o visual. E, também a Lânia Muller.

Aos colegas de Faculdade de Economia e Administração da Universidade Federal de Juiz de Fora, em especial, ao Moisés, Suzana, Fernando e Fernanda, Maria Isabel, Maria Helena, Rogério e Lori. Aos meus anjos da guarda da secretaria Helinho, Ana, Zé Carlos, e Adriana, da limpeza Priscila e Ézio e do futebol, Paulo.

Aos meus pais, Zair e Santos, ao meu irmão, Marco Antônio, aos meus tios, Cirene, Lair, Cecília e Antônio, e aos meus primos, em especial, Luciano e Paula, pelo incentivo constante durante todos esses anos.

Ao Willy, Pepê, Mumu e Pretinha pelas brincadeiras.

A Sílvio Oliveira que conseguiu me colocar em steady-state. E à Flávia.

À Ana Montes que me fez acreditar que meu sonho era possível.

A João Carlos Borges que me fez descobrir meu verdadeiro talento: limpar esferas.

A Deus por tudo isso. 


\section{SUMÁRIO}

Página

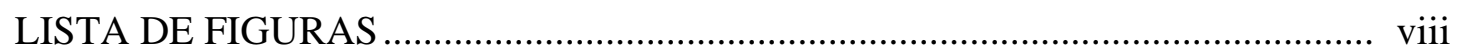

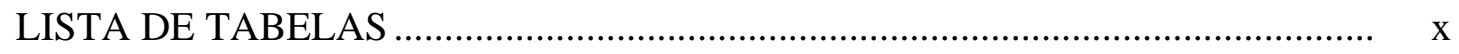

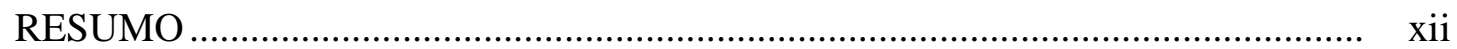

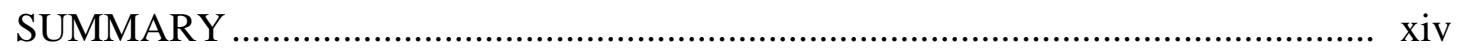

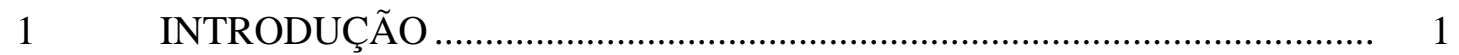

2 REVISÃO DE LITERATURA ......................................................... 4

$2.1 \quad$ O comércio internacional de lácteos nos anos recentes .................................. 4

2.2 A produção nacional, o comércio internacional de lácteos e o cenário macroeconômico ........................................................................................... 11

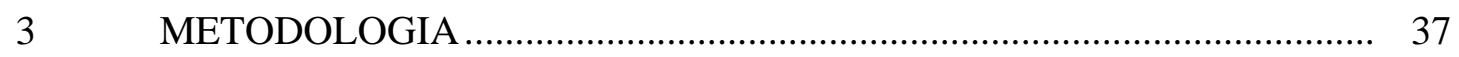

$3.1 \quad$ Referencial teórico ............................................................................. 37

3.1.1 Políticas comerciais ............................................................................... 37

3.1.2 Taxa de câmbio e a agricultura ................................................................... 44

3.2 Condicionantes das importações.................................................................. 47

3.3 Modelo econômico................................................................................... 49

3.3.1 Fundamentação gráfica do modelo ........................................................... 59

3.3.2 Especificação da equação de excesso de demanda ........................................ 64

3.4 Modelo empírico .................................................................................. 67

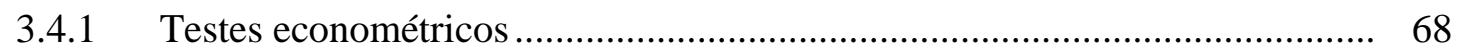

3.4.1.1 Teste de sentido de causalidade .............................................................. 68

3.4.1.2 O conceito e o teste de exogeneidade ........................................................ 71

3.4.1.3 Os testes de raiz unitária e co-integração...................................................... 73

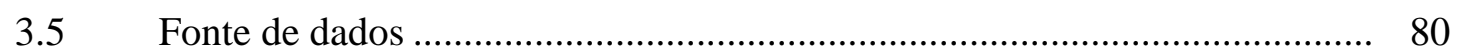




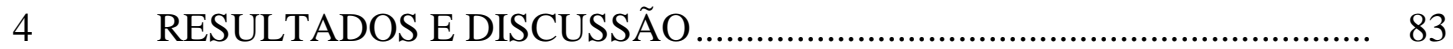

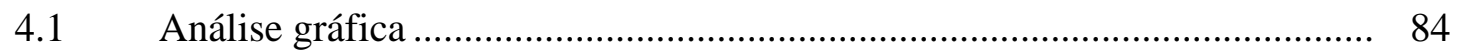

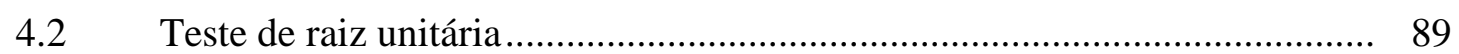

4.3 Teste de sentido de causalidade ................................................................ 93

4.4 Teste de Hausman ....................................................................................... 97

4.5 Teste de co-integração de Johansen.......................................................... 98

4.6 Estimação das funções de demanda e preço de leite importado ..................... 98

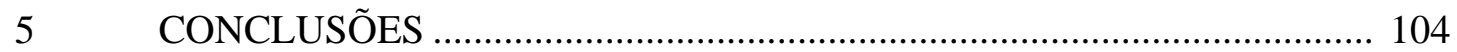

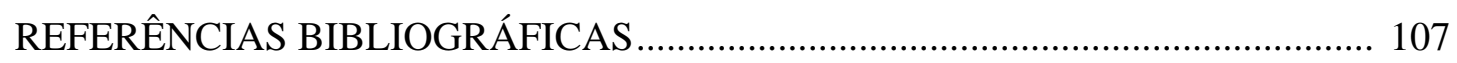




\section{LISTA DE FIGURAS}

Página

1 Produção leiteira em bilhões de litros, Brasil, 1991 a 2003.................................. 12

2 Importações brasileiras de leite, convertidos em leite fluido, em milhões de

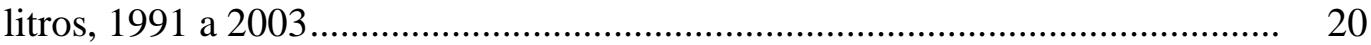

3 Participação do leite em pó nas importações de leite selecionados (em \%), Brasil,1991 a 2003

4 Importações de lácteos em milhões de equivalente litros de leite, Brasil, 1991 a setembro de 2003

5 Importações de leite em mil litros, Brasil, janeiro de 1991 a dezembro de 200323

6 Razão preço de importação e preço interno (US\$/R $\$$ )

7 Exportações brasileiras de leite fluido, 1991 a 2003 (em milhões de US\$) ........ 26

8 Exportações mensais de leite em mil litros, Brasil, janeiro de 1991 a dezembro de 2003

9 Índice da taxa de câmbio real (R\$/US\$) e saldo da balança comercial brasileira (em milhões de US\$ FOB)

10 Evolução do saldo comercial brasileiro (em US\$ FOB) com a Argentina, Paraguai, Uruguai e Mercosul, 1991 a 2003

11 Balança comercial brasileira (em mil litros) de produtos lácteos selecionados, janeiro de 1999 a dezembro de 2003

12 Efeito da imposição de tarifa de importação, país pequeno 39

13 Efeito de um subsídio à exportação, país pequeno 40 
14 Efeito de uma sobrevalorização cambial no mercado doméstico e no mercado externo.

15 Efeito de uma redução dos subsídios e de uma sobrevalorização cambial no mercado doméstico e no mercado externo

16 Diagrama back to back 59

17 Diagrama back to back com custo de transferência. 60

18 Diagrama back to back com alteração da demanda 62

19 Diagrama back to back com alteração de oferta 63

20 Diagrama back to back com diminuição de subsídio.

21 Evolução da importação de leite (em mil litros), Brasil, janeiro de 1991 a dezembro de 2003

22 Evolução dos preços nominais de importação de leite (US\$/mil litros) entre janeiro de 1991 a dezembro de 2003

23 Evolução dos preços internos reais de leite ( $\mathrm{R} \$ /$ mil litros) entre janeiro de 1991 a dezembro de 2003

24 Evolução da taxa de câmbio real mensal (R\$/US\$) entre janeiro de 1991 a dezembro de 2003, base 1999

25 Evolução do PIB real per capita (R\$/hab.), Brasil, entre janeiro de 1991 a dezembro de 2003, base 1990

26 Evolução das exportações mundiais de leite (em toneladas), período mensal, entre janeiro de 1991 a dezembro de 2003 


\section{LISTA DE TABELAS}

Página

1 Vinte maiores produtores mundiais de leite, em toneladas e em porcentagem da produção mundial, 1999 a 2002 ....................................................................... 5

2 Taxa de crescimento da produção (\%), produção per capita (kg/hab.), leite, países e regiões, anos selecionados

3 Consumo per capita mundial de leite (litros), países selecionados, 1995, 2000 e 2003

4 Vinte maiores exportadores de equivalente leite ${ }^{1}$, valor em mil dólares americanos, quantidade em toneladas e participação (\%), 2001.

5 Vinte maiores importadores de equivalente leite ${ }^{1}$, valor em mil dólares americanos, quantidade em toneladas e participação (\%), 2001........................... 9

6 Dez maiores exportadores e importadores líquidos de equivalente leite, 2001 ... 10

7 Tarifas consolidadas do segmento lácteo........................................................... 11

8 Evolução da participação dos diversos tipos de leite no mercado formal de leite fluido no Brasil, em porcentagem (\%) ..................................................... 13

9 Vendas de leite fluido e leite UHT no Brasil, em milhões de litros, 1990 a 2002.

10 Produção nacional de leite, em mil litros, 1990 a 2000. 15

11 Parâmetros da produção leiteira no Brasil, 1985 a 1996..................................... 16

12 Tarifa Externa Comum, Brasil ........................................................................... 18

13 Origem das importações brasileiras de lácteos, 1997 e 2002 ............................. 24

14 Destino das exportações brasileiras de leite e derivados, 1997 e 2002................ 27 
15 América Latina e Caribe: percentual de destino das exportações de bens, segundo esquemas de integração, 1988,1999 e 2000

16 Margem de dumping absoluta e relativa praticada pelas empresas dos países e regiões investigadas, no período de julho de 1998 a junho de 1999.

17 Subsídio equivalente ao produtor de leite, em países da OCDE, US\$ (em milhões) e em porcentagem,vários anos

18 Especificações das funções de demanda por importações estimadas, vários autores

19 Índices para conversão de produtos em leite fluido

20 Códigos NBM e NCM com descrição dos tipos de leite

21 Teste de estacionariedade em modelo com constante $(\alpha)$ e tendência $(T)$, estatística $\tau_{\tau}$

22 Teste de estacionariedade em modelo com constante ( $\alpha$ ), estatística $\tau_{\mu}$

23 Teste de estacionariedade em modelo sem constante e sem tendência, estatística $\tau$

24 Teste de raiz unitária em modelo sem constante e sem tendência, estatística $\tau$. 95

25 Resultados do teste de co-integração ............................................................. 96

26 Correlações cruzadas entre as variáveis utilizando 10 defasagens ..................... 96

27 Resultados do teste de causalidade de Granger com termo de correção de erro 97

28 Resultados do teste de Hausman ....................................................................... 98

29 Resultados do teste de co-integração de Johansen .............................................. 92

30 Estimativas do ajustamento em dois estágios da demanda por leite importado

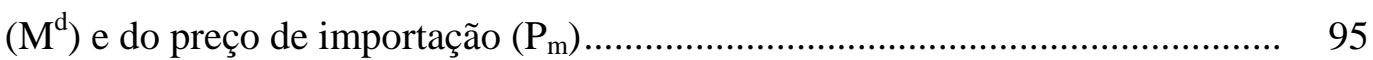

31 Resultados das substituições do sistema simultâneo 


\title{
POLÍTICAS MACROECONÔMICAS E SEUS EFEITOS SOBRE AS IMPORTAÇÕES DE LÁCTEOS NO BRASIL
}

\author{
Autor: DIONE FRAGA DOS SANTOS \\ Orientador: Prof. Dr. GERALDO SANT'ANA DE CAMARGO BARROS
}

\section{RESUMO}

Na década de 90 houve mudanças significativas no setor agroindustrial do leite no Brasil. Dentre elas destacam-se: i) a desregulamentação do rigoroso controle estatal após 46 anos (1945-1991); ii) o lançamento de novos produtos; iii) a entrada de multinacionais; iv) a criação do Mercado Comum do Cone Sul e v) a abertura comercial generalizada. O comércio mundial de lácteos tem a participação de poucos países, sendo os principais importadores e exportadores os países membros da Organização para Cooperação e Desenvolvimento Econômico (OCDE). Países como o Brasil e a Índia possuem parcelas pouco expressivas do volume de comércio. O objetivo geral da pesquisa é analisar os fatores que têm influenciado as importações de lácteos pelo Brasil no período de 1991 a 2003. A metodologia empregada para medir os impactos das importações de leite nas variáveis macroeconômicas foi a de séries temporais. Incorporou-se uma análise gráfica a partir do diagrama back to back analisado por Barros (1987). E, ainda, utilizou-se a equação de excesso de demanda para definir a demanda por importação de leite. Concluiu-se que as variáveis: preço de importação de leite, taxa de câmbio real, PIB per capita e preço interno de leite são significativas e apresentam sinais coerentes com a teoria econômica. As elasticidades estimadas foram todas próximas ou superiores à unidade, revelando um mercado bastante dinâmico com 
ajustes rápidos a curto prazo. As elasticidades foram de magnitudes bem parecidas, sugerindo uma boa integração do segmento leiteiro ao mercado internacional. Vale salientar que as dummies incluídas para captar as variações de políticas econômicas como estabilização monetária e políticas anti-dumping não apresentaram efeitos significativos. É possível que seus efeitos tenham sido captados por outras variáveis incluídas no modelo. 


\title{
MACROECONOMIC POLICIES AND THEIR EFFECTS ABOUT MILK IMPORTS IN BRAZIL
}

\author{
Author: DIONE FRAGA DOS SANTOS \\ Adviser: Prof. Dr. GERALDO SANT'ANA DE CAMARGO BARROS
}

\section{SUMMARY}

During the decade of the 1990's several significant changes took place in the milk agroindustry sector in Brazil: i) the sector was deregulated after 46 years of state control; ii) new milk products were created; iii) the market share of multinational enterprises increased; iv) the Common Market of the South (Mercosul) was created; v) the economy was opened through tariff reduction and deregulations. Only a few countries participate in the world milk trade. Major importers and exporters are members of OECD. The trade share of countries like Brazil and India in rather small. The general objective of this study is to analyze the factors that influenced the imports of milk by Brazil during the period 1991 to 2003. The milk imports market is analysed through "back to back" graphic system such that Brazil imports demand faces the world export supply. These two functions are then estimated. The variables dollar price of imported milk, real exchange rate, per capita GDP an domestic price of milk presented significant coefficient with sign coherent to economic theory. Estimated elasticities were all close to or higher than one, revealing a quite dynamic market with short term fast a adjustments. The magnitudes of the elasticities were very similar, suggesting a good integration of the milk sector to the international market. It should be pointed out that the dummy variables included in the model to capture the effects of the monetary stabilization and 
the anti-dumping measures did not present statiscally significant coefficients. It is possible that these effects have been capture by other variables in the model. 


\section{INTRODUÇÃO}

O sistema agroindustrial do leite no Brasil e o segmento de leite fluido, em particular, têm passado por importantes transformações desde o início da década de 90. A pecuária leiteira tem enfrentado um intenso processo de reorganização que pode aumentar sua competitividade frente à concorrência externa. O segmento experimentou simultaneamente a desregulamentação após 46 anos (1945 a 1991) de rigoroso controle governamental no mercado de leite fluido, o lançamento de novos produtos e derivados, a conformação do Mercado Comum do Cone Sul (Mercosul) e a abertura comercial generalizada (Martins et al. 2001).

A abertura econômica brasileira expôs o segmento lácteo à competição com empresas de grande porte e aos preços praticados no resto do mundo. No mercado interno, observou-se um processo de reestruturação das indústrias de laticínios direcionado à concentração das atividades e com a participação crescente de empresas multinacionais no mercado. Paralelamente, houve um aumento da participação relativa do leite longa vida (UHT) no mercado nacional de leite fluido ao longo da década de 90.

O comércio mundial de lácteos tem a participação de poucos países, sendo os principais importadores e exportadores os países membros da Organização para a Cooperação e Desenvolvimento Econômico ( $\left.\mathrm{OCDE}^{1}\right)$. Países em desenvolvimento, como Índia e Brasil, possuem parcelas pouco expressivas do volume de comércio, apesar de serem o segundo e o sexto produtor mundial, respectivamente em 2002.

\footnotetext{
${ }^{1}$ Alemanha, Dinamarca, França, Itália, Noruega, Suíça, Canadá, Austrália, Áustria, Finlândia, GrãBretanha, Holanda, Portugal, Turquia, Espanha, Nova Zelândia, Bélgica, Irlanda, Grécia, Islândia, Luxemburgo, Suécia, Estados Unidos, Japão, México, República Tcheca, Eslováquia, Polônia e Coréia.
} 
No mercado externo, houve um aumento da importação brasileira de lácteos oriundos da Argentina, Uruguai, União Européia e Nova Zelândia, países que possuem preços abaixo dos praticados no mercado internacional provavelmente influenciados pelas medidas de dumping durante a década de 90. Essa possibilidade de importações, segundo Barros et al (2001), passou a estabelecer um limite superior de preços na cadeia láctea brasileira.

O que se pretende responder com o trabalho é: a) de que forma e em que grau essa inserção influencia positiva ou negativamente o mercado interno; b) em que grau essas influências foram superadas pelo próprio setor ou por medidas adotadas pelo governo brasileiro.

O objetivo geral do presente trabalho é analisar os fatores que têm influenciado as importações de lácteos pelo Brasil no período de 1991 a 2003. Em termos específicos pretende-se:

- analisar o comportamento das quantidades importadas de lácteos frente ao comportamento dos preços de importação, taxa de câmbio real, renda per capita, preço doméstico de leite, estabilização monetária e política antidumping;

- enfocar o comércio internacional de leite no mundo destacando seus maiores exportadores e importadores;

- destacar as medidas implementadas pelo Brasil para impedir a prática de políticas comerciais que penalizam o produtor nacional.

A análise da demanda de importação desenvolvida neste trabalho, que incorpora as variáveis citadas anteriormente, é inédita se comparado ao que foi desenvolvido no artigo de Tannús (2000). Pois, a autora não analisou o efeito de variáveis importantes, como exemplo, taxa de câmbio, sendo que a estimação foi feita com dados anuais e sem todos os testes econométricos pertinentes como 
estacionariedade e co-integração. Com relação à literatura internacional, não foram encontrados trabalhos sobre estimação da demanda por importações de leite durante o período de realização da tese.

Ressalta-se que a contribuição do presente trabalho é a investigação a respeito do método adequado de estimação da função de demanda de importação de leite para o Brasil. Além disso, o acompanhamento das variáveis mensais durante os 13 anos de análise permitiu o conhecimento da evolução das importações brasileiras de lácteos e seus desdobramentos macroeconômicos.

O presente trabalho está organizado em cinco capítulos a contar com essa Introdução. No capítulo 2, referente à Revisão de Literatura, são descritos os elementos que vêm caracterizando o comércio internacional de leite, a inserção brasileira no mesmo e as políticas macroeconômicas no período de 1991 a 2003. Os referenciais teórico e empírico e a fonte de dados estão no capítulo 3, Metodologia. No capítulo 4 são apresentados e discutidos os resultados. No capítulo 5 encontram-se as principais conclusões do trabalho. 


\section{REVISÃO DE LITERATURA}

\subsection{O comércio internacional de lácteos nos anos recentes}

A Tabela 1 apresenta os dados da produção de leite nos principais países produtores em 1999 e 2002. Com base nos dados de 2002, os Estados Unidos são o maior produtor, com cerca de $20 \%$ da produção dos vinte maiores produtores, respondendo por $15 \%$ da produção mundial. A Federação Russa detém cerca de $9 \%$ da produção dos vinte maiores e 7\% da produção mundial.

No ano de 2002, o Brasil produziu, segundo a Food and Agricultural Organization (FAO) (2003), 23 milhões de toneladas métricas de leite, representando $4,7 \%$ da produção mundial, quantidade que o coloca como o sexto maior produtor do mundo. A produção brasileira vem crescendo a uma taxa superior à da produção mundial, o que determinou o aumento de sua participação na produção mundial. Em 1995, a participação brasileira foi de 3,6\% e o país apresentava-se como o sétimo maior produtor. 
Tabela 1. Vinte maiores produtores mundiais de leite, em toneladas e em porcentagem da produção mundial, 1999 e 2002

\begin{tabular}{|c|c|c|c|c|c|c|}
\hline \multirow[t]{2}{*}{ 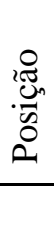 } & \multirow[t]{2}{*}{ 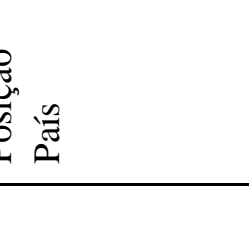 } & \multirow{2}{*}{$\begin{array}{r}\stackrel{\text { Sి }}{\rightarrow} \\
\text { Produção (t) }\end{array}$} & \multirow[b]{2}{*}{$\%$} & \multirow[t]{2}{*}{ 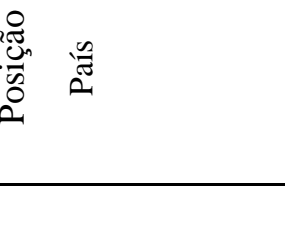 } & \multicolumn{2}{|l|}{ ণ্ণ } \\
\hline & & & & & Produção (t) & $\%$ \\
\hline & Mundo & 489.098.678 & 100,00 & Mundo & 499.141 .532 & 100,00 \\
\hline & Vinte Maiores & 362.815 .851 & 74,18 & Vinte Maiores & 370.747 .496 & 74,28 \\
\hline 1 & Estados Unidos & 73.804 .000 & 15,09 & 1 Estados Unidos & 75.025 .000 & 15,03 \\
\hline 2 & Índia & 36.000 .000 & 7,26 & 2 Índia & 35.000 .000 & 7,01 \\
\hline 3 & Fed. Russa & 31.972 .920 & 6,54 & 3 Fed. Russa & 32.700 .000 & 6,55 \\
\hline 4 & Alemanha & 28.334.212 & 5,79 & 4 Alemanha & 28.100 .000 & 5,63 \\
\hline 5 & França & 24.892 .000 & 5,09 & 5 França & 25.100 .000 & 5,03 \\
\hline 6 & Brasil & 21.700 .000 & 4,44 & 6 Brasil & 23.260 .000 & 4,66 \\
\hline 7 & Reino Unido & 15.014 .000 & 3,07 & 7 Reino Unido & 14.980 .000 & 3,00 \\
\hline 8 & Ucrânia & 13.200 .200 & 2,70 & 8 Ucrânia & 13.959 .000 & 2,80 \\
\hline 9 & Polônia & 12.271 .968 & 2,51 & 9 Nova Zelândia & 13.907 .885 & 2,79 \\
\hline 10 & Holanda & 11.740 .000 & 2,40 & 10 Polônia & 12.000 .000 & 2,40 \\
\hline 11 & Itália & 11.736 .000 & 2,40 & 11 Austrália & 11.620 .000 & 2,33 \\
\hline 12 & Nova Zelândia & 10.881 .000 & 2,22 & 12 China & 10.846 .329 & 2,17 \\
\hline 13 & Argentina & 10.631 .672 & 2,17 & 13 Itália & 10.700 .000 & 2,14 \\
\hline 14 & Austrália & 10.490 .000 & 2,14 & 14 Holanda & 10.450 .000 & 2,09 \\
\hline 15 & México & 9.170 .930 & 1,88 & 15 Paquistão & 10.400 .000 & 2,08 \\
\hline 16 & Turquia & 8.800 .000 & 1,80 & 16 México & 9.560 .200 & 1,92 \\
\hline 17 & Japão & 8.459 .694 & 1,73 & 17 Turquia & 8.489 .082 & 1,70 \\
\hline 18 & Canadá & 8.164 .000 & 1,67 & 18 Japão & 8.350 .000 & 1,67 \\
\hline 19 & Paquistão & 8.039 .000 & 1,64 & 19 Argentina & 8.200 .000 & 1,64 \\
\hline 20 & China & 7.514 .255 & 1,54 & 20 Canadá & 8.100 .000 & 1,62 \\
\hline
\end{tabular}

Fonte: FAO (2003)

A produção mundial de leite tendeu à elevação em países em desenvolvimento como China e Índia, enquanto o inverso aconteceu em países desenvolvidos (ver Tabela 2). 
Tabela 2. Taxa de crescimento da produção (\%), produção per capita (kg/hab.), leite, países e regiões, anos selecionados

\begin{tabular}{lcrrrr}
\hline \multicolumn{1}{c}{ Países/Regiões } & $\begin{array}{c}\text { Taxa de } \\
\text { crescimento } \\
\text { produção } \\
\text { Países/Anos }\end{array}$ & $\begin{array}{c}\text { Produção kg/per } \\
\text { capita }\end{array}$ & $\begin{array}{c}\text { Produção } \\
\text { kg/per capita }\end{array}$ & $\begin{array}{c}\text { Produção kg/per } \\
\text { capita }\end{array}$ & $\begin{array}{c}\text { Produção } \\
\text { kg/per capita }\end{array}$ \\
\hline China & $1991-2002$ & 1991 & 1995 & 2000 & 2002 \\
Índia & 7,0 & 4,14 & 4,96 & 6,73 & 11,01 \\
América Latina e Caribe & 4,0 & 26,69 & 27,99 & 33,43 & 34,78 \\
País em desenvolvimento & 3,0 & 95,75 & 103,49 & 111,29 & 112,55 \\
País desenvolvido & 4,0 & 25,78 & 27,65 & 31,48 & 32,87 \\
Mundo & 0,0 & 288,43 & 265,44 & 258,99 & 260,98 \\
\hline
\end{tabular}

Fonte: FAO (2004)

O crescimento da produção nos países não reverteu o quadro de concentração de consumo. De acordo com a Tabela 3, em 1995, os países desenvolvidos tiveram um consumo per capita de 1,7 vezes superior à média de consumo dos países em desenvolvimento (PED). Em 2000, mostrou-se ser 2,0 vezes maior que a média dos PED. E, as estimativas para 2003 do Departamento de Agricultura dos Estados Unidos da América (USDA) (Estados Unidos, 2004) revelam que consumo per capita dos países desenvolvidos foi 1,8 vezes superior à média dos PED. 
Tabela 3. Consumo per capita mundial de leite (litros), países selecionados, 1995, 2000 e 2003

\begin{tabular}{|c|c|c|c|}
\hline \multirow[b]{2}{*}{ Países } & \multicolumn{3}{|c|}{ kg/pessoa/ano } \\
\hline & 1995 & 2000 & $2003^{*}$ \\
\hline \multicolumn{4}{|c|}{ América do Norte } \\
\hline Canadá & 96,3 & 93,1 & 88,5 \\
\hline Estados Unidos & 99,9 & 95,2 & 92,6 \\
\hline México & 36,3 & 39,0 & 38,9 \\
\hline \multicolumn{4}{|l|}{ América do Sul } \\
\hline Argentina & 59,5 & 61,3 & 52,4 \\
\hline Brasil & 67,4 & 72,3 & 67,7 \\
\hline Chile & 28,1 & 29,6 & 29,0 \\
\hline \multicolumn{4}{|l|}{ União Européia } \\
\hline Alemanha & 71,2 & 65,4 & 64,8 \\
\hline França & 76,1 & 70,4 & 69,1 \\
\hline Itália & 64,8 & 61,5 & 60,9 \\
\hline \multicolumn{4}{|l|}{ Ex-URSS } \\
\hline Rússia & 98,7 & 97,0 & 96,9 \\
\hline Ucrânia & 68,2 & 63,1 & 70,8 \\
\hline \multicolumn{4}{|l|}{ Ásia } \\
\hline China & 2,1 & 3,0 & 4,2 \\
\hline Japão & 41,0 & 39,2 & 38,8 \\
\hline Índia & 30,9 & 32,9 & 32,4 \\
\hline \multicolumn{4}{|l|}{ Oceania } \\
\hline Austrália & 103,7 & 103,9 & 99,4 \\
\hline Nova Zelândia & 123,4 & 90,6 & 89,8 \\
\hline
\end{tabular}

Fonte: Estados Unidos (2004)

* preliminar 
A Tabela 4 apresenta o valor das exportações dos vinte maiores exportadores de equivalente leite e as suas respectivas quantidades. Os vinte maiores países exportadores de equivalente leite detinham cerca de $89 \%$ das exportações mundiais do produto no ano de 2001. Observa-se ainda que existem diferenças das participações nos valores exportados e nas quantidades, refletindo desigualdades na composição das exportações. Por exemplo, a França que detém 13,06\% do valor das exportações mundiais de equivalente leite e apenas 12,75\% das quantidades. Este fato revela que os produtos exportados têm preços mundiais mais elevados do que a média. Em contrapartida, a Nova Zelândia detém 13\% das quantidades exportadas de equivalente leite e 10,49\% do valor das exportações do produto, indicando grosso modo, que suas exportações de equivalente leite ocorrem com preços inferiores à média.

Em relação às importações de equivalente leite, ocorre um menor grau de concentração conforme mostra a Tabela 5. Os vinte maiores importadores adquirem 75\% do total das importações mundiais no produto. É importante destacar na Tabela 5, que os seis maiores importadores mundiais, responsáveis por 44,5\% do valor das importações, são países membros da União Européia (UE). Percebe-se que os países que se destacam como exportadores de lácteos são também grandes importadores, o que caracteriza o elevado grau de comércio intra-indústria existente nesse segmento. 
Tabela 4. Vinte maiores exportadores de equivalente leite ${ }^{1}$, valor em mil dólares americanos, quantidade em toneladas e participação (\%), 2001

\begin{tabular}{|c|c|c|c|c|c|}
\hline \multirow[t]{2}{*}{ Posições } & \multirow[t]{2}{*}{ Países } & \multirow{2}{*}{$\begin{array}{c}\text { Valor } \\
\text { US\$1.000 }\end{array}$} & \multirow{2}{*}{$\begin{array}{c}\text { Quantidade } \\
\mathrm{t}\end{array}$} & \multicolumn{2}{|c|}{ Participações } \\
\hline & & & & Valor (\%) & Qtde(\%) \\
\hline & Mundo & 27.629.224 & 71.888 .620 & 100,00 & 100,00 \\
\hline & Vinte maiores & 24.710.717 & 63.865 .630 & 89,44 & 88,84 \\
\hline 1 & Alemanha & 4.117.629 & 10.511 .542 & 14,90 & 14,62 \\
\hline 2 & França & 3.608.166 & 9.166 .400 & 13,06 & 12,75 \\
\hline 3 & Holanda & 3.008 .513 & 6.546 .840 & 10,89 & 9,11 \\
\hline 4 & Nova Zelândia & 2.897.098 & 9.343 .692 & 10,49 & 13,00 \\
\hline 5 & Bélgica & 1.755 .853 & 4.250 .514 & 6,36 & 5,91 \\
\hline 6 & Austrália & 1.592 .518 & 4.933 .888 & 5,76 & 6,86 \\
\hline 7 & Dinamarca & 1.276 .547 & 2.128.986 & 4,62 & 2,96 \\
\hline 8 & Irlanda & 1.114.076 & 2.673 .918 & 4,03 & 3,72 \\
\hline 9 & Itália & 933.475 & 1.130 .587 & 3,38 & 1,57 \\
\hline 10 & Reino Unido & 796.740 & 2.152 .778 & 2,88 & 2,99 \\
\hline 11 & Estados Unidos & 638.173 & 2.762 .723 & 2,31 & 3,84 \\
\hline 12 & Espanha & 543.475 & 1.088 .267 & 1,97 & 1,51 \\
\hline 13 & Áustria & 501.125 & 1.169 .497 & 1,81 & 1,63 \\
\hline 14 & Polônia & 421.596 & 1.391 .532 & 1,53 & 1,94 \\
\hline 15 & Suíça & 319.956 & 433.990 & 1,16 & 0,60 \\
\hline 16 & Argentina & 282.510 & 952.989 & 1,02 & 1,33 \\
\hline 17 & Ucrânia & 274.502 & 1.158 .159 & 0,99 & 1,61 \\
\hline 18 & Canadá & 270.436 & 868.411 & 0,98 & 1,21 \\
\hline 19 & República Tcheca & 202.544 & 814.633 & 0,73 & 1,13 \\
\hline 20 & Suécia & 155.785 & 386.284 & 0,56 & 0,54 \\
\hline
\end{tabular}

Fonte: FAO (2003)

${ }^{1} \mathrm{~A}$ ordem se baseia nos valores exportados 
Tabela 5. Vinte maiores importadores equivalente leite ${ }^{1}$, valor em mil dólares americanos, quantidade em toneladas e participação (\%), 2001

\begin{tabular}{|c|c|c|c|c|c|}
\hline \multirow[t]{2}{*}{ Posição } & \multirow[t]{2}{*}{ Países } & \multirow{2}{*}{$\begin{array}{c}\text { Valor } \\
\text { US\$1.000 }\end{array}$} & \multirow{2}{*}{$\begin{array}{c}\text { Quantidade } \\
\mathrm{t}\end{array}$} & \multicolumn{2}{|c|}{ Participações } \\
\hline & & & & Valor(\%) & Qtde (\%) \\
\hline & Mundo & 26.909 .490 & 67.120 .530 & 100,00 & 100,00 \\
\hline & Vinte maiores & 20.217.477 & 49.528 .475 & 75,13 & 73,79 \\
\hline 1 & Alemanha & 2.659.059 & 4.893 .537 & 9,88 & 7,29 \\
\hline 2 & Itália & 2.412 .626 & 5.202 .858 & 8,97 & 7,75 \\
\hline 3 & França & 1.884 .775 & 4.449 .944 & 7,00 & 6,63 \\
\hline 4 & Bélgica & 1.853 .034 & 4.118.281 & 6,89 & 6,14 \\
\hline 5 & Reino Unido & 1.621 .194 & 2.761 .465 & 6,02 & 4,11 \\
\hline 6 & Holanda & 1.544 .434 & 5.957 .434 & 5,74 & 8,88 \\
\hline 7 & Estados Unidos & 1.378 .054 & 1.873 .417 & 5,12 & 2,79 \\
\hline 8 & Espanha & 863.932 & 1.914 .453 & 3,21 & 2,85 \\
\hline 9 & México & 858.669 & 2.779 .261 & 3,19 & 4,14 \\
\hline 10 & China & 830.015 & 2.812 .550 & 3,08 & 4,19 \\
\hline 11 & Japão & 784.829 & 1.683 .286 & 2,92 & 2,51 \\
\hline 12 & Arábia Saudita & 546.334 & 1.055 .254 & 2,03 & 1,57 \\
\hline 13 & Argélia & 530.430 & 1.808 .415 & 1,97 & 2,69 \\
\hline 14 & Grécia & 446.220 & 1.235 .729 & 1,66 & 1,84 \\
\hline 15 & Filipinas & 436.459 & 1.596 .088 & 1,62 & 2,38 \\
\hline 16 & Federação Russa & 389.626 & 1.599 .123 & 1,45 & 2,38 \\
\hline 17 & Indonésia & 326.326 & 1.106 .029 & 1,21 & 1,65 \\
\hline 18 & Canadá & 292.183 & 733.786 & 1,09 & 1,09 \\
\hline 19 & Tailândia & 290.922 & 1.126 .882 & 1,08 & 1,68 \\
\hline 20 & Cingapura & 268.356 & 820.683 & 1,00 & 1,22 \\
\hline
\end{tabular}

Fonte: FAO (2003)

A Tabela 6 fornece os dados sobre as exportações e importações líquidas para o ano de 2001. O maior exportador líquido mundial é a Nova Zelândia, seguida da França e da Holanda. Já o maior importador líquido mundial é a Itália, seguida da Bélgica que é o sétimo maior exportador e quarto maior importador de lácteos. 
Tabela 6. Dez maiores exportadores e importadores líquidos de equivalente leite, 2001

\begin{tabular}{llrrlr}
\hline Posição & \multicolumn{1}{c}{ Países } & $\begin{array}{c}\text { Exportações } \\
\text { US\$ } 1.000\end{array}$ & Posição & \multicolumn{1}{c}{ Países } & $\begin{array}{r}\text { Importações } \\
\text { US\$ 1.000 }\end{array}$ \\
\hline 1 & Nova Zelândia & 2.880 .411 & 1 & Itália & 1.479 .151 \\
2 & França & 1.723 .391 & 2 & Bélgica & 824.454 \\
3 & Holanda & 1.464 .079 & 3 & Reino Unido & 824.454 \\
4 & Alemanha & 1.458 .570 & 4 & Estados Unidos & 739.881 \\
5 & Austrália & 1.424 .268 & 5 & China & 647.416 \\
6 & Dinamarca & 1.054 .071 & 6 & Espanha & 320.457 \\
7 & Irlanda & 897.768 & 7 & Federação Russa & 266.821 \\
8 & Polônia & 300.934 & 8 & Brasil & 157.513 \\
9 & Ucrânia & 257.079 & 9 & Suécia & 24.495 \\
10 & Argentina & 255.024 & 10 & Canadá & 21.747 \\
\hline
\end{tabular}

Fonte: FAO (2003)

É importante enfatizar que o comércio de produtos lácteos é submetido de forma geral a pesadas barreiras tarifárias. A Tabela 7 apresenta as tarifas consolidadas na Organização Mundial de Comércio (OMC) em diversas regiões do mundo. A tarifa ad valorem média do segmento é de 86\%, segunda maior tarifa média do setor agrícola superada apenas pelo fumo. Com relação às regiões, observam-se valores em torno de 85\% na América do Norte e na União Européia. 
Tabela 7. Tarifas consolidadas do segmento lácteo

\begin{tabular}{lc}
\hline Regiões & Tarifa ad valorem média \\
\hline Mundo & 86 \\
Sul da África & 39 \\
Ásia - Pacífico & 73 \\
Sul da Ásia & 104 \\
África - sub-Saara & 75 \\
África do Norte $^{\prime}$ & 74 \\
Oriente Médio & 65 \\
Europa Oriental & 85 \\
Europa Ocidental & 230 \\
União Européia $^{1}$ & 87 \\
América do Sul & 43 \\
América Central & 68 \\
Ilhas do Caribe $_{\text {América do Norte }}$ & 87 \\
\hline
\end{tabular}

Fonte: Brandão e Leite (2001)

${ }^{1}$ Não inclui os países da União Européia

\subsection{A produção nacional, o comércio internacional de lácteos e cenário macroeconômico}

A década de noventa inicia-se com grandes transformações institucionais na economia brasileira. Em 1991, ocorre a desregulamentação do mercado de leite e de derivados, em que o governo deixa de fixar preços e de definir importações. A busca por maior inserção no comércio internacional, a formalização do Mercosul e a implantação do Plano Real ocorreram num ambiente em que o Governo Federal, visando o controle das taxas inflacionárias e a modernização produtiva procurou desregulamentar a 
economia. A desregulamentação se deu no momento em que se promovia a abertura comercial, e a consolidação do Mercosul.

Os reflexos dessas mudanças no ambiente macroeconômico fizeram com que a década de 90 guardasse um contraste com os 46 anos anteriores de intervenção governamental: aumentou a produção de leite entre 1990 e 2001. Segundo dados do IBGE (2003), a produção em 1990 que era de 14 bilhões de litros passou para cerca de 20,5 bilhões de litros em 2000, apresentando um crescimento de 42,8\% no período. Em 2002, a produção foi de 20,4 bilhões de litros, e em 2003 são de 21,3 bilhões de litros (ver Figura 1).

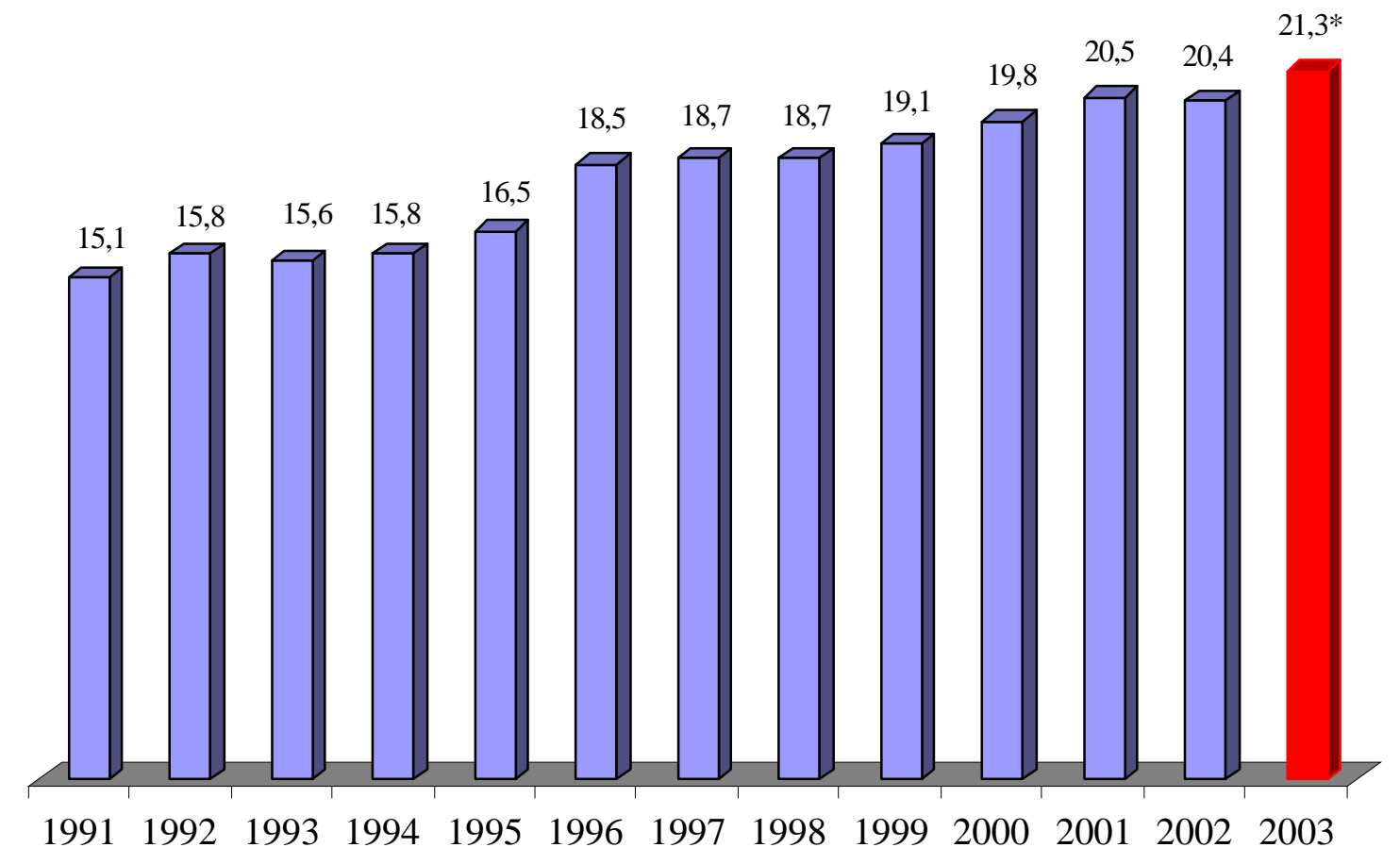

Figura 1 - Produção leiteira em bilhões de litros, Brasil, 1991 a 2003

Fonte: IBGE (2001) e Brasil (2004)

*estimativa 
Em 1990, a produção nacional de leite UHT era de 184 milhões de litros; já em 1997 a produção passou para 2.450 milhões de litros, um acréscimo de 1.231,5\% no período. O leite UHT aumentou sua participação no mercado de leite fluido no Brasil, atingindo 49,3\% em 1997 e 50,5\% em 1998, enquanto em 1990 esta participação era de apenas 4,4\% (Jank, 1999).

Percebe-se que a produção nacional respondeu positivamente ao período em que houve valorização cambial da moeda nacional. Apesar da maior exposição do país a uma competição dos produtos importados com preços artificialmente inferiores, notadamente o leite em pó, a produtividade cresceu e o segmento buscou modernizar-se.

Em nível doméstico, houve também mudança na preferência dos consumidores que passaram a demandar mais o leite UHT em detrimento ao leite ensacado. Essa mudança de comportamento foi fortemente influenciado pelo prazo de validade mais dilatado do leite UHT comparado ao leite ensacado e pela facilidade de acesso ao produto disponíveis nas gôndolas de supermercado. A Tabela 8 mostra a evolução relativa do mercado de leite UHT no Brasil em relação aos demais tipos de leite fluido sob inspeção. E a Tabela 9, as vendas de leite fluido e de UHT em que se observa o crescimento da parcela de mercado desse último.

Tabela 8. Evolução da participação dos diversos tipos de leite no mercado formal de leite fluido no Brasil, em percentagem (\%)

\begin{tabular}{crrrrrrrrr}
\hline Tipo & 1990 & 1991 & 1992 & 1993 & 1994 & 1995 & 1996 & 1997 & 1998 \\
\hline A + B & 8,9 & 12,2 & 10,8 & 15,5 & 12,5 & 12,9 & 10,0 & 8,0 & 8,0 \\
C & 86,7 & 82,6 & 79,9 & 72,1 & 65,8 & 60,8 & 52,0 & 42,7 & 41,5 \\
UHT & 4,4 & 5,2 & 9,3 & 12,4 & 21,7 & 26,3 & 38,0 & 49,3 & 50,5 \\
\hline
\end{tabular}

Fonte: Jank (1999) e Barros et al (2001) 
Tabela 9. Vendas de leite fluido e leite UHT no Brasil, em milhões de litros, 1990 a 2002

\begin{tabular}{lccc}
\hline Anos & Leite fluido & Leite UHT & Parcela de mercado \\
\hline 1990 & 4241 & 187 & 4,4 \\
1991 & 3951 & 204 & 5,2 \\
1992 & 3693 & 355 & 9,6 \\
1993 & 3162 & 456 & 14,4 \\
1994 & 3615 & 730 & 20,2 \\
1995 & 4200 & 1050 & 25,0 \\
1996 & 4535 & 1700 & 37,5 \\
1997 & 4720 & 2450 & 51,9 \\
1998 & 5080 & 3100 & 61,0 \\
1999 & 5125 & 3425 & 66,8 \\
2000 & 5230 & 3600 & 68,8 \\
2001 & 5390 & 3950 & 73,3 \\
2002 & 5700 & 4220 & 74,0 \\
\hline
\end{tabular}

Fonte: Associação Brasileira de Leite Longa Vida (ABLV) (2004)

A produção nacional (por região geográfica e por estados), visualizada na Tabela 10, esteve concentrada na região Sudeste, principalmente no estado de Minas Gerais. No período de 1995 a 2002, a produção brasileira cresceu 36,98\% atingindo um crescimento anual de 4,62\%. Para esse significativo crescimento foi importante a abertura de novas fronteiras como a região do Cerrado, especialmente Goiás, as regiões do Triângulo Mineiro e Alto Paranaíba em Minas Gerais e outras regiões emergentes como Rondônia, Mato Grosso e sul do Pará.

A Tabela 11 apresenta alguns dados acerca da produção de leite brasileira para os anos de 1985 e 1996. Os números indicam um aumento da produção nacional de leite numa proporção maior que o número de vacas ordenhadas. Segundo Barros et al 
(2001) houve uma elevação de 36\% na produtividade (litros/vaca ordenhada/ano). Embora os autores destaquem que a produtividade é uma medida parcial, eles acrescentam que o número de produtores caiu apenas 3,1\% no período. Essa medida torna-se um forte sinalizador de que houve uma mudança na escala primária de produção.

Tabela 10. Produção nacional de leite, em mil litros, 1990 a 2000

\begin{tabular}{|c|c|c|c|c|c|c|c|c|c|}
\hline REGIÕES & 1992 & 1993 & 1994 & 1995 & 1996 & 1997 & 1998 & 1999 & 2000 \\
\hline NORTE & 725.496 & 725.131 & 651.980 & 706.693 & 770.786 & 840.879 & 798.541 & 958.378 & 1.049 .769 \\
\hline RO & 261.972 & 269.624 & 169.031 & 202.188 & 317.250 & 335.913 & 371.975 & 408.749 & 422.255 \\
\hline $\mathrm{AC}$ & 20.660 & 30.125 & 30.299 & 29.696 & 31.356 & 31.831 & 32.850 & 36.625 & 40.804 \\
\hline $\mathrm{AM}$ & 38.204 & 41.337 & 45.139 & 48.976 & 27.004 & 32.487 & 35.436 & 36.054 & 36.680 \\
\hline $\mathrm{RR}$ & 13.625 & 0 & 11.675 & 11.209 & 10.659 & 9.523 & 8.816 & 10.000 & 9.958 \\
\hline PA & 273.767 & 293.014 & 297.451 & 308.184 & 237.899 & 290.210 & 311.315 & 311.162 & 380.319 \\
\hline $\mathrm{AP}$ & 1.686 & 2.210 & 2.545 & 2.709 & 2.468 & 2.832 & 2.713 & 3.062 & 3.735 \\
\hline TO & 115.582 & 88.821 & 95.840 & 103.731 & 144.150 & 138.083 & 35.436 & 152.726 & 156.018 \\
\hline NORDESTE & 2.266 .926 & 1.682 .910 & 1.772 .817 & 1.886 .614 & 2.355 .006 & 2.388 .556 & 2.069.954 & 2.041 .816 & 2.159 .230 \\
\hline MA & 131.075 & 133.554 & 140.462 & 145.109 & 139.371 & 138.961 & 137.548 & 142.596 & 149.976 \\
\hline PI & 55.484 & 46.469 & 51.746 & 55.588 & 75.110 & 75.504 & 71.062 & 73.302 & 76.555 \\
\hline CE & 304.458 & 243.088 & 267.555 & 292.346 & 390.384 & 387.990 & 313.297 & 325.267 & 331.873 \\
\hline $\mathrm{RN}$ & 121.520 & 74.275 & 92.407 & 105.608 & 159.591 & 161.629 & 129.904 & 129.165 & 144.927 \\
\hline PB & 157.873 & 97.790 & 124.420 & 140.018 & 150.189 & 149.802 & 86.863 & 95.684 & 105.843 \\
\hline PE & 314.633 & 186.355 & 209.686 & 212.709 & 421.987 & 357.853 & 285.827 & 266.171 & 292.130 \\
\hline $\mathrm{AL}$ & 217.109 & 182.872 & 189.662 & 201.077 & 223.266 & 301.114 & 244.928 & 214.813 & 217.887 \\
\hline SE & 98.923 & 78.811 & 66.897 & 66.013 & 134.806 & 127.228 & 118.022 & 122.424 & 115.142 \\
\hline BA & 865.851 & 639.696 & 629.982 & 668.146 & 660.302 & 688.475 & 682.503 & 672.394 & 724.897 \\
\hline SUDESTE & 7.216.493 & 7.344.116 & 7.351.889 & 7.539.462 & 8.338.196 & 8.395.742 & 8.465.196 & 8.540 .201 & 8.573.731 \\
\hline MG & 4.502 .655 & 4.526 .961 & 4.577 .620 & 4.762 .543 & 5.601 .112 & 5.602 .015 & 5.688 .011 & 5.801 .063 & 5.865 .486 \\
\hline ES & 310.381 & 374.396 & 365.182 & 362.696 & 319.677 & 339.339 & 340.075 & 367.903 & 378.068 \\
\hline RJ & 380.534 & 395.523 & 403.898 & 432.380 & 432.019 & 451.223 & 455.144 & 457.736 & 468.752 \\
\hline SP & 2.022 .923 & 2.047 .236 & 2.005 .189 & 1.981 .843 & 1.985 .388 & 2.003 .165 & 1.981 .966 & 1.913 .499 & 1.861 .425 \\
\hline SUL & 3.585 .639 & 3.685 .566 & 3.830 .620 & 4.102.597 & 4.241 .529 & 4.345 .130 & 4.410 .591 & 4.606.119 & 4.904 .356 \\
\hline PR & 1.277 .282 & 1.363 .237 & 1.424 .283 & 1.576 .541 & 1.514 .481 & 1.579 .837 & 1.625 .226 & 1.724 .917 & 1.799 .240 \\
\hline SC & 707.888 & 735.867 & 780.122 & 815.379 & 866.064 & 852.169 & 870.809 & 906.540 & 1.003 .098 \\
\hline RS & 1.600 .469 & 1.586 .462 & 1.626 .215 & 1.710 .677 & 1.860 .984 & 1.913 .124 & 1.914 .556 & 1.974 .662 & 2.102 .018 \\
\hline C.OESTE & 1.989 .455 & 2.163 .156 & 2.176.251 & 2.238 .993 & 2.809 .864 & 2.695 .192 & 2.844 .738 & 2.923 .521 & 3.080 .121 \\
\hline MS & 446.166 & 467.902 & 454.674 & 454.743 & 407.069 & 414.947 & 426.896 & 409.044 & 427.261 \\
\hline MT & 250.704 & 268.850 & 286.431 & 307.426 & 375.397 & 380.517 & 406.374 & 411.390 & 422.743 \\
\hline GO & 1.276 .464 & 1.405 .778 & 1.409 .351 & 1.450 .157 & 1.999.398 & 1.868.979 & 1.978 .579 & 2.066 .404 & 2.193.799 \\
\hline DF & 16.121 & 20.626 & 25.795 & 26.667 & 28.000 & 30.749 & 32.889 & 36.683 & 36.318 \\
\hline BRASIL & 15.784 .009 & 15.600 .879 & 15.783 .557 & 16.474 .359 & 18.515 .381 & 18.665 .499 & 18.589 .020 & 19.070 .035 & 19.767.207 \\
\hline
\end{tabular}

Fonte: IBGE (2003) 
Tabela 11. Parâmetros da produção leiteira no Brasil, 1985 e 1996

\begin{tabular}{lccc}
\hline Descrição & 1985 & 1996 & $\%$ \\
\hline Produção anual (bilhões de litros) & 12,85 & 17,93 & 39,6 \\
\% da produção proveniente de gado leiteiro & 65,3 & 75,1 & 15,0 \\
\% da produção proveniente de gado de corte e leite & 11,5 & 7,3 & $-36,9$ \\
\% da produção proveniente de gado de corte e demais & 23,2 & 17,6 & $-23,8$ \\
$\mathrm{~N}^{0}$. vacas ordenhadas (milhões de cabeças) & 13,4 & 13,7 & 2,5 \\
Litros/vaca ordenhada/dia & 2,6 & 3,6 & 36,1 \\
$\mathrm{~N}^{\circ}$. de produtores de leite & 1,87 & 1,81 & $-3,1$ \\
Litros/produtor/dia & 18,8 & 27,1 & 44,0 \\
\hline
\end{tabular}

Fonte: Barros et al (2001)

Outro ponto salientado por Barros et al. (2001) é que o aumento na proporção da produção originado de gado leiteiro especializado atingiu, em 1996, 75\% da produção brasileira, contra 65\% há 11 anos. É interessante observar também que a maior redução proporcional foi na produção leiteira advinda de gado de dupla aptidão, que em 1996, não chegava a representar 8\% da produção nacional.

As entrevistas realizadas para a elaboração do estudo de Barros et al. (2001: 48) demonstraram que o conceito de "gado leiteiro" do IBGE é bastante elástico e não significa que seja um gado de bom padrão genético. Segundo a pesquisa de campo nas regiões, o gado que predomina é o “cruzado”, denominação genérica para um gado sem padrão definido de raça, incluindo parcelas geralmente, pequenas de sangue holandês ou outra raça especializada na produção leiteira. São raras as regiões onde predomina o gado de melhor padrão genético.

Em 2001, o valor bruto da produção agropecuária, um indicador da renda do setor rural, foi de 84 bilhões de reais, destes cerca de 35 bilhões de reais são de produtos pecuários, tendo o leite participado com 19\% ou 6,6 bilhões de reais do valor bruto da produção agropecuária (IBGE, 2003).

Como gerador de empregos totais, o segmento de laticínios superou setores tradicionais como da construção civil e indústria têxtil, segundo a pesquisa de Martins e 
Guilhoto (2001). Na comparação de 43 setores da economia brasileira, o segmento de laticínios colocou-se em décima segunda posição. Ao procederem à simulação de política pública, referente à aquisição anual de um bilhão de litros de leite pelos estados seriam gerados 159.424 novos postos de trabalho permanentes.

A rápida expansão da produção de leite esbarra na baixa produtividade das propriedades leiteiras se comparadas às de outros países do Mercosul. Como conseqüência da baixa produtividade, há ineficiência no uso dos fatores de produção, causando elevação dos custos. Isto torna a atividade pouco competitiva, tanto em relação ao custo de oportunidade do leite comparado ao de outras atividades agropecuárias, bem como à capacidade de competir com produtos lácteos de outros países.

Este novo cenário tem se caracterizado pela expulsão de produtores e laticínios do mercado, por não se mostrarem competitivos. Representantes de produtores têm argumentado que as condições vigentes nos países exportadores, onde subsídios são dados aos produtores, dificultam a plena competição do produto nacional com o produto estrangeiro. As dificuldades de competição brasileira do segmento lácteo aumentaram quando da criação da união aduaneira do Mercosul em 1995. Com ela estabeleceu-se a TEC (Tarifa Externa Comum) entre os países membros do bloco em relação a terceiros mercados. As tarifas de lácteos para as importações da União Européia eram de 16\% na Argentina, enquanto no Brasil os lácteos figuravam na lista de exceções, apresentando uma TEC de 35\%.

No período de janeiro de 1995 a junho de 1998, as tarifas permaneceram diferenciadas e possibilitaram a prática de “triangulação”, ou seja, a entrada no Brasil de produtos lácteos subsidiados e originários de países que não participavam do bloco, usufruindo as condições favoráveis existentes no comércio entre os países que compõem o Mercosul.

Entretanto, após junho de 1998, houve pressões por parte do Brasil para que se elevasse a TEC, que passou então a 30\% para Brasil, Argentina e Uruguai, vigorando até dezembro de 2000. De julho de 1998 a dezembro de 2000, praticamente não houve 
“triangulação”. Em janeiro de 2001, a TEC deveria voltar ao nível de 16\%, entretanto, o Brasil não retirou os lácteos da lista de exceções. Em 2001, a tarifa de importação de lácteos foi de 27\% no Brasil e de 16\% na Argentina (Campos, 2001). Como informa a resolução CAMEX, no 4 de 13/02/2004, a TEC para a entrada de leite no Brasil está em 14\% para leite UHT e em 16\% para leite em pó desnatado, leite em pó integral e creme de leite (Tabela 12).

Tabela 12. Tarifa externa comum ${ }^{1}$, Brasil

\begin{tabular}{|c|c|c|}
\hline Código NCM & DESCRIÇÃO & $\begin{array}{c}\text { Alíquota } \\
\text { (\%) }\end{array}$ \\
\hline 0401.10 .10 & $\begin{array}{l}\text { Leite UHT ("Ultra High Temperature") } \\
\end{array}$ & 14 \\
\hline 0401.10 .90 & Outros & 12 \\
\hline 0401.20 .10 & Leite UHT ("Ultra High Temperature") & 14 \\
\hline 0401.20 .90 & Outros & 12 \\
\hline 0401.30 .10 & Leite & 12 \\
\hline 0401.30 .21 & UHT ("Ultra High Temperature") & 14 \\
\hline 0401.30 .29 & Outros & 12 \\
\hline 0402.10 .10 & $\begin{array}{l}\text { Com um teor de arsênio, chumbo ou cobre, considerados } \\
\text { isoladamente, inferior } \quad \text { a } 5 \text { ppm }\end{array}$ & 16 \\
\hline 0402.10 .90 & Outros & 16 \\
\hline 0402.21 .10 & Leite integral & 16 \\
\hline 0402.21 .20 & Leite parcialmente desnatado & 16 \\
\hline 0402.21 .30 & Creme de leite (nata*) & 16 \\
\hline 0402.29 .10 & Leite integral & 16 \\
\hline 0402.29 .20 & Leite parcialmente desnatado & 16 \\
\hline 0402.29 .30 & Creme de leite (nata*) & 16 \\
\hline 0402.91 .00 & --Sem adição de açúcar ou de outros edulcorantes & 14 \\
\hline 0402.99 .00 & --Outros & 14 \\
\hline 0403.10 .00 & -Iogurte & 16 \\
\hline 0403.90 .00 & -Outros & 16 \\
\hline 0404.10 .00 & $\begin{array}{l}\text {-Soro de leite, modificado ou não, mesmo concentrado ou } \\
\text { adicionado de açúcar ou outros edulcorantes }\end{array}$ & 14 \\
\hline
\end{tabular}

Fonte: Brasil (2004)

${ }^{1}$ Atualizada até a Resolução da CAMEX, nº 4 de 13/02/2004 D.O.U. de 17/02/2004, seção 1 
Segundo Jank et al. (1999), historicamente, as importações tinham a função de regular o mercado interno na entressafra, que eram monopolizadas pelo governo até a década de 80. A partir da década de 90, o setor privado foi o responsável por fazer as importações de lácteos no país. Atualmente, podem importar lácteos tanto empresas que possuem fábricas quanto empresários “sem-fábrica” que querem ganhar com os diferenciais de preços, taxas de juros, câmbio e prazos de pagamentos.

Na Figura 2 pode-se visualizar a evolução das importações brasileiras de leite UHT, de leite em pó_ integral e desnatado_e de creme de leite no período de 1991 a 2003. Percebe-se pelo exame da Figura 2 que as importações de leite UHT se tornaram um pouco maiores após a implementação do Plano Real, contribuindo para que em 1995 houvesse um pico de importações do produto pelo país. A partir de então, as importações foram suavizadas diante da utilização do produto nacional de melhor qualidade (graças às condições de armazenamento em resfriadores, por exemplo) para a fabricação de leite UHT². Em contrapartida, as importações de leite em pó, em conjunto, foram significativas no período com pico de importação em 1996.

O Brasil é o segundo maior importador mundial de leite em pó integral, representando, na média dos últimos cinco anos, 7,7\% das importações desse produto, uma média de 103 mil toneladas anuais entre 1998 e 2003. O leite em pó integral representou, em 2003, 54\% do total das importações brasileiras de lácteos (BRASIL, 2004).

Em 1995, as importações de leite UHT e leite em pó em conjunto representaram 11\% da produção nacional. Em 1996, elas alcançaram cerca de 21\%. Esse incremento na parcela de importação em relação à produção relaciona-se à prática de “triangulação” de produtos originários de terceiros mercados via Mercosul e ao maior consumo de leite no mercado interno, diante da estabilidade monetária. A partir de 1998, quando da entrada em vigor da nova TEC para o leite a participação da importação de

\footnotetext{
${ }^{2}$ A Portaria 196 do Ministério da Agricultura de 23/09/94 estabeleceu a proibição em qualquer época do ano e em qualquer região a elaboração e comercialização do leite esterilizado através do processo UHT a partir da reconstituição de leite em pó.
} 
leite em pó e de leite UHT em relação à produção brasileira foi de 8,6\%; no ano de 1999 atingiu 9,8\%, e em 2000 ficou em 6,5\%. De 2001 até 2003, as participações foram de $3,9 \%, 6,6 \%$ e de $3,5 \%$, respectivamente. 


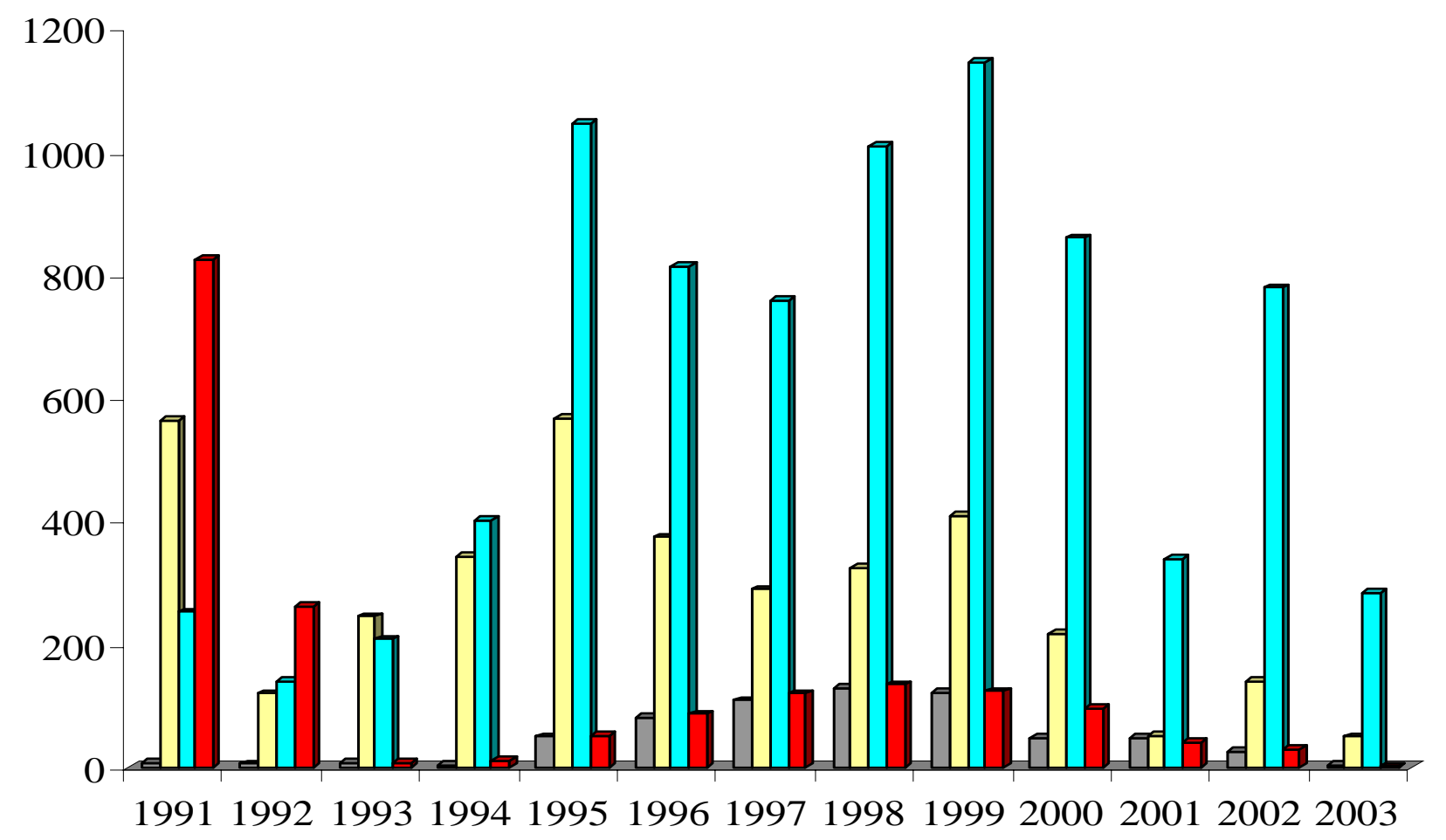

$\square$ Creme de leite $\square$ Leite em pó desnatado $\square$ Leite em pó integral $\square$ Leite UHT

Figura 2 - Importações brasileiras de leite, convertidos em leite fluido, em milhões de litros, 1991 a 2003 Fonte: Brasil (2003) 
Na Figura 3 pode-se visualizar a participação do leite em pó sobre o total de leite $^{3}$ importado pelo país durante os anos de 1991 a 2003. O tipo de leite mais importado pelo Brasil no referido período foi o leite em pó, integral e desnatado, sendo a participação do mesmo sob o total em torno de $99 \%$ a $82 \%$.

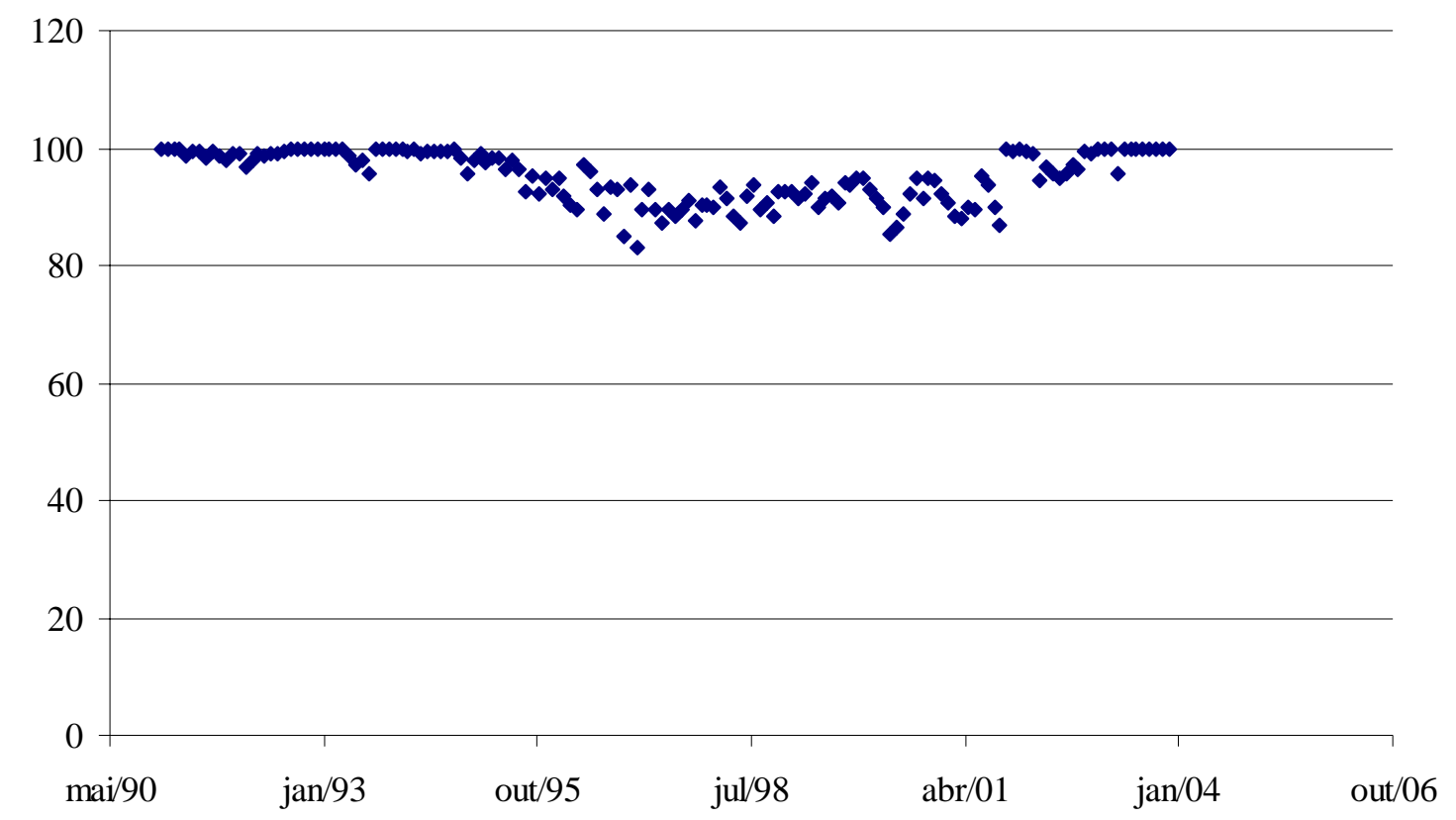

Figura 3 - Participação do leite em pó nas importações de leite selecionados (em \%), Brasil, 1991 a 2003

Fonte: Brasil (2004)

Em relação à política cambial, se podem destacar dois períodos em que o câmbio influenciou o comportamento das importações de lácteos. De julho de 1994 a janeiro de 1999, a moeda nacional esteve sobrevalorizada frente ao dólar o que refletiu numa maior importação de leite UHT e de leite em pó. No período de 1990 a 1999, os gastos brasileiros com as importações de leite e laticínios oriundas do Uruguai

\footnotetext{
${ }^{3}$ Volume total de leite importado refere-se à totalidade das importações de leite UHT, leite em pó_integral e desnatado_e creme de leite.
} 
cresceram 240\% (de US\$ 27 milhões para US\$ 92 milhões). Neste mesmo período, os gastos com importações de leite e laticínios oriundas da Argentina aumentaram 299\%, de US\$ 72 milhões para US\$ 287 milhões (SECEX, 2003). A partir de 1999, com a desvalorização cambial, observa-se queda das importações. Este período coincide também com as reduções tarifárias no sentido de conter as importações.

Segundo informações da SECEX (2003), as importações brasileiras de lácteos, em equivalente litros de leite, foram de 1,93 milhão em 1997 e, de 1,40 milhão em 2002. A Figura 4 mostra a evolução das importações de lácteos em equivalentes litros de leite no período de 1991 a 2003 segundo dados do Sistema Alice da SECEX (2003).

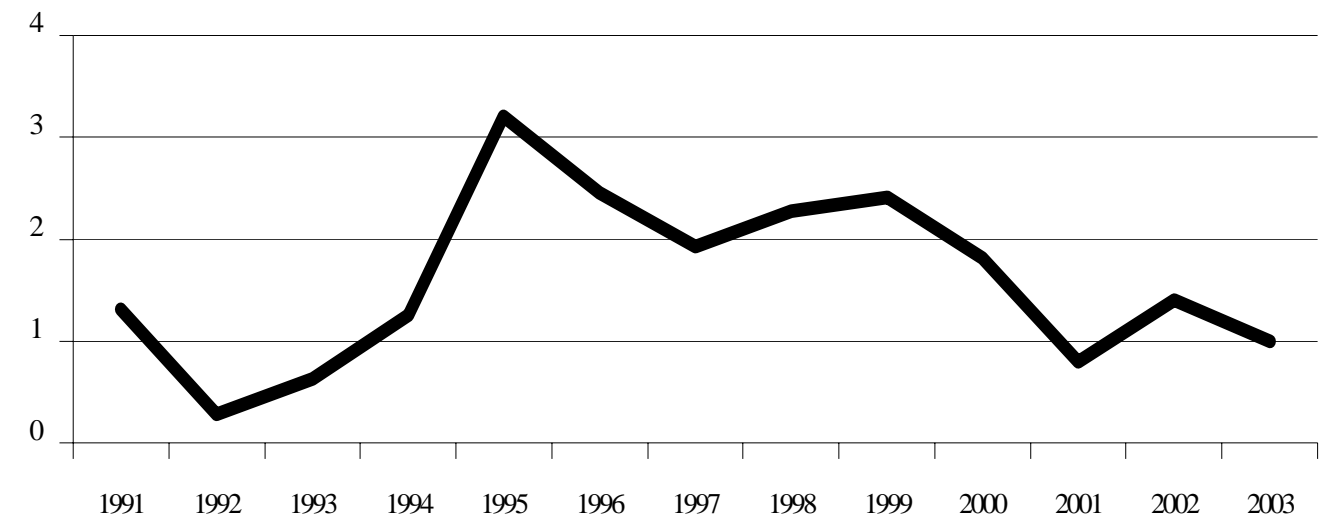

Figura 4 - Importações de lácteos em milhões de equivalente litros de leite, Brasil, 1991 a setembro de 2003

Fonte: Brasil (2003)

Como se observa na Figura 5, as importações totais de leite que incluem leite em pó integral, leite em pó desnatado e leite UHT foram mais significativas nos períodos 1995, 1996 e 1999. Como já foi observado anteriormente, esse quadro reflete a política 
de sobrevalorização da moeda nacional, maior integração com os parceiros do Mercosul e maior consumo de leite da população brasileira frente à produção nacional. 


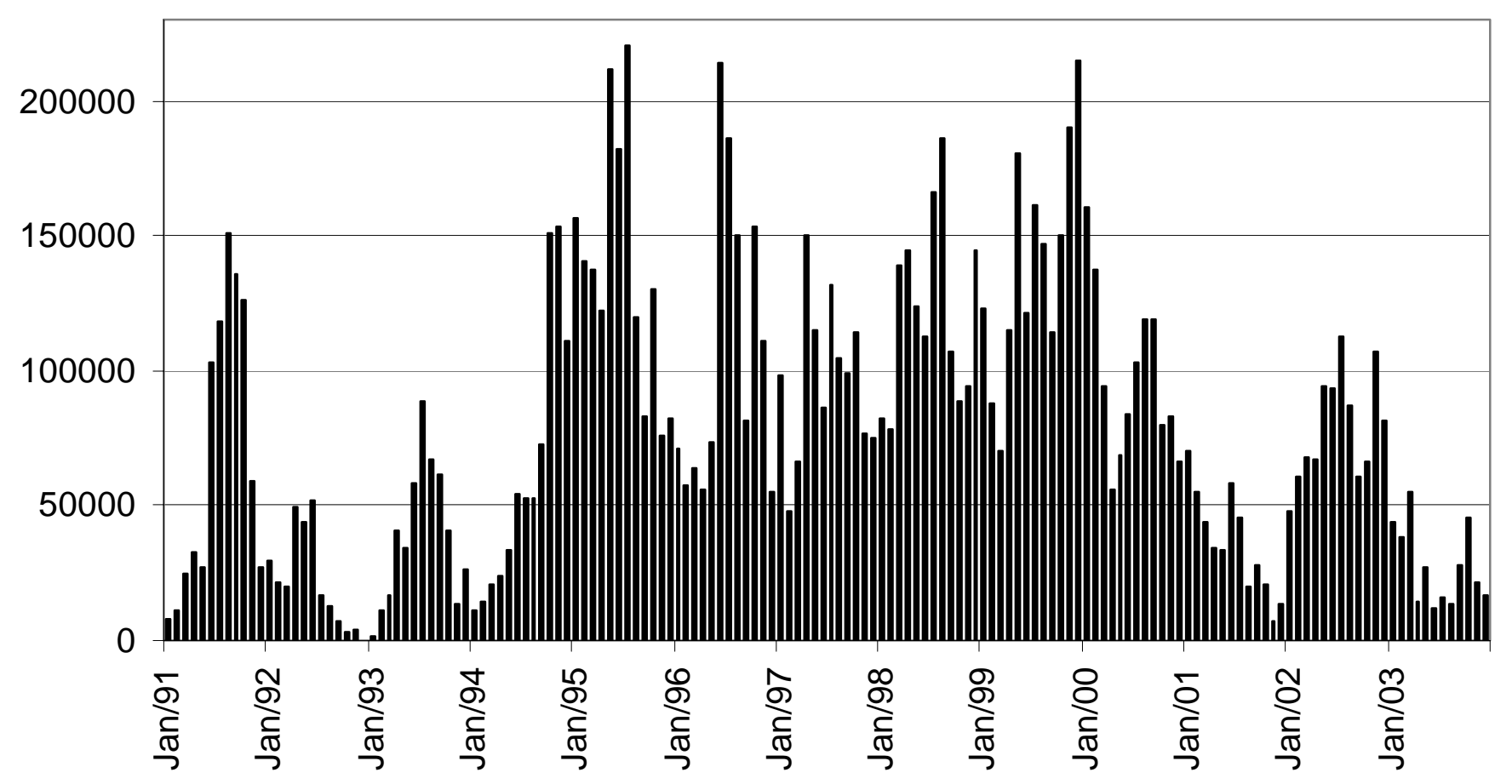

Figura 5 - Importações de leite em mil litros, Brasil, janeiro de 1991 a dezembro de 2003

Fonte: Brasil (2003) 
Nos anos de 2000 o processo de importação continua, porém em níveis mais baixos em relação à década de 90 . Esse fenômeno pode ser em parte relacionada à maior produção nacional, à desvalorização cambial e à política anti-dumping brasileira que impediu que grandes volumes de leite fossem importados com preços desleais.

Os dados do Ministério do Desenvolvimento, Indústria e Comércio (Brasil, MDIC, 2003) apresentam as origens das importações brasileiras entre 1997 a 2002. Pela visualização da Tabela 13 pode-se perceber que, por exemplo, a Argentina e o Uruguai continuam sendo nossos maiores fornecedores de lácteos; e a Nova Zelândia perdeu um pouco da parcela no comércio com o Brasil.

Tabela 13. Origem das importações brasileiras de lácteos, 1997 e 2002

\begin{tabular}{|c|c|c|c|c|c|}
\hline \multirow[t]{2}{*}{ Posição } & \multicolumn{2}{|l|}{1997} & \multirow[t]{2}{*}{ Posição } & \multicolumn{2}{|l|}{2002} \\
\hline & Países & $\%$ & & Países & $\%$ \\
\hline 1 & Argentina & 46,15 & 1 & Argentina & 52,54 \\
\hline 2 & Uruguai & 19,58 & 2 & Uruguai & 26,68 \\
\hline 3 & Nova Zelândia & 10,25 & 3 & Nova Zelândia & 6,75 \\
\hline 4 & Austrália & 4,80 & 4 & Estados Unidos & 4,09 \\
\hline 5 & Holanda & 2,61 & 5 & França & 2,46 \\
\hline 6 & Dinamarca & 2,48 & 6 & Holanda & 1,54 \\
\hline 7 & Estados Unidos & 2,11 & 7 & Dinamarca & 1,32 \\
\hline 8 & França & 2,03 & 8 & Polônia & 1,30 \\
\hline 9 & Reino Unido & 1,86 & 9 & Outros & 3,33 \\
\hline 10 & Chile & 1,82 & & & \\
\hline 11 & Alemanha & 1,24 & & & \\
\hline 12 & Itália & 1,15 & & & \\
\hline 13 & Outros & 3,92 & & & \\
\hline
\end{tabular}

Fonte: Brasil (2003)

A pecuária leiteira nacional defronta-se com a sazonalidade de preços vis-àvis comércio internacional em que os preços do leite são distorcidos por subsídios. A 
sazonalidade é derivada da diferença da quantidade de leite produzida na safra e na entressafra. Assim tanto a importação de leite a preços artificialmente deprimidos quanto a sazonalidade da produção refletem em queda de preços ao produtor nacional. Essa situação fez com que, em novembro de 2002, o Conselho Monetário Nacional incluísse o leite entre os produtos amparados pela Política de Garantia de Preços Mínimos (PGPM).

A Figura 6 expõe a razão preço internalizado (US\$/l) e preço interno (R $\$ / 1)$ que se torna os preços relativos dos tipos de leites importados. Para cada litro importado a relação variou de 0,16 a 0,69. Nota-se que a razão de preços (US\$/R $\$$ ) cresceu ao longo do tempo, ou seja, os preços domésticos caíram relativamente direcionando para a queda das importações e, mesmo, aumento das exportações.

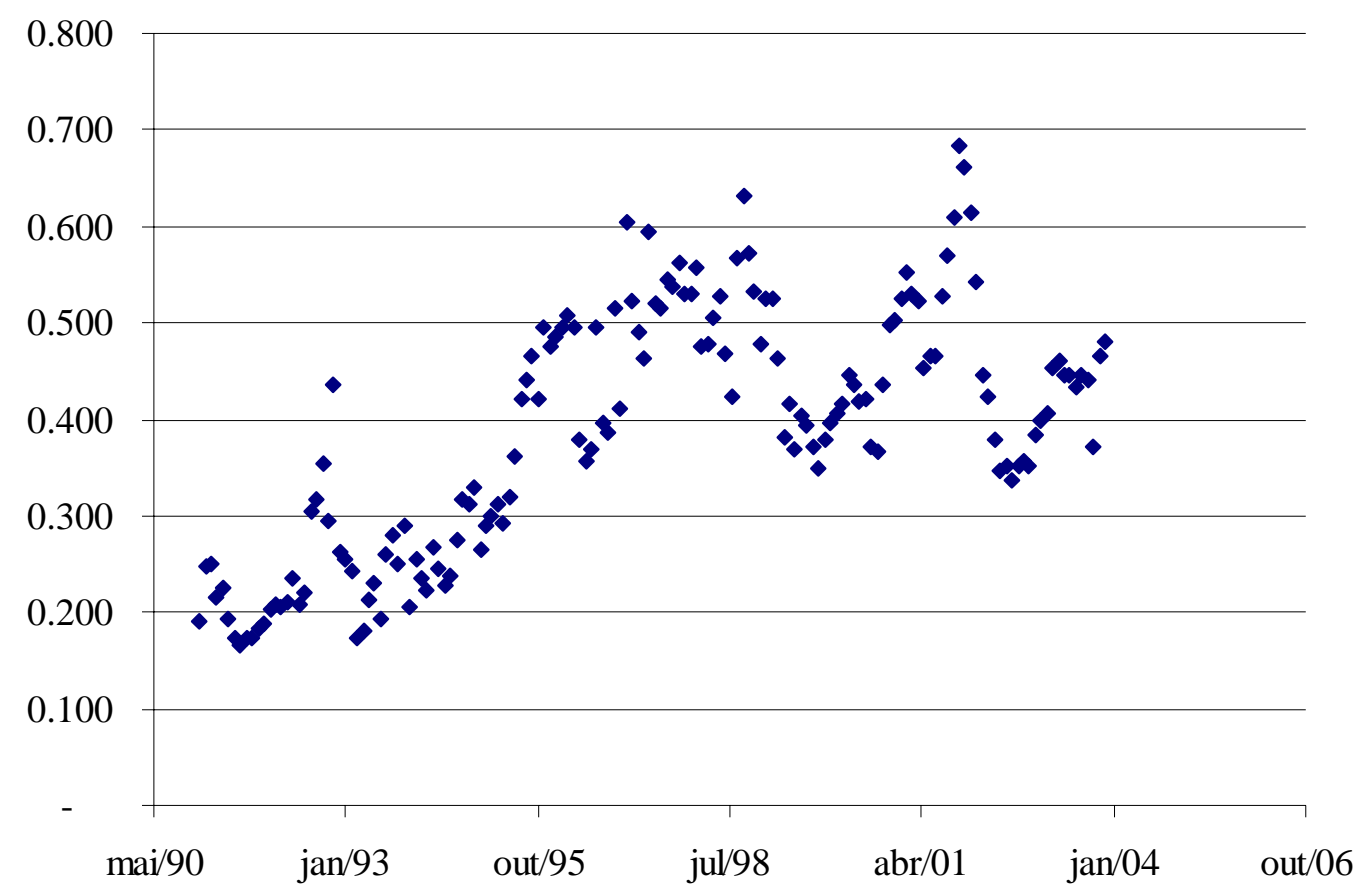

Figura 6 - Razão preço de importação e preço interno (US\$/R\$)

Fonte: Brasil (2003) e Centro de Pesquisas Avançadas em Economia Aplicada (CEPEA) (2004) 
Durante o período analisado o país foi um importador natural de leite. Esse quadro pode ser melhor observado com os dados a respeito do comportamento das exportações brasileiras de leite entre 1991 a 2003. A partir da análise dos dados de exportação percebe-se uma tendência do país se tornar um possível exportador do produto, graças à dinamicidade do segmento que o levou a tomar algumas decisões importantes tanto no que se refere ao aumento de produtividade quanto no que diz respeito ao cumprimento de exigências relacionadas às regulamentações internacionais do comércio a partir do fim da Rodada Uruguai. O intuito de incluir as exportações de leite é fazer um contraponto aos dados de importação do produto.

Segundo informações de Brasil (2003) as exportações brasileiras de lácteos foram de 10,2 milhões de dólares em 2003 contra 13,1 milhões de dólares em 1993 (ver Figura 7).

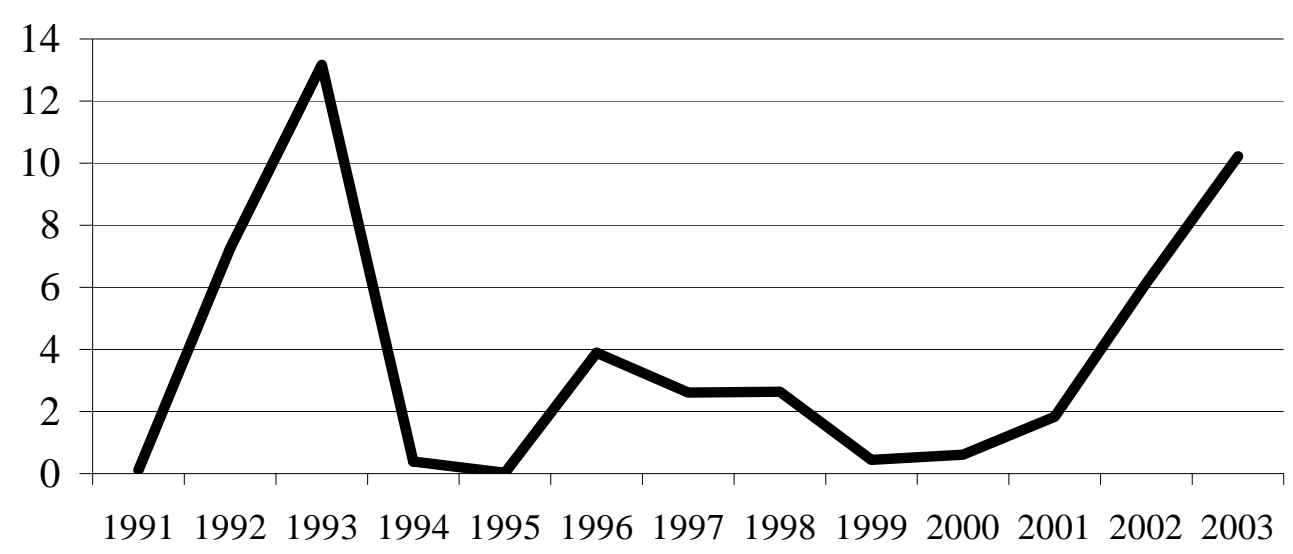

Figura 7 - Exportações brasileiras de leite fluido, 1991 a 2003 (em mil litros)

Fonte: Brasil (2003) 
A Tabela 14 mostra os destinos das exportações nacionais de lácteos para os anos de 1997 e 2002. Pela visualização da tabela pode-se perceber que, por exemplo, a Angola, em 1997, participava com aproximadamente de 2,48\% das exportações brasileiras de lácteos, em 2002, participou com cerca de 13,10\% delas, sendo o mais importante parceiro comercial do setor lácteo do país. Em contrapartida, a Argentina continuou a ser uma forte parceira no que tange o comércio intrabloco que se estabeleceu frente à criação do Mercosul.

Tabela 14. Destino das exportações brasileiras de leite e derivados, 1997 e 2002

\begin{tabular}{llrllc}
\hline Posição & \multicolumn{2}{c}{1997} & Posição & \multicolumn{2}{c}{2002} \\
& Países & $\%$ & & Países & $\%$ \\
\hline 1 & Argentina & 26,84 & 1 & Angola & 13,10 \\
2 & Venezuela & 15,38 & 2 & Argentina & 12,78 \\
3 & Rússia & 12,97 & 3 & Alemanha & 12,08 \\
4 & Japão & 8,28 & 4 & Estados Unidos & 10,86 \\
5 & Uruguai & 8,11 & 5 & Argélia & 9,18 \\
6 & Paraguai & 7,56 & 6 & Japão & 6,23 \\
7 & Holanda & 4,85 & 7 & Filipinas & 4,29 \\
8 & Colômbia & 4,34 & 8 & Venezuela & 4,11 \\
9 & Costa do Marfim & 2,58 & 9 & Paraguai & 4,08 \\
10 & Angola & 2,48 & 10 & Trinidad e Tobago & 3,76 \\
11 & Bolívia & 1,29 & 11 & Omã & 3,36 \\
12 & Outros & 5,32 & 12 & Chile & 2,18 \\
\hline
\end{tabular}

Fonte: Brasil (2003)

A Figura 8 apresenta as exportações mensais de leite no período de janeiro de 1991 a dezembro de 2003. Estas exportações incluem leite em pó desnatado, leite em pó integral, leite UHT e leite condensado convertidos em leite fluido. Segundo Martins (2003) os anos 1991 a 1993 foram de extrema instabilidade para a cadeia do leite, por dois motivos: instabilidade na economia e na cadeia especificamente, pois os produtores 
experimentavam as primeiras negociações com a indústria, na medida em que governo deixou de tabelar o produto em 1991. Percebe-se que, paralelo a esses dois fatores, o ano de 1993 apresentou uma desvalorização da moeda nacional que favoreceu a entrada do produto no exterior. Para o total de exportações de 1993, o produto que mais contribuiu foi o leite em pó desnatado com mais de $65 \%$ do total. 


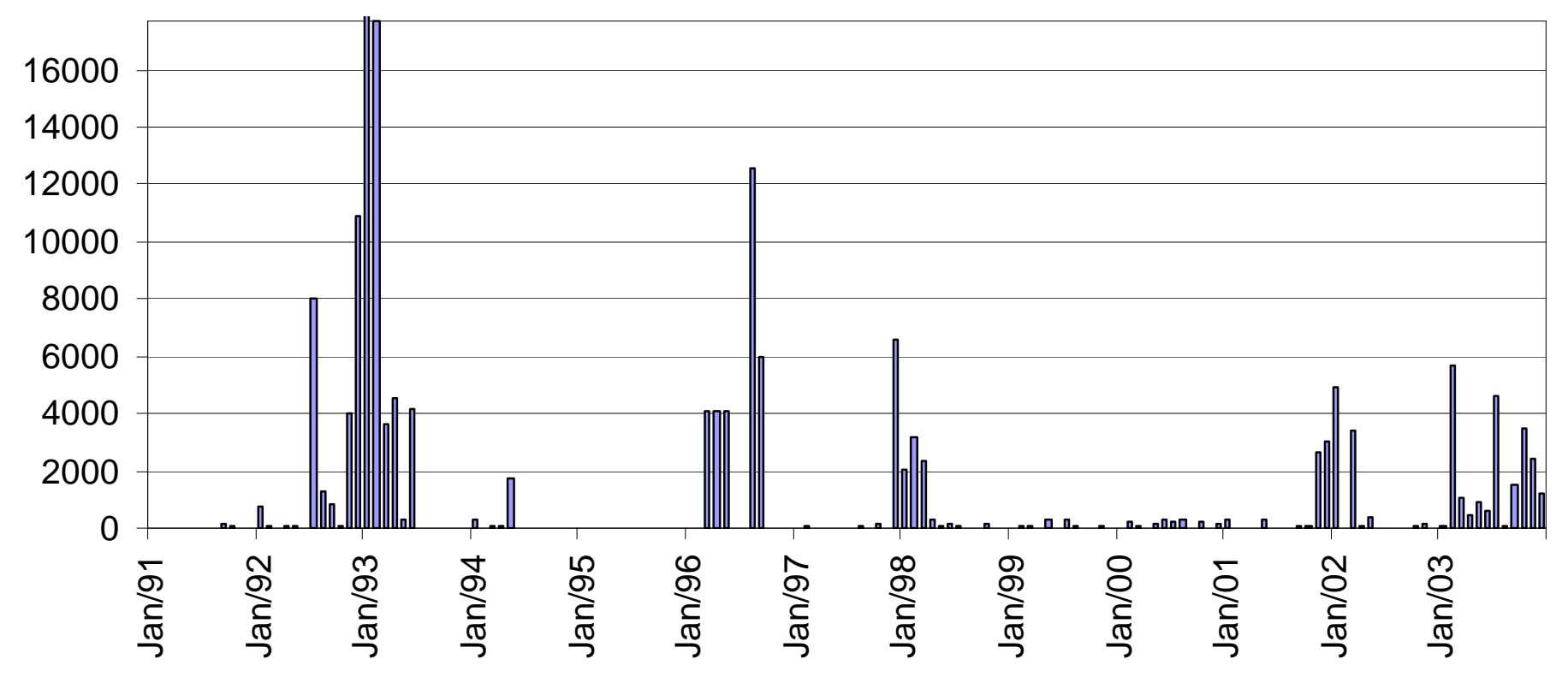

Figura 8 - Exportações mensais de leite em mil litros, Brasil, janeiro de 1991 a dezembro de 2003

Fonte: Brasil (2003) 
No período recente, entre 2002 e 2003 houve uma exportação de mais de três mil toneladas de leite influenciada pela implantação da SERLAC, trading exportadora composta pela Sertranding, Itambé, Embaré, Cooperativa Central de Laticínios do Estado de São Paulo (CCL), Confepar e Ilpisa que tem por meta a inserção do país no mercado exportador de lácteos e pela maior exportação de leite condensado.

Destacam-se as mudanças de postura da condução da política cambial pelo Banco Central a partir da implementação do Plano Real. A perspectiva é estabelecer um inter-relacionamento das mudanças econômicas e o comportamento das importações brasileiras de leite no período de 1994 a 2003.

De acordo com Alves et al. (1999), a sobrevalorização da moeda nacional aumentou depois de 1994 com o Plano Real, utilizando-se o conceito de "âncora cambial” para conter o processo inflacionário. Outros programas de estabilização similares basearam-se na taxa de câmbio, enquanto ocorria um déficit em conta corrente no Balanço de Pagamentos que levaram o país à vulnerabilidade aos movimentos de capital especulativos. A Figura 9 apresenta o saldo da balança comercial e o comportamento da taxa real de câmbio. Em um estudo feito por Silva e Barros (2003), percebeu-se que os efeitos macroeconômicos sobre um aumento de $10 \%$ da renda medida pelo PIB real em relação às importações do agronegócio elevariam as mesmas em 3,31\%. Já uma valorização da taxa de câmbio em torno de $10 \%$ elevaria as importações em 27\%. Esses valores são expressivos e levam a concluir em relação às mesmas estimativas para as exportações brasileiras do agronegócio, que a evolução da atividade econômica brasileira impacta mais acentuadamente as importações do agronegócio. 


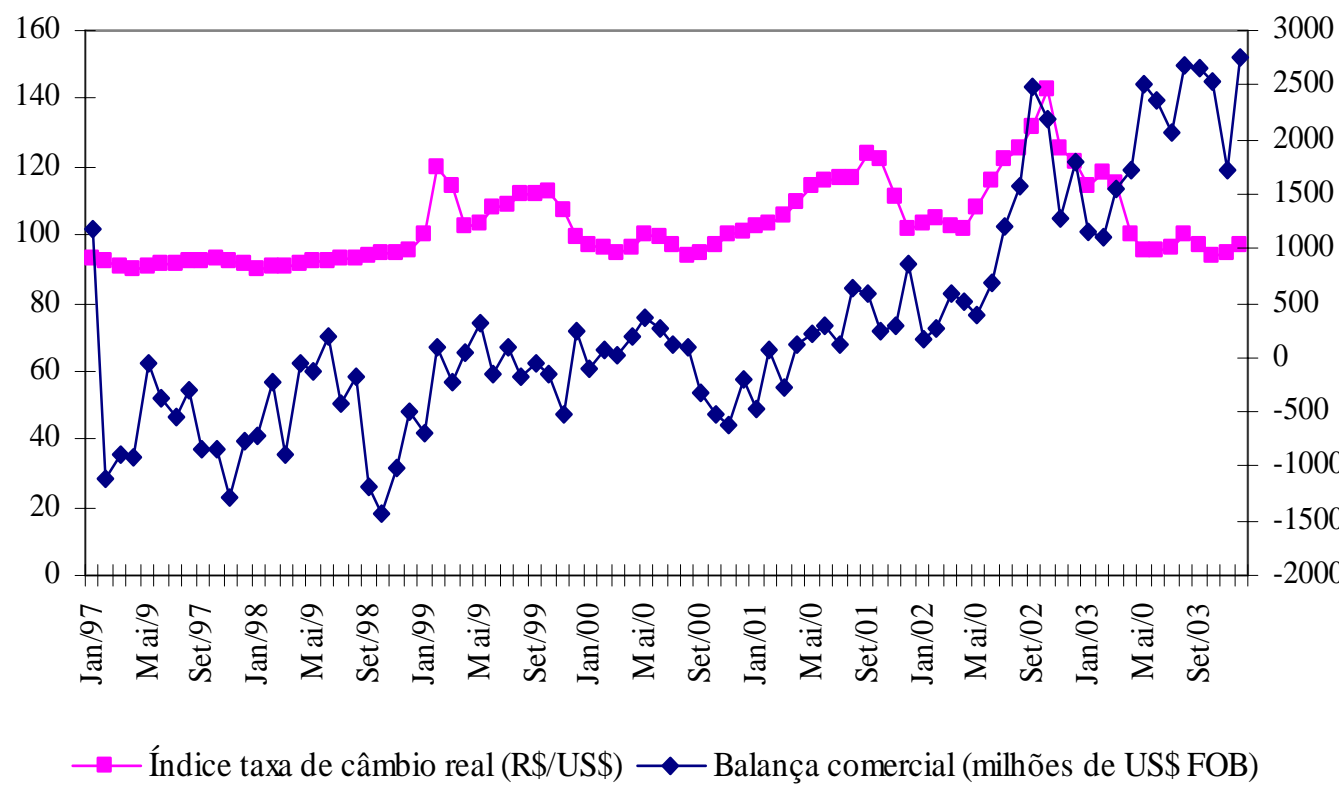

Figura 9 - Índice da taxa de câmbio real (R\$/US\$) e saldo da Balança comercial brasileira (em milhões de US\$ FOB)

Fonte: Fundação Getúlio Vargas (FGV) (2004) e Instituto de Pesquisa em Economia Aplicada (IPEA) (2004)

Com relação à posição do saldo comercial brasileiro em relação aos países do Mercosul, Lirio e Campos (2003) salientam que a reversão da posição no saldo comercial doméstico, em si, não foi de responsabilidade exclusivamente do intercâmbio com a Argentina. Percebe-se que o saldo comercial brasileiro com o Mercosul acompanha as variações ocorridas com a balança comercial do Brasil com a Argentina (ver Figura 10). A mesma ocorrência é constatada nas relações comerciais com os Estados Unidos e a União Européia. Segundo os autores, o saldo comercial com os Estados Unidos passou de um superávit de US\$ 2.299 milhões, em 1993, para um déficit de US\$ 1.650, em 1995; no caso da União Européia, o saldo reverteu-se de US\$ 3.556 milhões para um déficit de US\$ 361 milhões no mesmo período. 


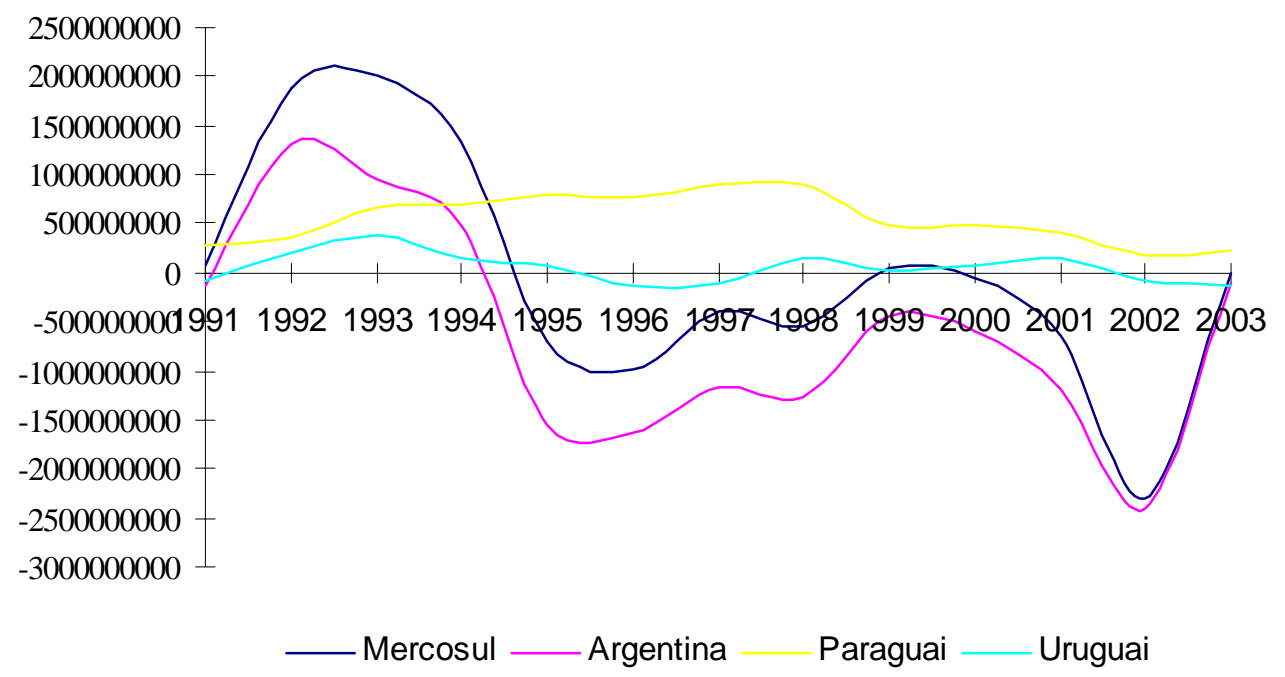

Figura 10 - Evolução do saldo comercial brasileiro (em US\$ FOB) com a Argentina, Paraguai, Uruguai e Mercosul, 1991 a 2003

Fonte: Brasil (2004)

De acordo com Machado e Ribeiro (1999), a alteração no regime cambial brasileiro deflagrou a mais séria crise enfrentada pelo Mercosul desde a celebração do Tratado de Assunção. Essa alteração cambial incorporou um elemento novo às relações econômicas entre os quatro países e suscitou uma série de reivindicações por parte, principalmente, do empresariado argentino. Nessa ocasião foram acionados diversos instrumentos protecionistas, sob o argumento de que os efeitos da desvalorização do real poderiam ser danosos à economia Argentina.

Para Lirio e Campos (2003), atualmente, os efeitos da desvalorização da moeda brasileira já foram incorporados ao contexto de comercialização entre os dois países. Entretanto, as tensões desencadeadas repercutiram em novas propostas de negociação, envolvendo a possibilidade de utilização de acordos setoriais voltados às 
restrições voluntárias de comércio e a criação de um sistema de salvaguardas intrabloco, nos termos estabelecidos pela OMC, com o intuito de garantir maior transparência e a transitoriedade no uso desses mecanismos. Deve-se ressaltar, no entanto, que a Argentina desvalorizou o peso em 30\% em janeiro de 2002. Essa medida tornou os produtos argentinos mais competitivos, elevando o superávit comercial do país com o Brasil.

No processo de estruturação do Mercosul, uma das características flagrantes é o expressivo aumento do fluxo de comércio intrabloco, que, de acordo com Lirio e Campos (2003), decorrem do aprofundamento das preferências comerciais arquitetadas pelos países membros do grupo. O intercâmbio comercial intrazona tem-se mostrado bastante dinâmico conforme revela a Tabela 15.

Tabela 15. América Latina e Caribe: percentual de destino das exportações de bens, segundo esquemas de integração, 1988, 1999 e $2000^{a}$

\begin{tabular}{lcccccccccccc}
\hline \multirow{2}{*}{ País/Bloco } & \multicolumn{3}{c}{ ALADI } & \multicolumn{4}{c}{ MERCOSUL } & \multicolumn{4}{c}{ ANDINA } & \multicolumn{4}{c}{ MUNDO } \\
& 1988 & 1990 & 2000 & 1988 & 1990 & 2000 & 1988 & 1990 & 2000 & 1988 & 1990 & 2000 \\
\hline Argentina & 19,3 & 25,3 & 49,0 & 9,6 & 14,8 & 35,9 & 5,4 & 4,1 & 5,4 & 65,7 & 55,8 & 9,7 \\
Bolívia & 47,1 & 44,8 & 48,2 & 40,1 & 34,5 & 18,5 & 4,6 & 6,5 & 26,3 & 8,2 & 14,2 & 7,0 \\
Brasil & 11,1 & 10,2 & 26,3 & 4,6 & 4,2 & 16,5 & 3,9 & 2,8 & 4,8 & 80,5 & 82,8 & 52,4 \\
Chile & 13,0 & 12,3 & 23,2 & 8,1 & 7,9 & 11,5 & 4,5 & 3,7 & 8,2 & 74,4 & 76,1 & 57,1 \\
Paraguai & 37,4 & 40,2 & 42,3 & 35,2 & 41,3 & 45,3 & 7,2 & 5,3 & 5,8 & 20,2 & 13,2 & 6,6 \\
Uruguai & 27,1 & 39,5 & 62,2 & 24,2 & 35,1 & 55,8 & 0,8 & 1,5 & 2,8 & 47,9 & 23,9 & 20,8 \\
\hline
\end{tabular}

Fonte: Banco Interamericano de Desenvolvimento (BID) (2001); Brasil (2001)

${ }^{\text {a }}$ Estimativas para o Chile, o Paraguai e o Uruguai

Pela análise individual da evolução do fluxo de comércio entre os parceiros do Mercosul ampliado (incluindo a participação de Chile e da Bolívia), constata-se, de 
acordo com a Tabela 15, que à exceção da Bolívia, todos os demais países tiveram suas exportações intra-regionais acentuadas na década de 90, com destaque para Brasil e Argentina (Lirio e Campos, 2003).

Após janeiro de 1999, houve uma desvalorização do real frente ao dólar, que juntamente com o aumento da TEC do Mercosul, impediram que as importações de lácteos pudessem crescer de forma expressiva. Além disso, o Brasil conseguiu provar a prática de dumping nas importações de leite em pó, integral e desnatado, não fracionado oriundas da Argentina, Nova Zelândia, União Européia e do Uruguai. Assim, a partir de fevereiro de 2001, concedeu-se ao Brasil o direito anti-dumping sobre as mesmas para a correção das distorções de preços com as empresas argentinas. Em abril de 2001 concedeu-se o mesmo direito sobre as distorções com as do Uruguai. Estabeleceu-se uma margem média ponderada de subcotação com valores de 3,9\% para as importações de leite em pó da Nova Zelândia; 14,8\% para as oriundas da União Européia (com exceção da Dinamarca).

As empresas que passaram por investigação foram as australianas ${ }^{4}$, as neozelandesas, as da UE, as argentinas e as uruguaias. Em janeiro de 2001, a dinamarquesa, Arla Foods Ingredients amba e as argentinas, Nestlé Argentina S.A., Sancor Cooperativas Unidas Ltda. e Milkaut S.A. apresentaram proposta de compromissos de preços no intuito de eliminar a margem de dumping. O aumento de preços no que dispõe o Decreto nº 1.602 de 1995 não foram superiores ao necessário para cessar o dano causado à indústria doméstica. Assim, não houve prosseguimento da investigação de dumping.

O processo de investigação de prática de dumping ficou restrita assim às do Uruguai, da Nova Zelândia (New Zealand Dairy Board - NZDB) e da UE exceto a dinamarquesa Arla Foods Ingredients amba.

\footnotetext{
${ }^{4}$ Investigou-se a prática de dumping das empresas australianas, porém diante da participação das importações de leite, oriundas da Austrália ser de 2\%, segundo os dados da SECEX e dos questionários de exportadores estrangeiros e de importadores nacionais, volume insignificante nos termos que dispõe o $\S 3^{\circ}$ do artigo 14 do Decreto ${ }^{\circ}$ 1.602, de 1995, cessou-se a investigação.
} 
As empresas uruguaias investigadas foram: Mastellone Hermanos S.A., Verônica S.A., Manfrey Cooperativa de Tamberos Comercio e Industria Ltda., WillinerSucessores de Alfredo Williner S.A., Molfino Hnos. S.A. Em abril de 2001, as uruguaias também firmaram compromissos de preços com o Brasil, porém passaram por todo o processo de investigação.

Nesse processo apuraram-se os preços do leite de cada país e região, conforme Tabela 16. Os produtos importados investigados foram os sob código NCM 0402.10.10, 0402.10.90, 0402.21.10, 0402.29.10 e 0402.29.20. Respectivamente, leite UHT, contendo matéria gorda, 1\%, não concentrado, não adoçado; creme de leite em pó, matéria gorda, 1,5\%; leite em pó integral, matéria gorda, 1,5\%, concentrado; leite integral em pó, contendo matéria gorda, 1,5\%, adocicado e leite parcialmente desnatado, contendo matéria gorda $1,5 \%$, adocicado.

Tabela 16. Margem de dumping absoluta e relativa praticada pelas empresas dos países e regiões investigadas, no período de julho de 1998 a junho de 1999

\begin{tabular}{lcccc}
\hline \multicolumn{1}{c}{ País / Região } & Empresa & $\begin{array}{c}\text { Categoria de } \\
\text { Leite }\end{array}$ & $\begin{array}{c}\text { Margem de } \\
\text { dumping* } \\
(\mathrm{US \$} / \mathrm{kg})\end{array}$ & $\begin{array}{c}\text { Margem de } \\
\text { dumping } \\
\text { relativa }\end{array}$ \\
\hline Nova Zelândia & NZDB & Pó Integral & 0,13 & 8,9 \\
& Pó Desnatado & $(0,02)$ & $(0,1)$ \\
UE & Exceto Arla Foods & Pó Integral & 1,50 & 100,7 \\
& Ingredientes amba & Pó Desnatado & 1,98 & 147,8 \\
Uruguai & Empresas uruguaias & Pó Integral & 0,11 & 5,4 \\
& & Pó Desnatado & 0,41 & 24,2 \\
\hline
\end{tabular}

Fonte: Brasil (2001)

* a margem de dumping foi calculada com base na comparação entre o valor normal ${ }^{5}$ e os preços comparáveis de exportação

\footnotetext{
${ }^{5}$ Os valores normais obtidos para a NZDB foram de US\$1,62/kg para o leite em pó integral e de US\$ $1,43 / \mathrm{kg}$ para o leite em pó desnatado. Para as empresas da UE, respectivamente, US\$ 2,99/kg e US\$ $3,32 / \mathrm{kg}$. Para as uruguaias, respectivamente, US\$2,15/kg e US\$2,09/kg.
} 
Para as importações de leite oriundas da Argentina e do Uruguai estabeleceu-se o preço mínimo de US\$ 1,9 mil por tonelada para o leite em pó importado. As vendas realizadas a valores mais baixos do que os US\$ 1,9 mil por tonelada que foram taxadas em $11 \%$. O acordo de preços mínimos com a Argentina vale desde fevereiro de 2001, e com o Uruguai desde abril de 2001 como resultado da investigação sobre dumping da Confederação Nacional da Agricultura (CNA), encaminhado em 1999.

Em suma, o leite em pó, integral e desnatado, não fracionado entram no país com os seguintes direitos alfandegários originários: 1-UE têm tarifa ad valorem de 16\% adicionado ao anti-dumping de 14,8\%; 2- Nova Zelândia, tarifa ad valorem de 16\% e anti-dumping de 3,9\%; 3- Argentina, Uruguai e empresa Arla Foods Ingredients amba, compromisso de preços; 4- Demais países, tarifa ad valorem de $16 \%$.

A Figura 11 apresenta a balança comercial brasileira de produtos lácteos selecionados de janeiro de 1999 a dezembro de 2003. Percebe-se que em todo o período à exceção de 1993 o saldo comercial foi negativo, representando importações superiores às exportações. 


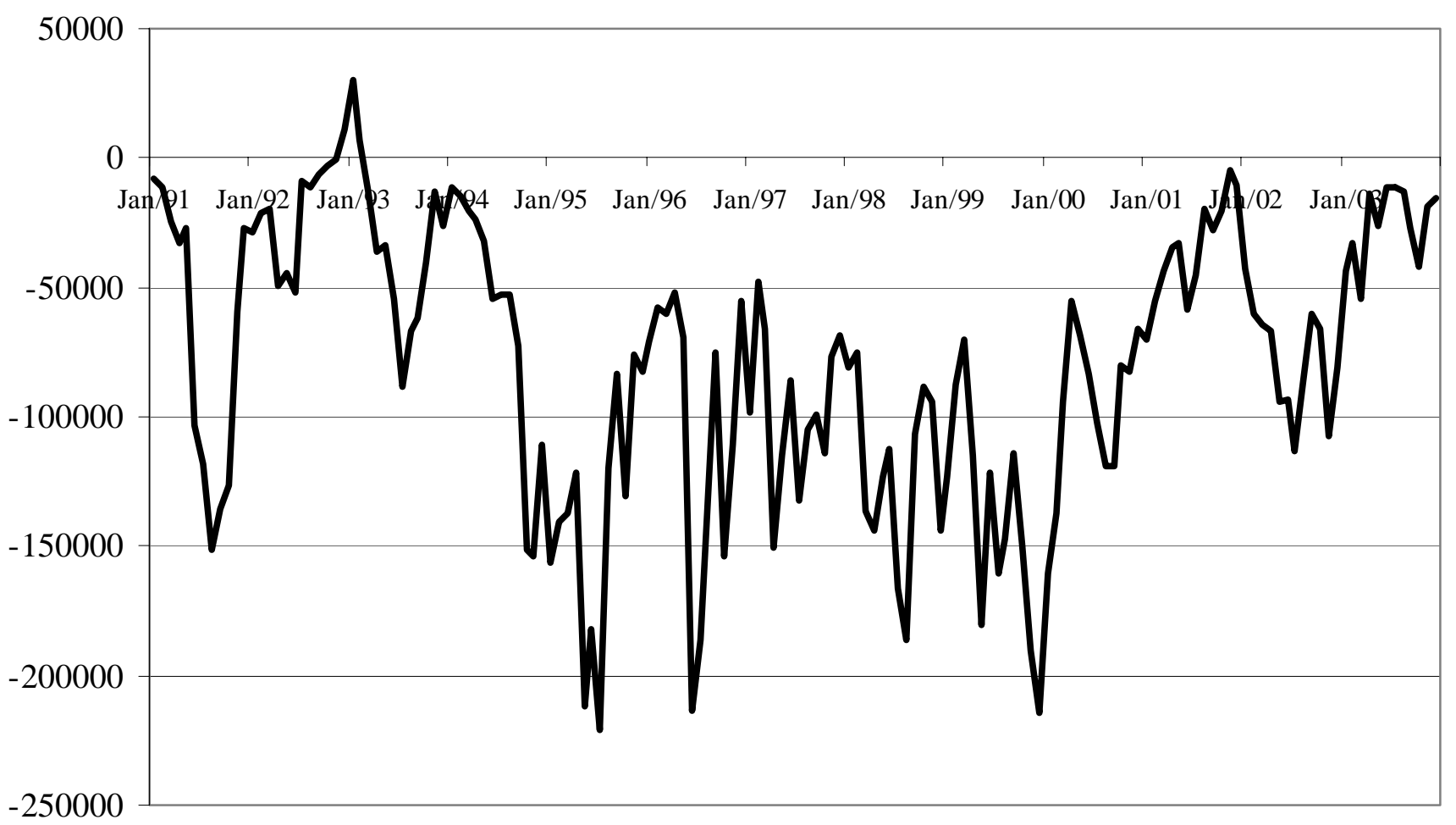

Figura 11 - Balança comercial brasileira (em mil litros) de produtos lácteos selecionados, janeiro de 1999 a dezembro de 2003

Fonte: Brasil (2004) 


\section{METODOLOGIA}

\subsection{Referencial teórico}

\subsubsection{Políticas comerciais}

\section{a) Tarifas de importação}

Para Brandão e Leite (2001), as distorções nos preços internacionais causadas pelas políticas comerciais permanecem elevadas no setor agrícola. A Rodada Uruguai do Acordo Geral sobre Tarifas e Comércio (GATT) determinou que os países convertessem barreiras não-tarifárias (cotas, tarifas variáveis) nos equivalentes tarifários, processo que ficou conhecido por "tarificação". Porém, as reduções efetivas de tarifa foram pouco significativas. No segmento lácteo, as reduções tarifárias obtidas na Rodada Uruguai foram extremamente baixas.

Porém, Thorstensen (1999) acredita que o acordo obtido na Rodada Uruguai foi importante, pois introduziu o setor agrícola nas normas e disciplinas do GATT; reduziu os subsídios às exportações e os apoios domésticos aos produtores; converteu as barreiras não tarifárias (por exemplo, cotas de importação) em tarifas equivalentes; consolidou todas as tarifas e as reduziu. A redução das tarifas significou uma diminuição de 37\%, em média, para todos os produtos, com reduções variando de 48\% para flores e plantas e até $26 \%$ para lácteos.

Essas opiniões contraditórias refletem o enfoque que cada autor tem do resultado da Rodada Uruguai. Os primeiros autores acreditam que o país poderia ter uma participação mais atuante no mercado internacional de leite diante do bom desempenho 
obtido pelo segmento ao longo da década de 90, e que uma das condições necessárias seria a redução dos apoios domésticos que, por exemplo, UE, Japão e EUA concedem aos produtores. A visão de Thorstensen (1999) partiu dos efeitos da Rodada Uruguai em termos de proposta regulatória do comércio internacional entre as nações, que procurou enfocar a redução das proteções econômicas obtidas.

No período anterior à Rodada Uruguai, a adoção de tarifas sobre importações levava a desequilíbrios nos diferentes mercados causando perda de eficiência. No mercado interno haveria aumento de preços, causando um incremento da produção e uma redução do consumo e da quantidade importada.

Segundo Carvalho e Silva (2002), o governo intervém no mercado com o intuito de favorecer o produtor nacional, constituindo uma proteção que pode reduzir as importações ou promover as exportações. Para os países com participação expressiva no comércio internacional, o objetivo das tarifas é dar vantagem ao produtor doméstico frente à concorrência externa.

As Figuras 12 e 13 incorporarão a partir deste momento o caso de um país pequeno, que significa o caso de um país exportar ou importar sem a possibilidade de influenciar os preços internacionais. Como o Brasil possui uma participação de 1\% no comércio internacional total, desconsiderando segmentos específicos, ele é considerado país pequeno. Dessa forma, os efeitos da tarifa de importação podem ser observados na Figura 12.

Supondo livre comércio, o preço internacional é igual ao preço no mercado doméstico $\left(\mathrm{P}_{\mathrm{m}}\right)$ que para o caso de um país pequeno é sua própria curva de oferta perfeitamente elástica. Com a introdução de uma tarifa sobre a importação de determinado produto ocorrerá alteração de preço no mercado doméstico $\left(\mathrm{P}_{\mathrm{m}}\right)$. A curva de oferta desloca-se para cima $\left(\mathrm{P}_{\mathrm{m}}{ }_{\mathrm{m}}\right)$, fazendo com que haja uma maior oferta do produto no mercado interno favorecida pelo aumento de preço. Contudo, há uma diminuição da importação e do consumo doméstico desse produto diante do aumento de preço. 


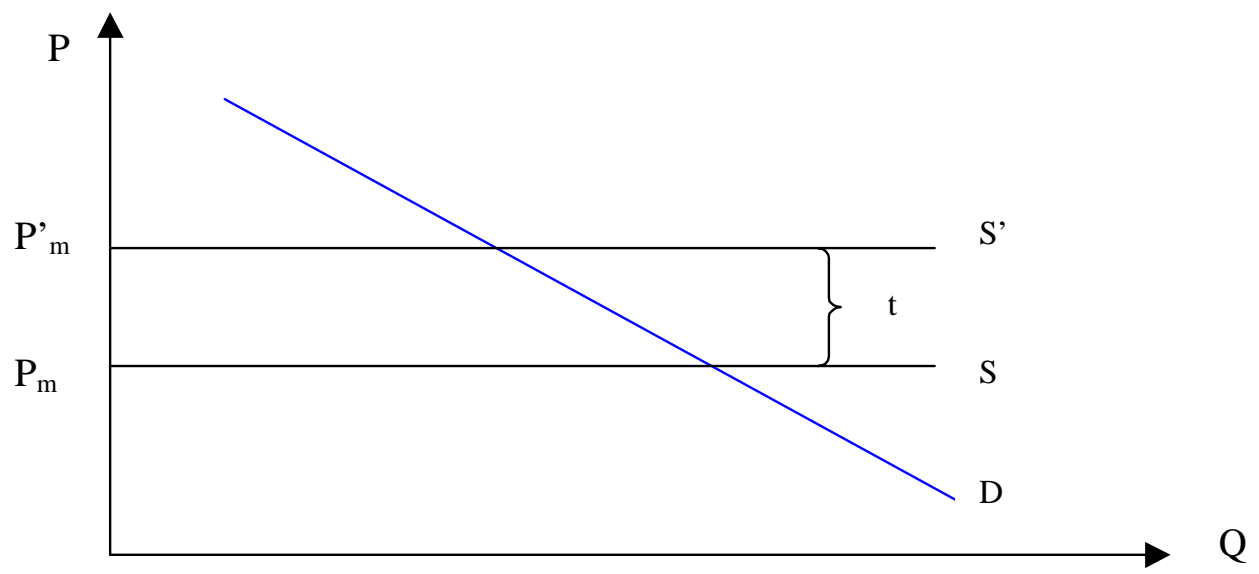

Figura 12 - Efeito da imposição de tarifa de importação, país pequeno Fonte: Carvalho e Silva (2002)

\section{b) Subsídios}

O subsídio utilizado para estimular as exportações, embora proibido pela OMC é praticada na atualidade no comércio de produtos agrícolas nos países desenvolvidos, como a União Européia. Deve-se levar em consideração que a adoção de um subsídio em um país grande representa um subsídio indireto aos consumidores de países pequenos como o Brasil. A Figura 13 representa o efeito do subsídio à exportação para um país pequeno.

Se o governo opta por subvencionar a exportação por meio de subsídio, s, sobre o preço internacional $\left(\mathrm{P}_{\mathrm{x}}{ }^{*}\right)$, o exportador nacional receberá o preço $\mathrm{P}_{\mathrm{x}}=(1+\mathrm{s}) \mathrm{P}_{\mathrm{x}}{ }^{*}$. $\mathrm{O}$ que leva a expansão da produção de $\mathrm{x}$ de $\mathrm{Q}_{2}$ para $\mathrm{Q}_{4}$. $\mathrm{O}$ importador paga $\mathrm{P}_{\mathrm{x}}{ }^{*}$ já que o governo subsidia o produto, e o produtor nacional recebe $\mathrm{P}_{\mathrm{x}}$ pela mercadoria exportada. 


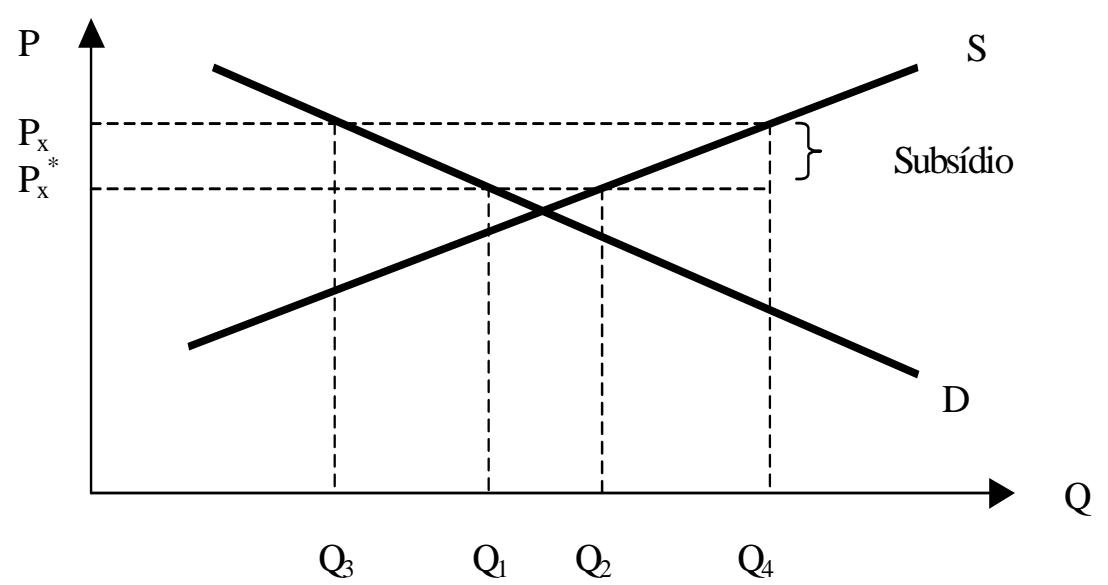

Figura 13 - Efeito de um subsídio à exportação, país pequeno

Fonte: Carvalho e Silva (2002)

Se ocorrer o subsídio em um país grande, aquele que influencia os preços internacionais dos produtos, para o país importador, a política de subsídios às exportações favorece o consumidor, que paga menor preço pelo produto. Porém, prejudica os produtores do setor nacional que competem com o produto importado subsidiado.

Martins (2002) cita o grau de subsídio ao leite aplicado pelos países da OCDE que pode ser entendido com a introdução do conceito de $\operatorname{SEP}^{6}$ (Subsídio de Equivalência ao Produtor).

A Tabela 17 apresenta os níveis de SEP para 11 países e na média OCDE. Os dados referem-se ao período de 1991 a 2003. Com os dados até 2002, percebe-se que

${ }^{6}$ A OCDE, desde 1987, mede o SEP que em sua forma algébrica é dado por: $\% S E P=\frac{S E P}{Q \cdot P_{p}+P P} \cdot 100$, em que SEP por países ou por mercadoria em termos monetários; $P P=$ pagamento aos produtores; $Q$. $P_{p}=$ valor da produção a preços de mercado e $Q$. $P_{b}$ valor da produção com o apoio governamental (Portugal, 2004). 
no período anterior ao Acordo Agrícola assinado ao final da Rodada Uruguai em 1994 os países apresentaram elevada taxa de proteção a seus mercados internos, o que dificultava a importação de produtos lácteos, à exceção da Nova Zelândia. Os dados referendam o que Brandão e Leite (2001) já haviam destacado, porém por outros indicadores. 
Tabela 17. Subsídio equivalente ao produtor de leite, em países da OCDE, US\$ (em milhões) e em porcentagem, vários anos

\begin{tabular}{|c|c|c|c|c|c|c|c|c|c|c|c|c|c|c|c|}
\hline Países & & $\begin{array}{c}\text { Média } \\
1986- \\
1988\end{array}$ & $\begin{array}{c}\text { Média } \\
2001- \\
2003\end{array}$ & 1991 & 1992 & 1993 & 1994 & 1995 & 1996 & 1997 & 1998 & 1999 & 2000 & 2001 & 2002 \\
\hline \multirow[t]{2}{*}{ Austrália } & US\$ & 300 & 291 & 615 & 606 & 499 & 543 & 509 & 479 & 533 & 425 & 281 & 253 & 258 & 277 \\
\hline & \% SEP & 29 & 14 & 39 & 35 & 29 & 30 & 23 & 21 & 25 & 23 & 15 & 13 & 12 & 15 \\
\hline \multirow[t]{2}{*}{ Canadá } & US\$ & 1742 & 1646 & 2173 & 1828 & 1727 & 1617 & 1386 & 1353 & 1570 & 1641 & 1620 & 1590 & 1442 & 1539 \\
\hline & \% SEP & 61 & 55 & 64 & 58 & 59 & 55 & 47 & 46 & 53 & 59 & 57 & 55 & 51 & 55 \\
\hline \multirow[t]{2}{*}{ Rep.Tcheca } & US\$ & 325 & 268 & 392 & 316 & 268 & 186 & 241 & 253 & 197 & 302 & 216 & 128 & 148 & 307 \\
\hline & \% SEP & 45 & 37 & 55 & 42 & 37 & 28 & 31 & 31 & 30 & 43 & 35 & 23 & 24 & 42 \\
\hline \multirow[t]{2}{*}{ UE } & US\$ & 20.866 & 18.796 & 26.297 & 27.776 & 25.379 & 24.471 & 28.796 & 26.274 & 22.601 & 25.360 & 21.018 & 15.049 & 15.386 & 18.446 \\
\hline & \% SEP & 57 & 47 & 59 & 59 & 59 & 57 & 54 & 51 & 50 & 57 & 51 & 42 & 42 & 49 \\
\hline \multirow[t]{2}{*}{ Hungria } & US\$ & 182 & 353 & 182 & 170 & 195 & 221 & 168 & 128 & 204 & 319 & 293 & 201 & 248 & 413 \\
\hline & \% SEP & 37 & 51 & 36 & 35 & 39 & 44 & 33 & 27 & 40 & 54 & 50 & 37 & 42 & 57 \\
\hline \multirow[t]{2}{*}{ Finlândia } & US\$ & 75 & 72 & 78 & 81 & 67 & 59 & 64 & 61 & 62 & 76 & 75 & 70 & 55 & 73 \\
\hline & \% SEP & 81 & 78 & 83 & 82 & 80 & 77 & 74 & 73 & 76 & 81 & 80 & 78 & 73 & 80 \\
\hline \multirow[t]{2}{*}{ Japão } & US\$ & 4.326 & 4.509 & 4.695 & 5.112 & 5.869 & 6.167 & 6.539 & 5.245 & 4.640 & 4.394 & 5.124 & 5.200 & 4.379 & 4.391 \\
\hline & \% SEP & 84 & 77 & 81 & 80 & 83 & 83 & 81 & 76 & 76 & 79 & 81 & 79 & 76 & 77 \\
\hline \multirow[t]{2}{*}{ Coréia } & US\$ & 680 & 816 & 703 & 656 & 680 & 687 & 762 & 752 & 626 & 524 & 728 & 880 & 747 & 890 \\
\hline & \% SEP & 73 & 68 & 76 & 72 & 73 & 71 & 68 & 66 & 66 & 65 & 70 & 71 & 66 & 70 \\
\hline \multirow[t]{2}{*}{ México } & US\$ & 389 & 1.117 & 943 & 956 & 1.239 & 1.052 & -2 & 455 & 748 & 921 & 1.094 & 1.142 & 1.271 & 1.220 \\
\hline & \% SEP & 34 & 40 & 50 & 46 & 52 & 48 & 0 & 24 & 35 & 43 & 44 & 41 & 43 & 43 \\
\hline
\end{tabular}


Tabela 17. Subsídio equivalente ao produtor de leite, em países da OCDE, US\$ (em milhões) e em porcentagem, vários anos

\begin{tabular}{|c|c|c|c|c|c|c|c|c|c|c|c|c|c|c|c|}
\hline Países & & $\begin{array}{c}\text { Média } \\
1986- \\
1988 \\
\end{array}$ & $\begin{array}{c}\text { Média } \\
2001- \\
2003\end{array}$ & 1991 & 1992 & 1993 & 1994 & 1995 & 1996 & 1997 & 1998 & 1999 & 2000 & 2001 & 2002 \\
\hline \multirow[t]{2}{*}{ Nova Zelândia } & US\$ & 74 & 15 & 10 & 10 & 10 & 12 & 17 & 16 & 15 & 12 & 13 & 12 & 14 & 12 \\
\hline & \% SEP & 9 & 1 & 1 & 1 & 1 & 1 & 1 & 1 & 1 & 1 & 1 & 1 & 1 & 1 \\
\hline \multirow[t]{2}{*}{ Noruega } & US\$ & 958 & 983 & 1.375 & 1.512 & 1.221 & 1.196 & 1.225 & 1.218 & 1.162 & 1.176 & 1.032 & 900 & 813 & 1.015 \\
\hline & \% SEP & 75 & 76 & 80 & 80 & 77 & 77 & 76 & 77 & 77 & 78 & 75 & 73 & 72 & 78 \\
\hline \multirow[t]{2}{*}{ Polônia } & US\$ & -165 & 267 & -353 & -42 & -101 & -267 & 27 & -74 & 130 & 397 & 235 & 180 & 285 & 336 \\
\hline & \% SEP & -11 & 12 & -24 & -2 & -6 & -17 & 1 & -3 & 6 & 18 & 11 & 9 & 12 & 15 \\
\hline \multirow[t]{2}{*}{ Rep. Eslovaca } & US\$ & 112 & 117 & 119 & 88 & 128 & 94 & 87 & 60 & 101 & 143 & 98 & 74 & 67 & 123 \\
\hline & \% SEP & 40 & 37 & 45 & 33 & 43 & 36 & 29 & 20 & 34 & 49 & 38 & 30 & 26 & 40 \\
\hline \multirow[t]{2}{*}{ Suíça } & US\$ & 1.973 & 1.980 & 2.465 & 2.431 & 2.342 & 2.463 & 2.796 & 2.626 & 2.190 & 2.123 & 1.974 & 1.692 & 1.779 & 2.025 \\
\hline & \% SEP & 82 & 78 & 81 & 80 & 80 & 80 & 79 & 78 & 77 & 78 & 81 & 74 & 75 & 79 \\
\hline \multirow[t]{2}{*}{ Turquia } & US\$ & 333 & 447 & 817 & 984 & 934 & 728 & 955 & 989 & 1.233 & 1.164 & 985 & 792 & 126 & 544 \\
\hline & \% SEP & 35 & 26 & 49 & 52 & 50 & 45 & 47 & 45 & 53 & 53 & 44 & 39 & 9 & 34 \\
\hline \multirow[t]{2}{*}{ EUA } & US\$ & 48.107 & 43.393 & 54.081 & 56.242 & 53.315 & 52.031 & 50.773 & 50.061 & 45.723 & 54.170 & 48.704 & 37.877 & 41.328 & 41.254 \\
\hline & \% SEP & 60 & 48 & 53 & 51 & 51 & 48 & 35 & 44 & 45 & 60 & 56 & 44 & 53 & 46 \\
\hline \multirow[t]{2}{*}{ OCDE } & US\$ & 48.107 & 43.393 & 54.081 & 56.242 & 53.315 & 52.031 & 50.773 & 50.061 & 45.723 & 54.170 & 48.704 & 37.877 & 41.328 & 41.454 \\
\hline & \% SEP & 59 & 48 & 58 & 57 & 57 & 55 & 50 & 50 & 49 & 57 & 53 & 45 & 46 & 48 \\
\hline
\end{tabular}

Fonte: OCDE (2004) 
O presente estudo não pretende estimar o efeito das tarifas e subsídios sobre a importação de leite brasileira, porém destacou-os como dois instrumentos de política comercial que afetam os preços internacionais do produto. Sabe-se que existiu durante todo o período de estudo proteção à produção leiteira nos países com os quais o Brasil importou leite. Porém, não havia disponível uma série de dados sobre subsídios e tarifas que se adequassem com as demais séries tomadas mês a mês. Todavia, ressalta-se que o preço de importação do leite, presente no modelo econométrico, incluirá implicitamente o efeito das tarifas e dos subsídios. Porém, a não incorporação dos mesmos limitará o modelo a ser estimado.

\subsubsection{Taxa de câmbio e a agricultura}

Schuh (1974) propôs na década de 70 a inclusão da variável taxa de câmbio no estudo dos problemas agrícolas norte-americanos. O autor delineia seu modelo como na Figura 14. Nela considera-se a agricultura no agregado e que a mesma possui potencial para ser um setor exportador. As curvas SS e DD representam a oferta doméstica e as condições de demanda, respectivamente, e $\mathrm{I}_{\mathrm{D}}$, a demanda internacional por produtos agrícolas. Pressupõe-se que o país não pode influenciar o preço de suas exportações, por isso $I_{D}$ é muito elástica. Além disso, $I_{D}$ é construída assumindo uma taxa de câmbio de equilíbrio.

Se $\mathrm{I}_{\mathrm{D}}$ prevalece, o preço doméstico será $\mathrm{P}_{1}$, determinado pelo mercado externo e pelas condições de oferta de longo prazo em outros países. Dadas as précondições, a quantidade produzida é $\mathrm{Q}_{2}$ e a quantidade demandada internamente, $\mathrm{Q}_{1}$. A quantidade $\mathrm{Q}_{1} \mathrm{Q}_{2}$ será exportada ao preço $\mathrm{P}_{1}$. A renda total do setor agrícola é representada por $\mathrm{OP}_{1} \mathrm{BQ}_{2}$, com $\mathrm{OP}_{1} \mathrm{AQ}_{1}$ obtida no mercado interno e $\mathrm{Q}_{1} \mathrm{ABQ}_{2}$, no mercado externo. 


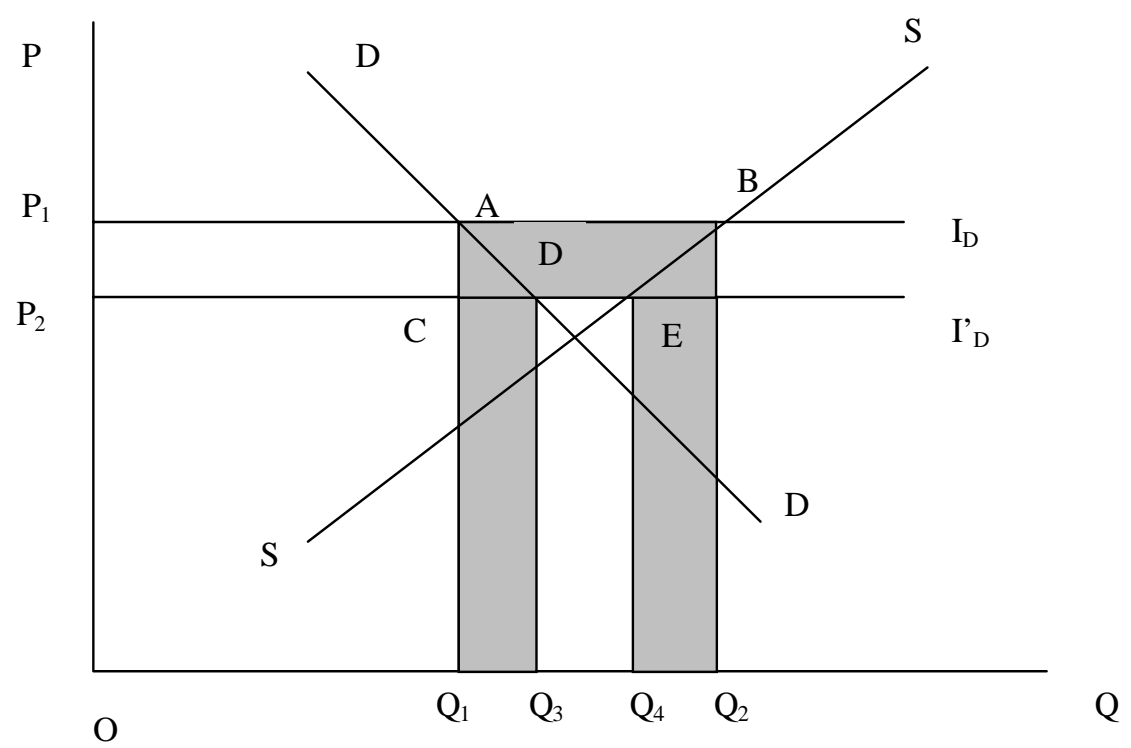

Figura 14 - Efeito de uma sobrevalorização cambial no mercado doméstico e no mercado externo

Fonte: Schuh (1974)

Admitindo-se que a moeda do país seja sobrevalorizada. A conseqüência no mercado interno é a queda de $I_{D}$ para I'D, ceteris paribus. Em termos do mercado externo, a conseqüência da sobrevalorização cambial é aumentar o preço dos produtos em dólar, o que reduz a quantidade exigida.

Ao menor preço, a quantidade interna demandada aumenta para $\mathrm{Q}_{3}$ e a quantidade ofertada declina para $\mathrm{Q}_{4}$. As exportações reduzem para $\mathrm{Q}_{3} \mathrm{Q}_{4}$ com preço $\mathrm{P}_{2}$. A área sombreada indica a magnitude pela qual é reduzido o valor das exportações do setor agrícola. A renda total é reduzida de $\mathrm{OP}_{1} \mathrm{BQ}_{2}$ para $\mathrm{OP}_{2} \mathrm{EQ}_{4} \mathrm{com} \mathrm{OP}_{2} \mathrm{DQ}_{3}$ obtida no mercado interno e $\mathrm{Q}_{3} \mathrm{DEQ}_{4}$, no mercado externo. 
Supõe-se que um país A necessite de importações agrícolas para regular seu mercado interno. Considere SS e DD sendo a oferta doméstica e as condições de demanda, respectivamente, e $\mathrm{I}_{S}$, a oferta internacional de produtos agrícolas. Pressupõese que o país seja tomador de preços internacionais, assim IS é perfeitamente elástica. E IS é construída assumindo uma taxa de câmbio de equilíbrio (Figura 15).

Se $\mathrm{I}_{\mathrm{S}}$ prevalece o preço doméstico será $\mathrm{P}_{1}$, determinado pelas condições predeterminadas, a quantidade produzida é $\mathrm{Q}_{2}$ e a quantidade demandada internamente, $\mathrm{Q}_{1}$. A quantidade $\mathrm{Q}_{1} \mathrm{Q}_{2}$ será importada ao preço $\mathrm{P}_{1}$.

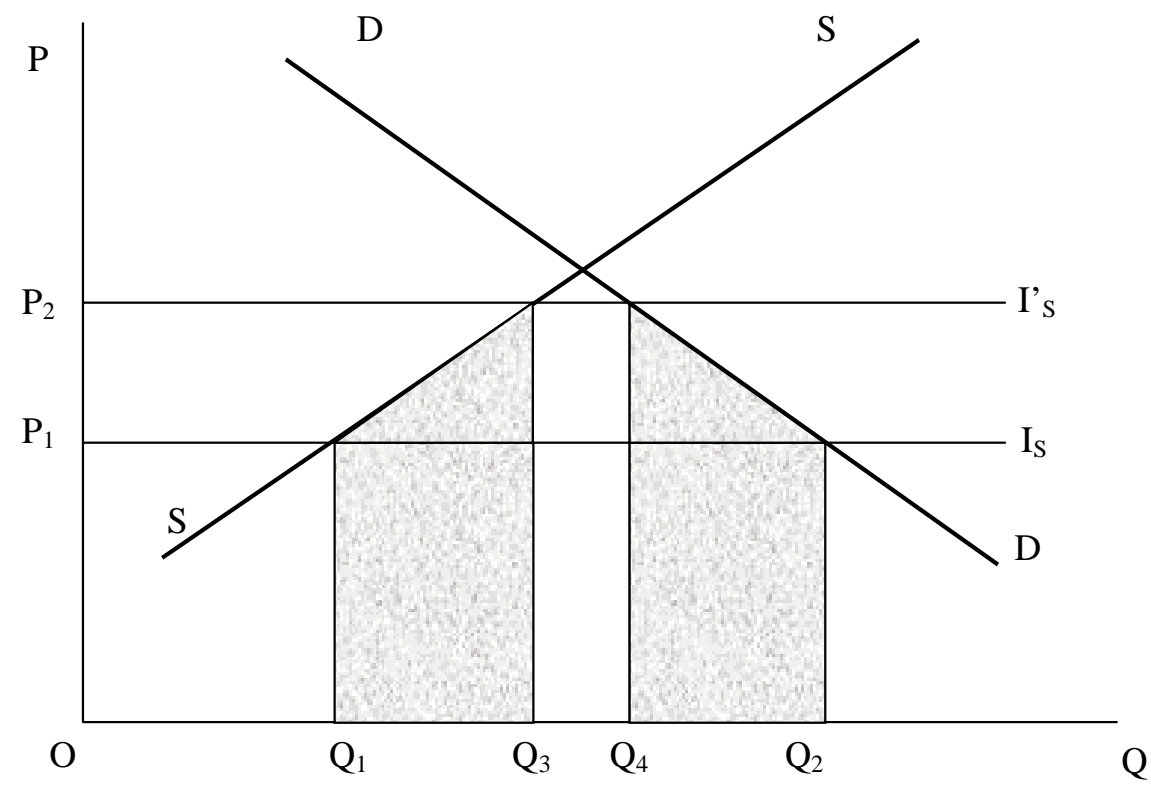

Figura 15 -Efeito de uma redução dos subsídios e de uma sobrevalorização cambial no mercado doméstico e no mercado externo 
Admite-se, inicialmente, que os subsídios nos países desenvolvidos reduzam. O efeito no mercado doméstico é o deslocamento de I $I_{S}$ para I's, ceteris paribus. Em termos de mercado externo, a conseqüência da redução dos subsídios é aumentar o preço internacional, de $\mathrm{P}_{1}$ para $\mathrm{P}_{2}$. Se houver ainda uma sobrevalorização cambial, o efeito no mercado interno é elevar o preço dos produtos em dólar, o que diminui a quantidade exigida.

Ao maior preço, a quantidade interna demandada reduz de $\mathrm{Q}_{1}$ para $\mathrm{Q}_{3}$ e a quantidade ofertada de $\mathrm{Q}_{2}$ para $\mathrm{Q}_{4}$ com o preço $\mathrm{P}_{2}$. A área hachurada informa o tamanho da redução do valor das importações do setor agrícola.

Outros autores como Greenshields (1974) chegaram à conclusão de que a taxa de câmbio não tem sido significativa para determinar o nível de comércio agrícola entre Estados Unidos e Japão na década de 60. O estudo de Greenshields (1974) pretendeu responder quais as variáveis que são significativas para o comércio entre os dos países.

Collins et al. (1980) argumentaram que o modelo apropriado para os efeitos da taxa de câmbio requer o reconhecimento de que em muitos países existem políticas agrícolas que isolam o mercado interno dos mercados internacionais. O resultado do seu modelo foi que as políticas que isolam o mercado externo do mercado doméstico diminuem os efeitos das mudanças da taxa de câmbio.

Orden (1986) utiliza o método VAR (vetor auto-regressivo) para analisar os efeitos da oferta monetária, da taxa de câmbio e da taxa de juros sobre as exportações agrícolas e sobre os preços recebidos pelos produtores norte-americanos. O autor concluiu que estas variáveis apresentam uma regra significativa na determinação das exportações agrícolas e dos preços agrícolas. A política monetária é forte o suficiente para determinar os preços relativos na agricultura quando os estoques monetários estão grandes. A taxa de câmbio e a taxa de juros têm um maior efeito no valor total das exportações se comparado à oferta monetária. 


\subsection{Condicionantes das importações}

Martins (2002) sistematizou o mercado internacional de lácteos enfocando as distorções que afetam a eficiência e a competitividade do produto brasileiro frente aos importados. $\mathrm{O}$ autor procurou distinguir três pontos principais: i) a regulamentação do mercado lácteo; ii) o cenário existente no mercado internacional de lácteos; e iii) o Acordo Agrícola após o término da Rodada Uruguai. Para tanto, o autor fez uma pesquisa abrangente da literatura internacional com o objetivo de conhecer os resultados das simulações acerca dos efeitos da desregulamentação do mercado de lácteos.

Turnbull (1999) salienta que as políticas protecionistas contribuem para que somente 5\% da produção mundial de leite sejam transacionadas no mercado mundial. Bailey (1997) reforça essa estimativa de Turnbull (2001), acrescentando que os subsídios à produção doméstica, as barreiras às importações e os subsídios às exportações distorcem o mercado internacional de lácteos e afetam as economias das nações de diversas formas.

Tendo as teorias de comércio internacional como suporte, faz-se necessário que se estabeleçam diretrizes das mesmas. Ela será calcada em três pilares básicos: i) as políticas domésticas; ii) as políticas de importação e iii) as políticas de exportação. A inclusão das políticas de exportação foi necessária diante da possibilidade de inversão do saldo da balança comercial de lácteos e do desempenho favorável da produção frente às mudanças nas políticas macroeconômicas do segmento leiteiro.

No caso do setor lácteo, a UE, por exemplo, subsidia o leite em pó destinado ao consumo humano e animal e estoques de manteiga. Em contrapartida, os Estados Unidos, Japão e também a UE utilizam a merenda escolar como mecanismo de sustentação da demanda por lácteos. A Nova Zelândia e a Austrália subsidiam os insumos usados pelos fazendeiros [ZHU et al., 1999 citado em Martins (2002)].

Para Martins (2002), as políticas macroeconômicas que afetaram o segmento lácteo brasileiro podem ser resumidas pela desregulamentação a partir da década de 90. 
Em países como Brasil e México, que não possuíam auto-suficiência, a abertura econômica atuou como redutor de preços internos de derivados lácteos. Esse fato favoreceu o controle das taxas de inflação pelo Estado. Nos países exportadores de leite, como Uruguai e Argentina, a desregulamentação assegurou o ingresso contínuo de divisas, porém diante da crise estatal nesses países, não houve a possibilidade de implementação de políticas que inserissem definitivamente os dois países no cenário internacional como exportadores de lácteos.

Embora Martins (2002) afirme que as reformas de regulamentação de mercados implementadas na América Latina, não tiveram como objetivo a inserção ao Acordo Agrícola ${ }^{7}$ (AA) e que o esforço maior foi tentar preservar a renda dos produtores rurais de leite brasileiros. Há que se destacar que os países da América Latina foram signatários do AA, e estão incorporando-o por meio de suas legislações nacionais. O que se conclui que as bases para a entrada do AA existiam e estão em plena discussão.

Em suma, para Martins (2002), a desregulamentação do mercado brasileiro foi mais uma conseqüência das políticas macroeconômicas implementadas pelo governo federal de liberalização do comércio, formação do Mercosul, estabilização monetária e das alterações na política cambial do que uma conseqüência direta do Acordo Agrícola. Todavia, como previa o AA houve a redução das tarifas ad valorem brasileiras que para o autor foi conseqüência direta do estabelecimento da TEC do Mercosul e não do Acordo.

\subsection{Modelo econômico}

Com o intuito de analisar o efeito das políticas macroeconômicas sobre as importações de lácteos brasileiras foi especificado um modelo econométrico para a demanda de importação no período de 1991 a 2003. Porém, fez-se necessário uma breve

\footnotetext{
${ }^{7}$ Ao final da Rodada Uruguai, em 1994, estabeleceu-se o Acordo Agrícola. Este acordo resultou em normas relativas ao acesso a mercado, a políticas de apoio interno e aos subsídios às exportações.
} 
revisão do estado da arte em que se encontram os modelos econômicos para especificação da função de demanda por importação.

No estudo de Castro e Cavalcanti (1997), houve a estimativa de equações de exportação e de importação - totais e desagregadas por fator agregado e categoria de uso, respectivamente - para o Brasil, a partir de dados anuais em valor (em dólares) para o período de 1955 a 1995. Os procedimentos econométricos utilizados deram atenção à não-estacionariedade das variáveis sob análise, e se basearam nos conceitos de cointegração e no modelo de correção de erros. Os autores apresentaram algumas projeções de crescimento das exportações e importações para o período de 1996 a 2000, sob diferentes cenários.

O trabalho de Castro e Cavalcanti (1997) não diferiu muito de outras pesquisas até então publicadas como Dib (1985), Zini Junior (1988), Fachada (1990), Portugal (1992) e Zagury (1994). As variáveis condicionantes das importações foram duas: nível de atividade e preços relativos. Utilizaram o PIB (Produto Interno Bruto) como proxy para a primeira e a taxa de câmbio real para a última.

Em Hemphill (1974), foi desenvolvido e estimado um modelo econométrico no qual postulava-se que, nos países não desenvolvidos, as importações são fortemente influenciadas por suas receitas de divisas. Ou seja, o nível dessas últimas corresponderia a um indicativo do rigor dos controles tarifários e não tarifários sobre as importações. $\mathrm{O}$ autor testou essa hipótese para os seguintes países: Argentina, Burma, Chile, China, Colômbia, El Salvador, Índia e Tailândia. Seus testes rejeitam a hipótese de que as receitas de divisas não influenciavam as importações nesses países.

A intensidade da relação receita de divisas/importações pode ser sugerida pela magnitude das elasticidades estimadas em seu modelo. Quanto maior for a elasticidade do quantum importado em relação à receita de divisas, menor deve ser a capacidade de controle da disponibilidade de divisas por meio da política econômica. Nesse caso, a disponibilidade (receita) de divisas foi determinada pelos ciclos dos mercados de comércio e financeiro internacionais. Ou seja, um país com baixa 
capacidade de controle sobre os fluxos do balanço de pagamentos apresentariam alterações na intensidade da restrição externa ao seu crescimento bastante atreladas a mudanças e ciclos de mercados de comércio e de finanças internacionais, se comparado a outro país que apresentasse maior autonomia da política econômica sobre esses fluxos do balanço de pagamentos. Resende (2000) desenvolveu uma análise considerando o crescimento econômico e a disponibilidade de divisas para determinar as importações totais para o país. Para ele existem poucos graus de liberdade para a política macroeconômica, portanto existem dificuldades para a flexibilização da restrição externa - disponibilidade de divisas - que muitas vezes impedem o ajuste do balanço de pagamento, o que acaba por influenciar a demanda por importações. Assim, a adequação das importações à disponibilidade de divisas, ao longo dos ciclos econômicos financeiros internacionais, afetou com intensidade os níveis relativos de macrovariáveis da economia brasileira como: taxa de câmbio, juros, preços, salários, lucros e investimentos e das taxas de crescimento econômico. Assim, existem efeitos alternados sobre os estímulos à substituição de importação por produção doméstica e de substituição desta por importações.

Resende (2000) influenciado por Hemphil (1974) especificou uma função de demanda por importações que contempla, entre suas variáveis explicativas, uma variável que expressa a disponibilidade de divisas externas da economia brasileira. Ele avaliou seu grau de influência sobre a demanda de importações no Brasil. Ou seja, postulou-se que o aumento da disponibilidade de divisas externas provoca a redução de barreiras tarifárias e não tarifárias (o que estimula as importações), enquanto a redução da disponibilidade de divisas resulta na intensificação do uso de barreiras às importações.

Carvalho e Parente (1999) chamaram à atenção para a importância da mensuração de equações de demanda de importações tendo em vista o contexto da globalização no qual os países estão inseridos. Assim, com o crescimento dos processos de integração tornaram-se possíveis estudos ex-ante, que possibilitaram fazer inferências sobre prováveis efeitos destes acordos comerciais para os países envolvidos. Na pesquisa desses autores, houve a estimação de equações estruturais de demanda por 
importações mensais por categoria de uso para o Brasil no período de janeiro de 1978 a dezembro de 1996. Nos cinco setores, assumiu-se exogeneidade estrita para as variáveis explicativas: preço relativo do produto importado em relação ao produto doméstico, PIB brasileiro e taxa de utilização da capacidade instalada. Constatou-se a nãoestacionariedade das séries em questão; dessa forma, a estimação dos vetores de cointegração via procedimento uniequacional foram feitas a partir de uma regressão com defasagens distribuídas. E, as relações de longo e curto prazo foram sintetizadas empregando-se um mecanismo de correção de erros.

A especificação do modelo de demanda de importação de Hitiris e Petoussis (1984) teve por intuito captar o efeito das alterações de preço e tarifa de importação entre Grécia e Mercado Comum Europeu (MCE) no período de 1957 a 1977. Partiram da hipótese de que as mudanças nos preços e nas tarifas de importações têm efeitos idênticos se comparados. Pois queriam refutar a hipótese de Balassa ${ }^{8}$ citado por Hitiris e Petoussis (1984), que é a de que os importadores consideram as mudanças de tarifas como sendo permanentes e que os mesmos realocam seu volume de importação como se fossem alterações nos preços de importação. Vale ressaltar que, o conjunto de tarifas utilizado pelos autores é aquele que foi objeto da gradual redução tarifária acordada para a entrada da Grécia no MCE. Concluiu-se que os efeitos dos preços de importação e das tarifas sobre o volume de importação não podem ser considerados distintos.

Schmitz e Seale (2002) em seu artigo propuseram estimar empiricamente a sensibilidade das importações de frutas frescas feitas pelo Japão, entre 1971 a 1997, em relação às alterações do nível de renda e dos preços de importação. Usando dados anuais do volume de importações totais de sete frutas frescas (banana, laranja, limão, abacaxi, uva, frutas vermelhas e grapefruit) procuraram explicação para crescente dependência japonesa por importação agrícola vis-à-vis redução do número de produtores agrícolas japoneses. O modelo desenvolvido baseiou-se no de Rotterdam, obtido da maximização da utilidade do volume importado sujeito à restrição orçamentária.

\footnotetext{
${ }^{8}$ BALASSA, B. Trade liberalization among industrial countries. New York: Council on Foreign Relations/ McGraw Hill, 1967. 251p.
} 
O modelo de Brid (2002) tentou captar a melhor especificação da função de demanda por importação para o México entre os anos de 1970 e 1996. Não foi utilizada a análise de co-integração multivariada e, sim uma para o modelo com poucas variáveis, em virtude dos dados no país não serem confiáveis. A análise dos dados indicou que no sub-período, 1985-1987, quando a liberalização comercial foi rápida e radicalmente implementada, ocorreram trocas significativas nos parâmetros-chave da demanda por importações mexicanas. Um exemplo foi que o resultado da elasticidade de ingresso de importações de 1,522 e 2,411 se tornou superior se comparada ao estudo anterior de 0,60 e 1,80 , indicando ter havido uma modificação permanente no comportamento do total das importações no sub-período analisado.

Osaki e Barros (2003) estimaram a função de demanda por importação de batata semente com o intuito de analisar os efeitos sobre os preços das sementes (nacional e importada) e sobre a taxa de câmbio. O modelo econômico adotado foi especificado na forma logarítmica e os resultados obtidos mostraram que os coeficientes dos preços da semente importada e da semente nacional foram significativos ao contrário da taxa de câmbio que não foi estatisticamente significativa.

Em seu estudo, Osaki (2003) desenvolveu um sistema de equações de oferta e de demanda por cebola importada entre Brasil e Argentina após a criação do Mercosul. O método aplicado para a estimação do modelo foi o de mínimos quadrados de dois estágios, procedendo aos testes de estacionariedade e de co-integração. O resultado encontrado indicou um efeito relevante da variável preço da cebola nacional sobre o preço que foi pago à cebola argentina. Isto revelou uma efetiva integração entre os dois países no mercado desse produto. $\mathrm{O}$ autor destacou que uma variação positiva no preço da cebola nacional determina uma alta do preço do produto importado, indicando um ganho no prêmio de qualidade.

A Tabela 18 especifica as funções de demanda por importação estimadas pelos autores supra citados. 
Tabela 18. Especificações das funções de demanda por importações estimadas, vários autores

\begin{tabular}{|c|c|c|}
\hline Autores & Função de importação & Variáveis \\
\hline Leamer e Stern $(1970)^{9}$ & $M=f\left\{\frac{P_{m}}{P_{d}}, \frac{Y}{P_{d}}\right\}$ & $\begin{array}{l}M=\text { volume do produto importado; } P_{m}=\text { preço do } \\
\text { produto importado; } P_{d}=\text { preço do produto doméstico; } \\
\frac{P_{m}}{P_{d}}=\text { preço relativo do importado; } \frac{Y}{P_{d}}=\text { renda real }\end{array}$ \\
\hline Hemphil (1974) & $M_{t}=f\left\{R_{t-1}, F_{t}, \lambda F_{t}\right\}$ & $\begin{array}{l}M_{t}=\text { quantum importado em } \mathrm{t} ; F_{t}=\text { receita de divisas } \\
\text { em } t ; \lambda=F_{t}-F_{t-1} ; R_{t-1}=\text { nível de reservas externas } \\
\text { em } t-1\end{array}$ \\
\hline
\end{tabular}

Hitiris e Petoussis (1984) $\quad V_{t}=f\left\{Y_{t-1}, P_{t-1},(1+T), V_{t-1}, Q\right\}$

$V_{t}=$ volume de importações em $t ; Y_{t-1}=$ renda real em

$t-1 ; P_{t-1}=$ preço relativo em $t-1 ; T=$ valor da tarifa;

$Q=$ conjunto de dummies sazonais

${ }^{9}$ Ver mais detalhes em Osaki (2003) 
Tabela 18. Especificações das funções de demanda por importações estimadas, vários autores

\begin{tabular}{|c|c|c|}
\hline Autores & Função de importação & Variáveis \\
\hline Zini Junior & $\begin{array}{l}\text { 1) } M=f\left\{e \frac{P M}{P D}, T R, U, Y T\right\} \\
\text { 2) } M=f\{e P M, P D, T R, U, Y T\} \\
\text { 3) } M=f\left\{e \frac{P W W}{P W D}, \frac{P M}{P W W}, \frac{P D}{P W D}, T R, U, Y T\right\}\end{array}$ & $\begin{array}{l}M=\text { quantidade importada; } P D=\text { preço doméstico; } \\
P M=\text { preço de importação; } Y T=\text { produto potencial } \\
\text { doméstico; } e=\text { taxa de câmbio; } T R=\text { tarifa média; } \\
P W W=\text { preço por atacado no resto do mundo; } U= \\
\text { indicador de ciclos domésticos }\end{array}$ \\
\hline
\end{tabular}

$M=$ volume de importações totais; $Y=$ PIB;

$m_{b k}, m_{b i}, m_{b c}=$ importações de bens de capital, bens intermediários (exceto petróleo); e bens de consumo;

Castro e Cavalcanti $\quad M=f\left\{Y, m_{b k}, m_{b i}, m_{b c}, e, e_{b k}, e_{b i}, e_{b c}\right\}$ $e=$ taxa de cambio para o total das importações

deflacionado $\frac{I P A_{E U A}}{I P A_{B R A}} ; e_{b k}, e_{b i}, e_{b c}=$ taxa de câmbio para as categorias de uso

$M_{t}=$ quantum importado em $t ; e P m_{t}=$ valor das

Resende (1997) $M_{t}=f\left\{e P m_{t}, P d_{t}, Y^{*}, U_{t}, \operatorname{CapM}_{t}, M_{t-1}\right\}$ importações totais em $t ; P d_{t}=$ preço doméstico em $t$; $Y^{*}=$ PIB real em $t ; U_{t}=$ componente cíclico da renda; $\operatorname{CapM}_{t}=$ capacidade de importação em $\mathrm{t}$ 
Tabela 18. Especificações das funções de demanda por importações estimadas, vários autores

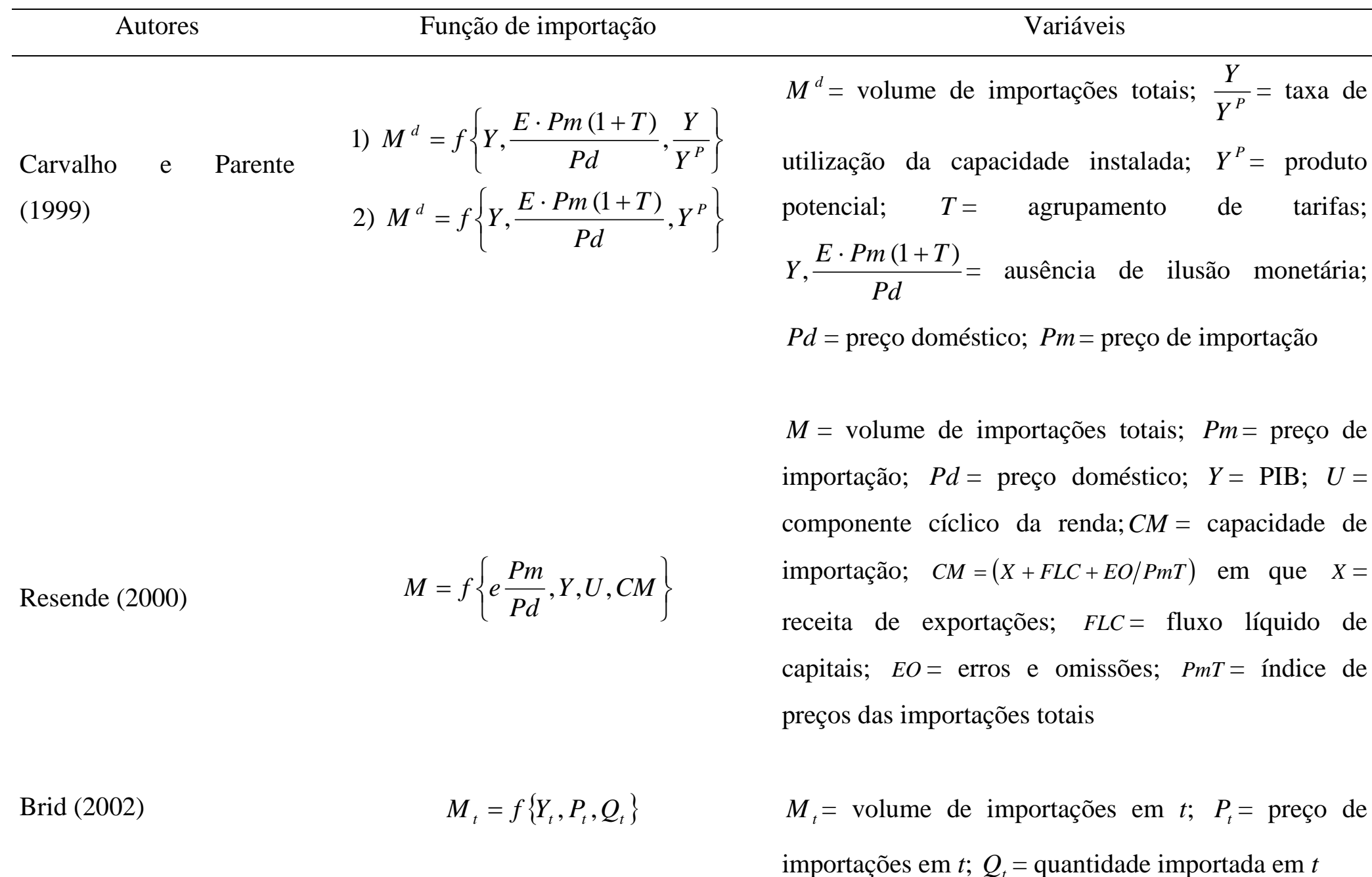


Tabela 18. Especificações das funções de demanda por importações estimadas, vários autores

\begin{tabular}{|c|c|c|}
\hline Autores & Função de importação & Variáveis \\
\hline Schmitz e Seale (2002) & $\begin{array}{ll}\operatorname{Max} & U(q) \\
\text { s.a. } & \sum\left(p_{i} q_{i}\right)=M\end{array}$ & $\begin{array}{l}U(q)=\text { função utilidade em função do consumo de } \\
\text { produtos importados; } M=\text { renda total; } p_{i}=\text { preço do i- } \\
\text { ésimo produto importado; } q=\text { quantidade do i-ésimo } \\
\text { produto importado }\end{array}$ \\
\hline Paiva (2003) & $M_{t}=f\left\{M_{t}, P I B_{t-1}, R E E R_{t-1}, C_{t}, D T_{t}\right\}$ & $\begin{array}{l}M_{t}=\text { volume de importações totais em } t ; \Delta M_{t}= \\
\text { volume de importações de semi-manufaturados em } t \\
P I B_{t-1}=\text { PIB real em } t-1 ; R E E R_{t-1}=\text { taxa de câmbio } \\
\text { efetiva em } t-1 ; C_{t}=\text { constante em } t ; D T_{t}=\text { dummy para } \\
\text { tarifa em } t\end{array}$ \\
\hline Osaki e Barros (2003) & $Q_{m}=f\{P d, P m, C, D\}$ & $\begin{array}{l}Q_{m}=\text { quantidade de produto importado; } P d=\text { preço } \\
\text { real do produto nacional; } P m=\text { preço real do produto } \\
\text { importado; } C=\text { taxa de câmbio real; } D=\text { dummy para } \\
\text { políticas cambiais distintas }\end{array}$ \\
\hline
\end{tabular}


O modelo econômico a ser utilizado no presente trabalho continua calcado nas variáveis relacionadas nos objetivos específicos. Cabe agora proceder às especificações gráfica e matemática do modelo, pois a partir delas será elucidada a questão quanto a qual equação de demanda por importação será estimada.

\subsubsection{Fundamentação gráfica do modelo}

O modelo econômico admite uma sustentação gráfica por meio do diagrama back to back analisado por Barros (1987). Na Figura 16, tem-se o diagrama em que à direita do eixo vertical estão as curvas nominais de oferta e da demanda para o país $a$. À esquerda, as curvas do país $b$ são invertidas, pois as quantidades para essa região são obtidas da direita para a esquerda a partir do ponto de origem $(\mathrm{O})$.

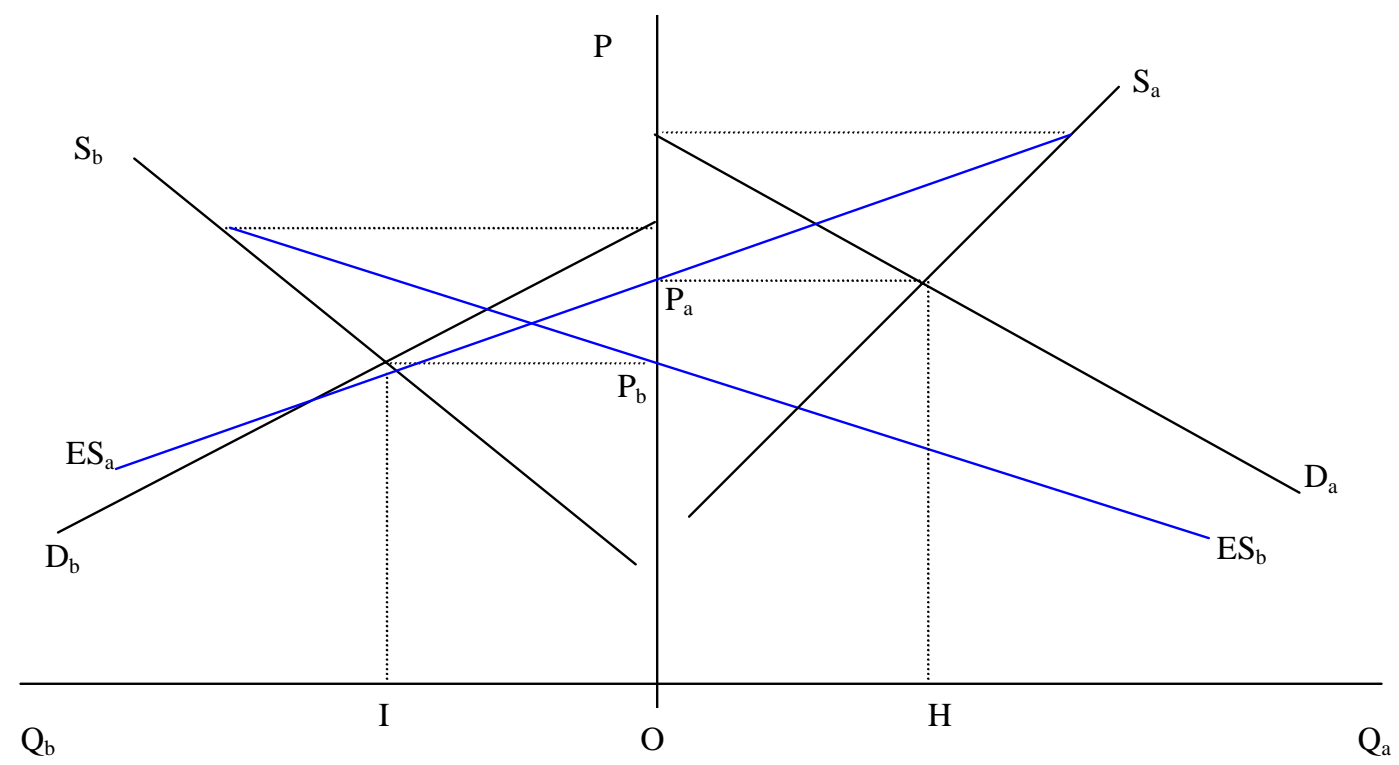

Figura 16 - Diagrama back to back

Fonte: Barros (1987) 
As curvas de excesso de oferta para os países são traçadas no intuito de mostrar os diferentes níveis de preços e seus respectivos montantes pelos quais a oferta excede a demanda. Obtém-se o excesso de oferta $\mathrm{ES}_{\mathrm{a}}$ e ES $\mathrm{b}$, tomando-se para cada nível de preço, a diferença horizontal entre a curva de oferta e a curva de demanda dos países.

Para referendar o modelo econômico proposto no trabalho, é necessário proceder algumas modificações no diagrama back to back apresentadas na Figura 16. Na Figura 17 observa-se que o país a representa o Brasil e o país $b$, o Resto do Mundo, a mercadoria em questão é o leite e ainda supondo: i) que o excesso de oferta no Brasil $\left(E S_{\mathrm{a}}\right)$ representa o mesmo que um excesso de demanda, dado preço interno, $\mathrm{P}_{\mathrm{a}}^{0}$, superior ao preço internacional e de equilíbrio (em moeda nacional), $\mathrm{P}_{\mathrm{RM}}^{0}$, assim $E S_{\mathrm{a}}$ é a curva de importação do produto; ii) que o excesso de oferta do Resto do Mundo é infinitamente elástica, que representa a oferta de exportação do produto.

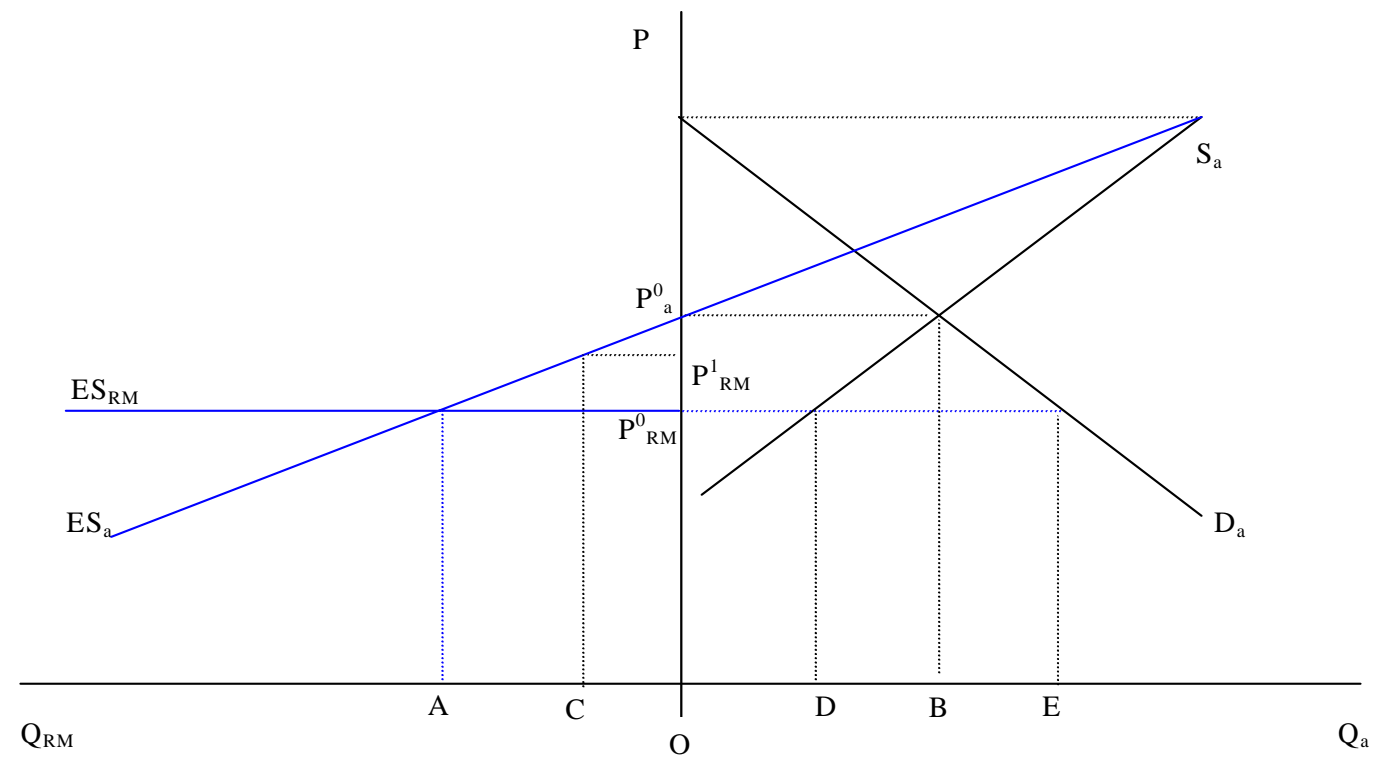

Figura 17 - Diagrama back to back com custo de transferência 
Supondo inicialmente que o custo de transferência (CT) seja maior que a diferença de preços $\left(\mathrm{P}_{\mathrm{a}}^{0}-\mathrm{P}_{\mathrm{RM}}^{0}\right)$ em que CT inclui transporte, tarifa e outros, então, não haverá comércio de leite do Resto do Mundo para o Brasil. Para o estabelecimento do comércio, considera-se que o custo de transferência seja nulo $(\mathrm{CT}=0)$. O preço nas duas regiões se estabelece quando $\mathrm{ES}_{\mathrm{a}}=\mathrm{ES}_{\mathrm{RM}}$. $\mathrm{O} \mathrm{P}_{\mathrm{RM}}^{0}$ é o preço no qual o leite será comercializado da região chamada, Resto do Mundo para o Brasil. Em $\mathrm{P}_{\mathrm{RM}}^{0}$, haverá demanda por importação no Brasil pela quantidade DE, o mesmo montante de excesso de oferta do Resto do Mundo OA. Quando o custo de transferência CT = k, então o preço no Brasil passará a ser $\mathrm{P}_{\mathrm{RM}}^{1}=\left(\mathrm{P}_{\mathrm{RM}}^{0}+\mathrm{k}\right)$, sendo que a quantidade importada pelo Brasil iguala-se a OC.

Se ocorrer um aumento de renda interna no Brasil isso possibilitará um acréscimo na demanda que se desloca de $\mathrm{D}_{\mathrm{a}}$ para $\mathrm{D}_{\mathrm{a}}$ a na Figura 18 . Com a nova curva de demanda por leite, $\mathrm{D}^{\prime}$, haverá um aumento do preço interno de $\mathrm{P}_{\mathrm{a}}^{0}$ para $\mathrm{P}_{\mathrm{a}}^{1}$ sem importação (CT $>\mathrm{P}^{1}{ }_{\mathrm{a}}-\mathrm{P}_{\mathrm{RM}}^{0}$ ). Com a alteração de preço, a curva de importação do Brasil desloca-se de ES $_{a}$ para ES' ${ }_{\text {a. }}$ A produção e o consumo nacionais serão iguais a OC a esse novo preço. Porém, o país importará a parcela BE oferecida ao preço $\mathrm{P}_{\mathrm{RM}}^{0}$ pelo Resto do Mundo se CT $=0$. Deve-se observar que a quantidade AO exportada pelo Resto do Mundo é igual à quantidade BD. E o montante a mais que se espera importar DE é igual à AF. 


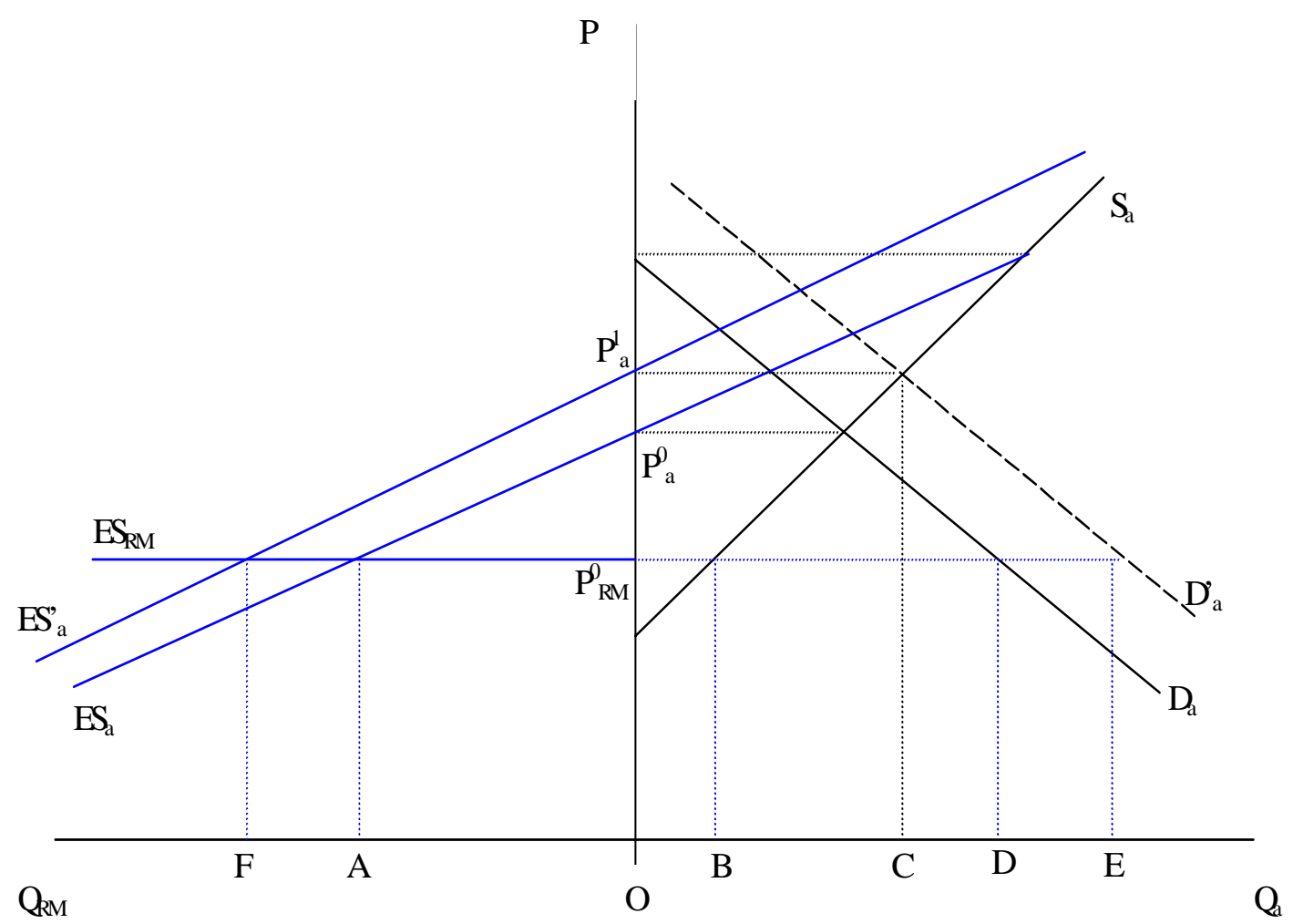

Figura 18 - Diagrama back to back com alteração da demanda

Supondo agora que haja um aumento de produtividade na produção de leite brasileira que aumente a oferta de leite no mercado interno, a curva $S_{a}$ se deslocará para a direita até $\mathrm{S}_{\mathrm{a}}$, reduzindo o preço interno de $\mathrm{P}^{0}{ }_{\text {a }}$ para $\mathrm{P}_{\mathrm{a}}^{1}$ e a quantidade importada de $\mathrm{BD}$ para $\mathrm{CD}$, supondo $\mathrm{CT}=0$. Ao preço $\mathrm{P}_{\mathrm{a}}^{0}$ haverá demanda por importação no montante $\mathrm{BD}$ (igual à $\mathrm{AO}$ ). $\mathrm{O}$ produtor nacional que antes ofertava $\mathrm{OB}$ ao preço internacional ofertará OC. As importações cairão de AO = BF para OE = CF (ver Figura 19). 


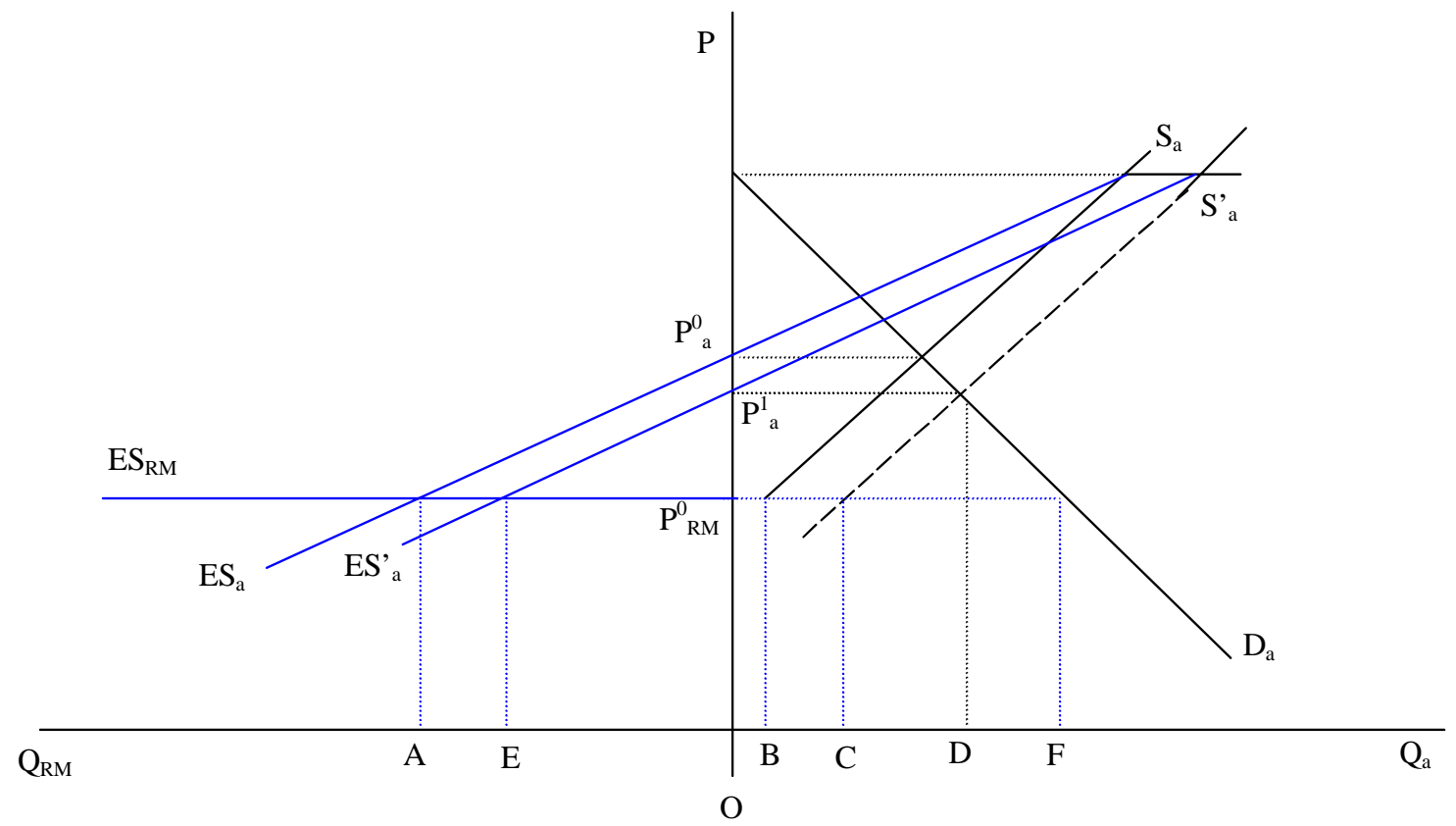

Figura 19 - Diagrama back to back com alteração de oferta

Se ocorrer uma diminuição dos subsídios diretos no Resto do Mundo, fazendo com que os preços internacionais aumentem $\left(\mathrm{P}_{\mathrm{RM}}^{\mathrm{O}}\right.$ para $\left.\mathrm{P}^{1}{ }_{\mathrm{RM}}\right)$ conforme apresentado na Figura 20 pelo deslocamento de $\mathrm{ES}_{\mathrm{RM}}$ para ES' ${ }_{\mathrm{RM}}$. Com esse aumento de preços, o Brasil que importava $\mathrm{BC}=\mathrm{AO}$ passa a exportar $\mathrm{OD}(=\mathrm{EF})$. 


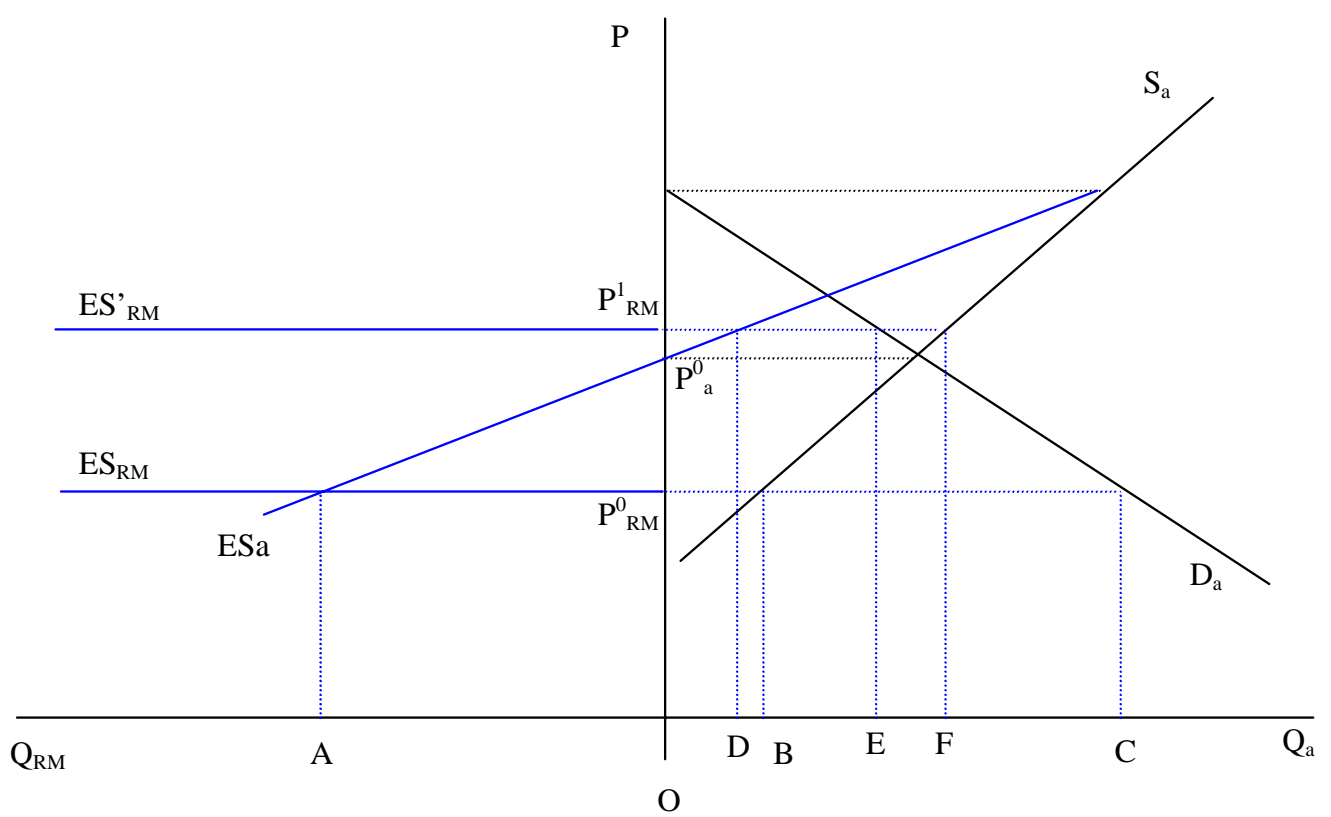

Figura 20 - Diagrama back to back com diminuição de subsídio

\subsubsection{Especificação da equação de excesso de demanda}

As representações gráficas feitas no item anterior para a conceituação da curva de excesso de demanda admitem um tratamento matemático para melhor definir o modelo a ser estimado no presente estudo. Vale destacar, que a estimação da função de demanda por leite importado proposta, parte da definição da função de excesso de demanda definida matematicamente por: 


$$
\begin{aligned}
& M^{d}=Q^{d}-Q^{s} \\
& M^{d}=Q^{d}(P d, P m, E, Y)-Q^{s}(P d, W) \\
& M^{d}=\left(\alpha_{0}+\alpha_{1} P d+\alpha_{2} P m+\alpha_{3} E+\alpha_{4} Y\right)-\left(\beta_{0}+\beta_{1} P d+\beta_{3} W\right) \\
& M^{d}=\left(\alpha_{0}-\beta_{0}\right)+\left(\alpha_{1}-\beta_{1}\right) P d+\alpha_{2} P m+\alpha_{3} E+\alpha_{4} Y-\beta_{3} W
\end{aligned}
$$

em que:

$M^{d}=$ função de excesso de demanda por leite importado;

$Q^{d} \quad=$ função de demanda por leite importado;

$Q^{s} \quad=$ função de oferta de leite;

$P d$ = preço do leite no mercado doméstico;

$\mathrm{Pm}$ = preço do leite no mercado externo;

$E \quad$ = taxa de câmbio;

$Y \quad$ = variáveis deslocadoras da demanda (renda interna, gosto e preferência);

$W$ = variáveis deslocadoras da oferta (safra, entressafra, melhoria genética);

$\alpha_{0}, \alpha_{1}, \alpha_{2}, \alpha_{3}, \alpha_{4}, \beta_{0}, \beta_{1}, \beta_{3}=$ coeficientes associados às variáveis explicativas.

Pode-se ainda, como forma de adequar o modelo proposto na equação 1 com os objetivos do trabalho, adicionar algumas variáveis qualitativas do tipo dummy. O objetivo é admitir que existam outras variáveis importantes na especificação da demanda por leite importado que não foram incorporadas na equação 1, como por exemplo, o efeito da estabilização monetária com o advento do Plano Real em julho de 1994 e o efeito das medidas anti-dumping que o governo implementou a partir de 1999. Matematicamente, tem-se: 


$$
M_{d}=\left(\alpha_{0}-\beta_{0}\right)+\left(\alpha_{1}-\beta_{1}\right) P_{d}+\alpha_{2} P_{m}+\alpha_{3} E+\alpha_{4} Y-\beta_{3} W+\gamma_{1} \mathrm{D}_{1}+\gamma_{2} \mathrm{D}_{2}
$$

em que:

$\mathrm{D}_{1}$ = dummy para a estabilização monetária;

$\mathrm{D}_{2} \quad$ = dummy para as medidas anti-dumping;

$\gamma_{1}, \gamma_{2}=$ coeficientes associados as variáveis dummies.

Será feito o teste de causalidade de Granger para a relação entre $M_{d}$ e $P_{m}$. Lembre-se que a formulação gráfica e algébrica adotada necessita da hipótese de que $P_{m}$ seja exógena em relação à $M_{d}$. Ou seja, $M_{d}$ não afeta $P_{m}$ contemporaneamente (por pressuposição) ou com defasagens. Caso esta relação se mostre bicausal, não se sustenta a exogeneidade em vista de efeito defasado de $M^{d}$ sobre $P_{m}$. Deve-se abrir, então, a possibilidade de ocorrer também efeito contemporâneo entre essas variáveis. Segundo Barros (1987), há que se substituir, portanto, a linha horizontal de $\mathrm{ES}_{\mathrm{RM}}$ por uma linha negativamente inclinada: maiores preços aumentam o excesso de oferta (medido da esquerda para a direita) mundial para o Brasil. Essa linha pode ser representada com $P_{m}$ como variável dependente e $M_{d}$ como variável explicativa.

$$
P_{m}=\lambda_{0}+\lambda_{1} M^{s}+\lambda_{2} L_{w}+v_{t}
$$

em que $M^{S}=$ oferta do resto do mundo para o Brasil, $L_{w}=$ total de exportações mundiais de leite e $\lambda_{1}>0$ e $\lambda_{2}<0$.

O modelo se equilibra quando $M^{d}=M^{s}=M$ 
Conforme Gujarati (2000) caso exista a simultaneidade os métodos de Mínimos Quadrados de Dois Estágios (MQ2E) e de variáveis instrumentais serão os indicados, pois seus estimadores serão consistentes e eficientes.

Para se testar a exogeneidade fraca far-se-á o teste de Hausman citado em Gujarati (2000). Ou seja, verificar-se-á se o resíduo da equação (3) é significativo pelo teste $t$ de Student na equação (4). Da mesma forma, se o resíduo da equação (4) for significativo pelo teste $t$ na equação (3) existirá causalidade fraca, condição suficiente para que exista causalidade entre a variável $M_{d}$ e $P_{m}$ (Greene, 2000; Judge et. al, 1985).

\subsection{Modelo empírico}

Para analisar empiricamente os determinantes das importações de leite pelo Brasil foi estimada a função de demanda por leite importado. A equação genérica de importação de leite para o Brasil é apresentada pela equação (3):

$$
\begin{aligned}
& M_{d}=\left(\alpha_{0}-\beta_{0}\right)+\left(\alpha_{1}-\beta_{1}\right) P_{d}+\alpha_{2} P_{m}+\alpha_{3} E+\alpha_{4} Y+\gamma_{1} \mathrm{D}_{1}+\gamma_{2} \mathrm{D}_{2}+\varepsilon_{\mathrm{t}} \\
& M_{d t}=\theta_{0}+\theta_{1} P_{d t}+\alpha_{2} P_{m t}+\alpha_{3} E_{t}+\alpha_{4} Y_{t}+\gamma_{1} \mathrm{D}_{1}+\gamma_{2} \mathrm{D}_{2}+\varepsilon_{t}
\end{aligned}
$$

em que:

$M_{d t}=$ quantidades mensais de importação de lácteos no período de 1991 a 2003;

$\theta_{0} \quad$ coeficiente autônomo;

$\theta_{1}, \alpha_{2}, \alpha_{3}, \alpha_{4}, \beta_{1}, \gamma_{1}, \gamma_{2}=$ coeficientes associados às variáveis explicativas;

$P_{d t} \quad=$ preços mensais de leite em $\mathrm{R} \$ / 1000$ litros no período de 1991 a 2003; 
$P_{m t} \quad=$ preços mensais de importação de lácteos em US\$/1000 litros no período de 1991 a 2003;

$E_{t} \quad$ = taxa mensal de câmbio real no período de 1991 a 2003;

$\mathrm{Y}_{\mathrm{t}} \quad$ = produto interno mensal per capita deflacionado pelo IGP-DI (FGV) no período de 1991 a 2003;

$D_{1} \quad$ = estabilização monetária no mês de julho de 1994 (0 até junho de 1994 e 1 nos demais meses de 1994);

$D_{2} \quad$ = medidas anti-dumping a partir de janeiro de 1999 (0 até dezembro de 1998 e 1 nos demais meses);

$\varepsilon_{t} \quad=$ erro aleatório no período analisado.

Os sinais esperados para os parâmetros da equação (3) são $\theta_{0}>0, \theta_{1}>0, \alpha_{2}<0, \alpha_{3}<0, \alpha_{4}>0, \gamma_{1}<0, \gamma_{2}>0$. A literatura consultada em vários trabalhos sobre estimação da equação de demanda de importação sugere que se aplique na equação (3) o modelo duplo-logaritmo.

Procurar-se-á determinar por meio do teste de sentido de causalidade de Granger, se a quantidade importada de leite ()é causada pelo preço de importação $\left(P m_{t}\right)$, vice-versa ou em ambos os sentidos. E, determinar se a exogeneidade é fraca por meio do teste de Hausman. Além disso, procede-se a uma série de testes econométricos como o de raiz unitária e o de co-integração de Johansen. 


\subsubsection{Testes econométricos}

\subsubsection{Teste do sentido de causalidade}

A análise quanto ao sentido de causalidade entre uma série de preços e outra de quantidades físicas será feita, empregando-se o procedimento estatístico sugerido por Granger (1969). No conceito de Granger, o teste de sentido de causalidade admite que uma variável $P$ causa a variável $Q$, se a inclusão de valores defasados da variável $P$ contribuir para explicar a variável $Q$. Dessa forma, a causalidade refere-se à capacidade de previsibilidade de uma variável a partir de outra.

Duas equações são necessárias para o teste de causalidade entre as duas variáveis, podendo ser estimadas por Mínimos Quadrados Ordinários (MQO):

$$
\begin{aligned}
& \ln P_{t}=\beta_{0}+\sum_{i=1}^{n} \beta_{1, i} \ln Q_{t-i}+\sum_{k=1}^{m} \beta_{2, k} \ln P_{1,(t-k)}+\mu_{t} \\
& \ln Q_{t}=\alpha_{0}+\sum_{k=1}^{m} \alpha_{1, k} P_{1,(t-k)}+\sum_{i=1}^{n} \alpha_{2, i} \ln Q_{1,(t-i)}+v_{t}
\end{aligned}
$$

nas quais:

$P_{t} \quad=$ preço no período $\mathrm{t} ;$

$Q_{t} \quad=$ quantidade no período $\mathrm{t} ;$

$\beta_{0}, \beta_{1, i}, \beta_{2, k}=$ parâmetros estimados na equação (5);

$\alpha_{0}, \alpha_{1, k}, \alpha_{2, i}=$ parâmetros estimados na equação (6);

$i, k \quad=$ números de defasagens;

$\mu_{t}, v_{t}=$ erros aleatórios. 
As hipóteses a serem testadas são de que os coeficientes dos valores passados da variável exógena das equações (5) e (6) sejam iguais a zeros, tem-se:

$$
\begin{aligned}
& \beta_{1,1}=\beta_{1,2}=\ldots=\beta_{1, n}=0 \\
& \alpha_{1,1}=\alpha_{1,2}=\ldots=\alpha_{1, m}=0
\end{aligned}
$$

O sentido de causalidade será verificado pelo teste $\mathrm{F}$, considerando-se os graus de liberdade adequados. Se as duas hipóteses acima forem rejeitadas, existe relação bi-causal; se ambas não forem rejeitadas, tem-se ausência de causalidade; se a hipótese de uma das equações for rejeitada e a outra não, a causalidade será unidirecional no sentido da variável exógena para a variável dependente da equação para a qual a hipótese nula for rejeitada.

Como o modelo proposto pelas equações (3) e (4) pode ser o de equações simultâneas, caso a relação seja bi-causal faz-se necessário conhecer o tipo de método de regressão a ser estimada: Mínimos Quadrados Indiretos (MQI) ou MQ2E. Para tanto é feito a identificação do rank das equações.

A condição de rank estabelece que se o modelo contém M equações ( $M$ variáveis endógenas), uma equação é identificável se existir pelo menos um determinante de ordem M-1 diferente de zero na matriz de coeficientes das variáveis do modelo (endógenas e exógenas) pertencentes às outras equações do sistema. A identificação das equações é feita com a seguinte fórmula: $\mathrm{K}-\mathrm{k}>\mathrm{m}-1$ onde $\mathrm{M}=$ número de equações (variáveis endógenas do sistema), $\mathrm{m}$ = número de variáveis endógenas na equação, $\mathrm{K}$ = número de variáveis predeterminadas no modelo e $\mathrm{k}=$ número de variáveis predeterminadas na equação. As variáveis predeterminadas são as exógenas e as endógenas defasadas.

Se $\mathrm{K}$ - k > m - 1 e rank da matriz é $\mathrm{M}-1$, a equação é sobre-identificada, emprega-se o método de MQ2E. Se $\mathrm{K}-\mathrm{k}=\mathrm{m}-1$ e o rank da matriz $\mathrm{M}-1$, a equação é exatamente identificada, utiliza-se o método de MQI ou MQ2E. Se o rank da matriz for 
menor que $\mathrm{M}-1$ ou se $\mathrm{K}-\mathrm{k}<\mathrm{m}-1$, a equação é sub-identificada, não podendo ser estimada.

Alguns cuidados devem ser tomados para se estimar as equações (5) e (6). Um deles é a definição do número de defasagens que devem ser usadas nessas equações. O número de defasagens da variável dependente é determinado tendo como base os resultados dos testes de Akaike - Akaike Information Criterion (AIC) e Schwartz Schwartz Bayesian Criterion (SBC). Esses testes não são específicos para a definição do número de defasagens, mas servem como uma orientação sobre a duração do efeito de perturbações sofridas pelas séries em tempo passado. Para a variável explicativa, o número de defasagens a ser considerado no modelo de causalidade pode ser função das defasagens dessa variável que apresentam correlação cruzada significativa com o termo não defasado da variável dependente.

As variáveis das equações (4) e (5) apresentam as variáveis em nível, porém, se elas possuírem raiz unitária ${ }^{10}$, as variáveis devem ser aplicadas na primeira diferença. Sendo co-integradas as variáveis relacionadas ao teste de causalidade, deve-se incorporar o termo de correção de erro às equações, para evitar problemas de especificação do modelo. Como a estimação do teste de sentido de causalidade especifica a relação entre duas variáveis, o teste de co-integração adotado é o sugerido por Engle e Granger (1987).

Segundo Bacchi (2001), o conceito de co-integração indica que as variáveis não-estacionárias podem apresentar uma relação de equilíbrio no longo prazo. Para Lütkepohl (1991), o teste de co-integração é definido por um processo $k$-dimensional $y_{t}$ integrado de ordem $d, y_{t} \sim \mathrm{I}(d)$, se $\Delta^{\mathrm{d}} \mathrm{y}_{\mathrm{t}}$ é estacionário e $\Delta^{\mathrm{d}-1} \mathrm{y}_{\mathrm{t}}$ não é estacionário. $\mathrm{O}$ processo $y_{t} \mathrm{I}(d)$ é chamado co-integrado se há uma combinação linear $c^{\prime} y_{t}$ a qual é integrada de ordem menor do que $d$. A identificação do vetor $c$ é importante para a correção do modelo estimado com as variáveis nas diferenças. Dessa maneira, o modelo estimado possui informações de curto e longo prazo entre as variáveis.

\footnotetext{
${ }^{10} \mathrm{O}$ teste de raiz unitária será explicado no item a seguir
} 
Conforme o método proposto por Engle e Granger (1987) para verificar a presença de co-integração, supondo o vetor $y_{t}$ com duas variáveis integradas de ordem 1 , verificar a co-integração entre essas variáveis significa testar se $u_{t}$ de uma equação de co-integração da forma:

$$
y_{1 t}=\theta+\lambda y_{2 t}+u_{t}
$$

em que $u_{t}$ é o ruído branco, i.e., $u_{t}, \mathrm{I}(0)$. Assim, $y_{1 t}$ será co-integrado e $u_{t-1}$ passar a ser o termo de correção de erro que recuperará as informações de longo prazo perdidas na diferenciação da série.

Se as variáveis co-integrarem, incluir-se-á uma variável defasada num período para mensurar o desvio em relação ao equilíbrio de longo prazo. Vale lembrar, que sem a realização do teste de co-integração o modelo poderá estar incorretamente especificado (Lütkepohl,1991).

\subsubsection{O conceito e o teste de exogeneidade}

Segundo Nakane (1994), a partir dos anos 70, os modelos de séries temporais do tipo Box-Jenkins começaram a proliferar. Tais modelos não vingaram completamente, pois estavam pouco associados à teoria econômica.

Engle et al. (1983) afirmaram que um conjunto de variáveis é exógeno quando o processo gerador pode ser desconsiderado para efeito de análise. O mérito do artigo foi estabelecer um arcabouço teórico para a identificação e relacionamento dos distintos conceitos de exogeneidade.

O conceito de exogeneidade forte, no sentido proposto na presente pesquisa, é o de causalidade no sentido de Granger. Há que se destacar que muitas vezes o teste de 
causalidade de Granger tem sido inadequadamente associado a testes de exogeneidade. Isso só pode ocorrer quando as previsões das variáveis endógenas forem o objetivo do estudo.

Em contrapartida, o de exogeneidade fraca segue o proposto por Koopmans (1950) em que se desconsidera o modelo marginal _ aquele que engloba todas as variáveis endógenas _ para fins de estimação sem perder informações importantes. Verificar-se-á exogeneidade fraca por meio do teste proposto por Hausman $(1978,1983)$ para se concluir que as variáveis exógenas incluídas no modelo são necessariamente exógenas.

Em suma, existirá exogeneidade forte entre as variáveis endógenas quando existir causalidade no sentido de Granger. Essa condição é necessária, porém não suficiente para o sentido de causalidade que se quer determinar. A condição suficiente é que a exogeneidade seja fraca (Greene, 2001, Judge et al., 1985).

Para o teste de Hausman se considera as equações (3) e (4):

Função de demanda por importação: $M_{d t}=\theta_{0}+\theta_{1} P_{d t}+\alpha_{2} P_{m t}+\alpha_{3} E_{t}+\alpha_{4} Y_{t}+\gamma_{1} \mathrm{D}_{1}+\gamma_{2} \mathrm{D}_{2}+\varepsilon_{t}$

Função de preço de importação: $\quad P_{m}=\lambda_{0}+\lambda_{1} M^{s}+\lambda_{2} L_{w}+v_{t}$

no equilíbrio $M^{s}=M^{d}=M$.

Considerando que $P_{d t}, E_{t}, Y_{t}, \mathrm{~L}_{\mathrm{w}}, D_{1}$ e $D_{2}$ sejam variáveis exógenas e conseqüentemente $M_{d}$ e $P_{m t}$, endógenas constrói-se as equações (3) e (4) na forma reduzida: 


$$
M_{d}=\Pi_{0}+\Pi_{1} P_{d t}+\Pi_{2} E_{t}+\Pi_{3} Y_{t}+\Pi_{4} L_{w}+\Pi_{5} D_{1}+\Pi_{6} D_{2}+\varpi_{t}
$$

$$
P_{m}=\Pi_{7}+\Pi_{8} P_{d_{t}}+\Pi_{9} E_{t}+\Pi_{10} Y_{t}+\Pi_{11} L_{w}+\Pi_{12} D_{1}+\Pi_{13} D_{2}+\delta_{t}
$$

em que $\varpi_{t}$ e $\delta_{t}$ são os termos de erro na forma reduzida. Estimando (8) por MQO temse:

$$
\begin{aligned}
& \hat{M}_{d}=\hat{\Pi}_{0}+\hat{\Pi}_{1} P_{d_{t}}+\hat{\Pi}_{2} E_{t}+\hat{\Pi}_{3} Y_{t}+\hat{\Pi}_{4} L_{w}+\hat{\Pi}_{5} D_{1}+\hat{\Pi}_{6} D_{2} \\
& \text { Assim, } M_{d}=\hat{M}_{d}+\hat{\varpi}_{t}
\end{aligned}
$$

na qual $\hat{M}_{d}$ são os $M_{d}$ estimados e $\hat{\varpi}_{t}$, os resíduos estimados. Substituindo (10) em (3) tem-se:

$$
P_{m}=\beta_{0}+\beta_{1} \hat{M}_{d}+\beta_{2} \hat{P}_{d}+\beta_{3} \hat{E}_{t}+\beta_{4} \hat{Y}_{t}+\beta_{5} \hat{L}_{w}+\beta_{6} \hat{D}_{1}+\beta_{7} \hat{D}_{2}+\beta_{1} \hat{\varpi}_{t}+v_{t}
$$

sendo os coeficientes de $\hat{M}_{d}$ e $\hat{\varpi}_{\mathrm{t}}$ são os mesmos.

Sob a hipótese nula de que não há exogeneidade fraca, a correlação entre $\hat{\varpi}_{t}$ e $v_{t}$ deve ser zero, assintoticamente. Na regressão da equação (12) verificar-se-á o coeficiente de $\varpi_{t}$ na referida equação é estatisticamente igual a zero. Se a hipótese nula for aceita conclui-se que não há exogeneidade fraca. Esta conclusão será alterada caso o coeficiente de $\varpi_{t}$ for estatisticamente significativo pelo teste $t$ de Student. Como sugere Gujarati (2000) deve-se levar em conta o teste F quando se considera na estimação de (12) as estimativas das variáveis endógenas $\hat{M}_{d}$ e $\hat{P}_{m}$. 


\subsubsection{Os testes de raiz unitária e co-integração}

O teste de raiz unitária tem por objetivo averiguar a estacionariedade das séries temporais. Em geral, as séries econômicas são não-estacionárias, sendo a variável preço muito sensível às oscilações de natureza macro ou microeconômica, como por exemplo, políticas governamentais, quebras de safras e variações sazonais.

Os trabalhos empíricos que utilizam dados de séries temporais não mais pressupõem estacionariedade dessas séries. Numa regressão, quando se analisam dados não-estacionários sem alguma transformação deles, a relação entre as variáveis obtida pelo alto valor do coeficiente de determinação $\left(\mathrm{R}^{2}\right)$ pode ser, na verdade, uma relação espúria (Gujarati, 2000).

Segundo Gujarati (2000), um processo estatístico é considerado estacionário se suas médias e variâncias são constantes ao longo do tempo e o valor da covariância entre dois períodos de tempo depende somente do intervalo de tempo e não do tempo para o qual a covariância é computada. Assim, uma série é considerada não-estacionária se possuir tendência estocástica. Portanto, a estacionariedade das variáveis consideradas no estudo deve ser previamente verificada, a fim de que as séries relacionadas no modelo estejam corretamente especificadas.

Segundo Engle e Granger (1987), Gujarati (2000) e Bacchi (2001), os modelos de correção de erro são empregados para resolver a perda de informação de longo prazo. Pois as séries co-integradas são diferenciadas para obter estacionariedade e para estudar as relações num contexto de curto e longo prazos.

Segundo Bacchi (2001), o desenvolvimento dos recursos computacionais acompanhado passo a passo as inovações metodológicas desse segmento da econometria, permitiram que um grande número de trabalhos fossem feitos, nos últimos anos, no âmbito econômico, considerando as propriedades de integração e co-integração das séries temporais . 
a) O teste de raiz unitária

Com o intuito de obter a ordem de integração das variáveis utilizar-se-ão os testes de raiz unitária do tipo Dickey-Fuller Aumentado (DFA) proposto por Dickey e Fuller (1981). A correta determinação da ordem de integração das variáveis se faz necessário para evitar que existam relações espúrias entre elas.

Como destacado anteriormente, considera-se um processo estatístico como sendo estacionário se suas médias e variâncias são constantes ao longo do tempo e o valor da covariância entre dois períodos de tempo dependerem somente do intervalo de tempo e não do tempo para o qual a covariância é computada (Gujarati, 1995). O teste de raiz unitária tem sido comumente utilizado na análise de estacionariedade das séries temporais. Os testes de raiz unitária consistem na estimação das seguintes equações:

$$
\begin{aligned}
& \Delta x_{t}=\alpha+\theta T+\beta x_{t-1}+\sum_{j=1}^{n} \gamma_{j} \Delta x_{t-j}+e_{t} \\
& \Delta x_{t}=\alpha+\beta \quad x_{t-1}+\sum_{j=1}^{n} \gamma_{j} \Delta x_{t-j}+e_{t} \\
& \Delta x_{t}=\beta \quad x_{t-1}+\sum_{j=1}^{n} \gamma_{j} \Delta x_{t-j}+e_{t}
\end{aligned}
$$

em que

$x_{t} \quad=$ uma variável considerada no modelo proposto;

$\alpha \quad=$ termo constante estimado;

$\theta, \beta$ e $\gamma_{\mathrm{j}}=$ coeficientes estimados; sendo: $\beta=\sum_{\mathrm{j}=1}^{\mathrm{n}} \gamma_{\mathrm{i}}-1$ e $\gamma_{i}=\left(\gamma_{1}+\gamma_{2}+\ldots+\gamma_{i}\right)-1$

$T \quad$ = tendência determinista do modelo;

$e_{t} \quad=$ termo correspondente aos resíduos da equação estimada.

Vale ressaltar que, o valor da defasagem $(p)$ deve ser tal que torne a série dos 
resíduos $\left(e_{t}\right)$, uma série denominada: “ruído branco”, isto é, uma série com média dos resíduos e autocorrelação dos erros iguais a zero. Alguns procedimentos são adotados para encontrar o valor de $p$, os mais comuns são o critério de Akaike (AIC) e o de Schwartz (SBC) $)^{11}$. Esses critérios escolhem o valor de $p$ que apresenta menor variância dos resíduos do erro.

O critério de Akaike e Schwartz foi utilizado para definir o número de defasagens da variável dependente no teste de causalidade de Granger. O intuito do critério é determinar o número de defasagens (p) que minimiza a soma dos quadrados dos resíduos estimados no processo auto-regressivo de ordem $p$. No caso da variável explicativa, utilizaram-se as defasagens significativas do teste de correlação cruzada entre as variáveis relacionadas ou, pelo menos, uma defasagem no caso de não haver nenhuma significativa, tendo em vista atender os procedimentos básicos do teste.

Como no teste de raiz unitária empregam-se as variáveis diferenciadas, o teste a ser realizado para a hipótese nula é $\mathrm{H}_{0}:|\beta|-1=0$. Se $\mathrm{H}_{0}$ for satisfeita, identificase que a série é não-estacionária, uma vez que a estacionariedade requer que $|\beta|-1<0$, i.e., é necessário que $\beta \in(-1,1)$. Se forem feitas mais de uma defasagem, o teste consiste em testar $\beta=\sum_{\mathrm{j}=1}^{\mathrm{n}} \gamma_{i}-1=0$ referente às equações descritas no anteriormente.

As estatísticas $\tau_{\beta \tau}$ e $\tau_{\alpha \mu}$ avaliam a significância das variáveis constante ( $\alpha$ ) e tendência $(\theta)$ do modelo, respectivamente. As estatísticas $\tau_{\tau}, \tau_{\mu}$ e $\tau$ são utilizadas para as equações (13), (14) e (15), as quais consideram os modelos para análise de estacionariedade $\left(\mathrm{H}_{0}: \beta=0\right)$ com constante e tendência, apenas com constante e sem constante e tendência, respectivamente, caso esses termos sejam não-significativos.

\footnotetext{
${ }^{11}$ Os critérios de AIC e SBC seguem as equações seguintes: AIC $=\ln \sigma^{2}+\frac{2}{N}$ (número de parâmetros) e $S C=\ln \sigma^{2}+\frac{\ln N}{N}$ (número de parâmetros), em que $\sigma^{2}$ é a soma dos quadrados dos resíduos estimados do processo auto-regressivo de ordem $n$ dividida pelo número de observações $(N)$. O modelo mais adequado é aquele que apresentar o menor valor para os critérios AIC e SBC [ver Lütkepohl (1991)].
} 
O teste de raiz unitária proposto por Enders (2004) é o seguinte:

1- Estimação de uma auto-regressão da equação (13) considerando o número de defasagens obtido do teste Akaike e Schwartz.

$$
\Delta x_{t}=\alpha+\theta T+\beta x_{t-1}+\sum_{j=1}^{n} \gamma_{j} \Delta x_{t-j}+e_{t}
$$

Conforme estatística $\tau_{\tau}$, testa-se a hipótese nula de que $\beta=0$. Se $\mathrm{H}_{0}$ for rejeitada, a série é estacionária ou não tem raiz unitária; se $\mathrm{H}_{0}$ não for rejeitada, a série é não estacionária e tem raiz unitária.

Com $\beta=0$ procede-se ao teste da existência da tendência em que $\mathrm{H}_{0}: \theta=0$, utilizando-se a estatística $\tau_{\theta \tau}$.

Caso $\theta \neq 0$ avalia-se o $\beta$ pelo teste $t$ de Student. Assim, se a hipótese nula $\left(\mathrm{H}_{0}: \beta=0\right)$ não foi rejeitada, conclui-se que existe raiz unitária e a série não é estacionária com tendência estocástica. Se a hipótese nula $\left(\mathrm{H}_{0}: \beta<0\right)$ for rejeitada, a série é estacionária em torno de uma tendência e não tem raiz unitária.

Se $\theta=0$, deve-se estimar a seguinte auto-regressão sem variável tendência mas com intercepto, ou seja, como a equação (14).

$$
\Delta x_{t}=\alpha+\beta x_{t-1}+\sum_{j=1}^{n} \gamma_{J} \Delta x_{t-j}+e_{t}
$$

2- Com a auto-regressão acima testa a hipótese $\beta=0$, utilizando a estatística $\tau_{\mu}$. Se $\mathrm{H}_{0}: \beta=0$ não for rejeitada, a série é estacionária ou não tem raiz unitária; se $\mathrm{H}_{0}: \beta$ $=0$ for rejeitada, a série é não estacionária e tem raiz unitária.

Com $\beta=0$, testa-se a existência da constante em que $\mathrm{H}_{0}$ : $\alpha=0$ utilizando-se a estatística $\tau_{\alpha \mu}$. 
Caso $\alpha \neq 0$, avalia-se $\beta$ pelo teste $t$. Assim, se a hipótese nula $\left(\mathrm{H}_{0}: \beta=0\right)$ não é rejeitada, conclui-se que existe raiz unitária e a série é não estacionária com tendência estocástica e drift. Se $\mathrm{H}_{0}: \beta<0$ for rejeitada, a série é estacionária em torno da média e não tem raiz unitária.

Se a hipótese nula $\left(\mathrm{H}_{0}: \alpha=0\right)$ não for rejeitada, estima-se a seguinte autoregressão sem tendência e sem intercepto, como na equação (15):

$$
\Delta x_{t}=\beta x_{t-1}+\sum_{j=1}^{n} \gamma_{j} \Delta x_{t-j}+e_{t}
$$

3- Com a auto-regressão acima testa a hipótese $\beta=0$, utilizando a estatística $\tau$. Se a hipótese nula é rejeitada, não existe raiz unitária e a série é estacionária. Se a hipótese nula não é rejeitada tem-se raiz unitária e a série não é estacionária.

Conduzir-se-á o teste de forma que, se não há rejeição da hipótese nula ( $\mathrm{H}_{0}$ : $\beta=0$ ) aplicar-se-á mais uma diferença às variáveis da equação acima, testando novamente a hipótese nula. Caso a série seja estacionária na primeira diferença ela será representada como sendo I (1), o que significa que a mesma é integrada de ordem 1.

b) Teste de raiz unitária com mais de uma quebra estrutural

A existência de quebra estrutural em séries econômicas viesa as estatísticas de Dickey-Fuller Aumentado (DFA) no sentido da não-rejeição da hipótese nula. Ou seja, o teste pode estar indicando a presença de tendência estocástica quando os dados são estacionários em torno de uma tendência determinista que contém quebra estrutural em algum ponto.

Perron (1989, 1993 e 1994) e Franses e Haldrup (1993) propõem alguns procedimentos para o teste de raiz unitária com a presença de quebra estrutural. A 
distinção entre os dois procedimentos relaciona-se à presença de uma ou mais de uma quebra estrutural, respectivamente.

Utilizou-se o procedimento de Franses e Haldrup (1993) que determina a inclusão de variáveis binárias do tipo pulse na autoregressão do teste de DFA conforme equação (16):

$$
\Delta Y_{t}=\left(\sum_{i=1}^{p} p_{i}-1\right) Y_{t-1}+\sum_{i=0}^{p} \sum_{j=1}^{k} w_{i j} D_{t-i}^{j}+\sum_{i=1}^{p-1} \lambda_{i} \Delta Y_{t-i}+e_{t}
$$

em que $D_{t-i}^{j}=$ variável binária do tipo pulse, sendo $D^{j}=1$ no momento da ocorrência do evento de quebra estrutural da série de dados econômicos e $D^{j}=0$ nos demais momentos.

O número de lags ( $p$ ) é idêntico ao da variável dependente que se está analisando, além disso, termos deterministas podem ser incluídos na estimação da regressão (Bacchi e Alves, 2004).

\section{c) O teste de co-integração de Johansen}

A metodologia de co-integração de Engle e Granger não é indicada para testar a co-integração quando existe a possibilidade de existir mais de um vetor de cointegração ou quando existe endogeneidade do regressor, i. e., uma relação causal no sentido da variável dependente para a(s) explicativa(s). O teste de co-integração indicado segue o proposto por Johansen (1988).

O procedimento de Johansen procura determinar o ranking de co-integração no seguinte modelo auto-regressivo vetorial (VAR) de ordem $p$ (Johansen, 1996):

$$
\Delta \mathbf{y}_{\mathbf{t}}=\sum_{i=1}^{p-1} \boldsymbol{\Gamma}_{\mathbf{i}} \Delta \mathbf{y}_{\mathbf{t}-\mathbf{i}}+\boldsymbol{\Pi} \mathbf{y}_{\mathbf{t}-\mathbf{1}}+\boldsymbol{\mu}+\varphi \mathbf{d}_{\mathbf{t}}+\boldsymbol{\varepsilon}_{\mathbf{t}}
$$


em que $\boldsymbol{y}_{\boldsymbol{t}}$ é um vetor com $k$ variáveis, $\boldsymbol{\varepsilon}_{\mathrm{t}} \sim N\left(0, \sum\right)$ e $\mathrm{E}\left(\varepsilon_{t} \varepsilon_{s}{ }^{\prime}\right)=0$ para qualquer $t$ diferente de $s$ e $\mathbf{d}_{\mathbf{t}}$ é um vetor de variáveis binárias para captar a variação estacional.

A matriz de coeficientes de $\boldsymbol{y}_{\boldsymbol{t}-1}$, matriz $\boldsymbol{\Pi}$, contém as informações de longo prazo entre as variáveis. Considerando $r$ o posto da matriz $\Pi$, a análise da equação (4) é a seguinte: se $r=k$, então $y_{t}$ é estacionário; se $r=0$, então $\Pi$ é uma matriz nula e $\Delta \mathbf{y}_{\mathbf{t}}$ é estacionário; finalmente, se $0<r<k$, existem matrizes $\boldsymbol{\alpha}$ e $\boldsymbol{\beta}$ de dimensão $k \times r$, tais que $\boldsymbol{\Pi}=\boldsymbol{\alpha} \boldsymbol{\beta}^{\prime}$ e o vetor $\boldsymbol{\beta}^{\prime} \mathbf{y}_{\mathbf{t}}$ é estacionário, havendo $r$ vetores de co-integração (as $r$ colunas de $\boldsymbol{\beta}$ ).

Para a identificação da presença e do número de vetores de co-integração, Johansen e Juselius (1990) apresentaram dois testes, o teste do traço ( $\left.\lambda_{\text {trace }}\right)$ e o teste do máximo autovalor $\left(\lambda_{\max }\right)$. Em um contexto multi-equacional, os critérios de AIC e SBC são utilizados para a determinação do valor $p$.

\subsection{Fonte de dados}

Os dados foram obtidos junto às instituições de pesquisas por meio magnético, impresso ou via Internet. Foram coletados dados a respeito das importações de lácteos e seus respectivos preços mensais no período proposto pela presente pesquisa no site do Sistema Alice da SECEX. Os dados de importações mensais de 1991 a 2003 referem-se aos produtos leite UHT, leite em pó integral, leite em pó desnatado e creme de leite. Esses produtos passaram por uma conversão para transformá-los em leite fluido como sugerido em Neves (2003) apresentado na Tabela 19. 
Tabela 19. Índices para conversão de produtos em leite fluido

\begin{tabular}{lc}
\hline \multicolumn{1}{c}{ Produtos } & Fator de multiplicação \\
\hline 1. Leite UHT & 1,0 \\
2. Leite em pó desnatado & 11,0 \\
3. Leite em pó integral & 8,2 \\
4. Creme de leite & 1,0 \\
\hline
\end{tabular}

Fonte: Neves (2003)

No período em estudo houve mudança de nomenclatura que passou de Nomenclatura Brasileira de Mercadorias (NBM) para Nomenclatura Comum do Mercosul (NCM) em 1996. Essas nomenclaturas são importantes, pois elas informam os códigos dos referidos produtos em análise. Apesar da troca de nomenclatura no período anterior à nomenclatura padronizada do Mercosul foi discutido com pesquisadores da área de lácteos pertencentes a órgãos como, por exemplo, Universidade Federal de Viçosa (UFV) - Projeto Nestlé, a CNA e a Confederação Brasileira das Cooperativas de Laticínios (CBCL). Os produtos e seus códigos NBM e NCM são apresentados na Tabela 18.

Os dados do Índice de Preço ao Consumidor - Disponibilidade Interna (IGPDI) foram coletados no site da FGV e nas publicações impressas da mesma. Os preços internos reais de leite foram informados pelo CEPEA e referem-se à Minas Gerais, maior produtor nacional. Os dados com relação à taxa de câmbio e o PIB real per capita mensal foram coletados no site do IPEA denominado IPEADATA. Os dados mensais do PIB disponíveis no IPEADATA compreendem ao período de 1991 a 2001. A proxy para o PIB mensal adotada é o nível de atividade econômica para os anos 2002 e de 2003 obtidos junto à Fundação Instituto de Pesquisa Econômica (FIPE). 
A produção mensal de leite no mundo foi informada pelo Serviço de Análise Estatística da $\mathrm{FAO}^{12}$. Vale ressaltar que, países como Bahrain, Barbados, Belize, Benin, Botswana, Brasil, Brunei, Camarões e Colômbia, que respondem por cerca de 6,0\% da produção mundial de leite, foram excluídos dessa estatística da FAO em virtude da indisponibilidade de pesquisas em termos mensais. Quaisquer diferenças entre os dados anuais disponibilizados no site da FAO e os que são utilizados nessa pesquisa são referentes, portanto, a inexistência de informações dos países citados.

\footnotetext{
${ }^{12}$ Dados obtidos junto a FAO, escritório Roma, e enviados por e-mail pelo Dr. Jorge Mernies, em meados
} de junho de 2004. 
Tabela 20. Códigos NBM e NCM com descrição dos tipos de leite

\begin{tabular}{|c|c|c|c|}
\hline Código NBM & Descrição & Código NCM & Descrição \\
\hline 0401.10 .0000 & $\begin{array}{l}\text { Leite / Creme de leite não } \\
\text { concentrado, não adocicado, } \\
\text { gordura } 1 \%\end{array}$ & 0401.10 .10 & $\begin{array}{l}\text { Leite UHT, contendo } \\
\text { matéria gorda }=>1 \% \text {, } \\
\text { não concentrado, não } \\
\text { adocicado }\end{array}$ \\
\hline & & 0401.10 .90 & $\begin{array}{l}\text { Creme de leite, matéria } \\
\text { gorda } 1 \%\end{array}$ \\
\hline 0401.20 .0000 & $\begin{array}{l}\text { Leite / Creme de leite, não } \\
\text { concentrado, não adocicado }\end{array}$ & 0401.20 .10 & Leite UHT $=>1 \%$ \\
\hline 0402.10 .0100 & $\begin{array}{l}\text { Leite em pó desnatado, } \\
\text { gordura } 1,5 \% \text {, exceto para } \\
\text { alimentação infantil }\end{array}$ & 0402.10 .90 & $\begin{array}{l}\text { Leite em pó, matéria } \\
\text { gorda }=>1,5 \% \\
\text { Creme de leite em pó, } \\
\text { matéria gorda => 1,5\% }\end{array}$ \\
\hline 0402.10 .0200 & 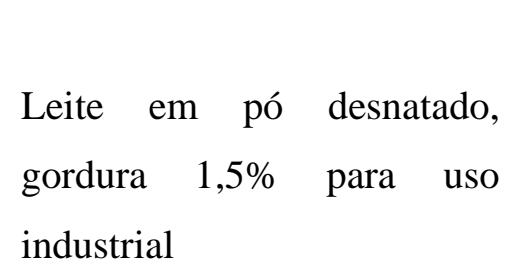 & $\begin{array}{l}0402.10 .10 \\
0402.10 .90\end{array}$ & $\begin{array}{l}\text { Leite em pó, matéria } \\
\text { gorda }=>1,5 \% \\
\text { Creme de leite em pó } \\
\text { matéria gorda }=>1,5 \%\end{array}$ \\
\hline 0402.21.0101 & $\begin{array}{l}\text { Leite em pó integral, gordura } \\
26 \% \text {, não adocicado }\end{array}$ & 0402.21 .10 & $\begin{array}{l}\text { Leite integral em pó, } \\
\text { matéria gorda => } \\
\text { 1,5\%, concentrado, não } \\
\text { adocicado }\end{array}$ \\
\hline
\end{tabular}

Fonte: Brasil (2003) 


\section{RESULTADOS E DISCUSSÃO}

A análise dos resultados foi dividida em cinco seções.

A primeira seção destaca a visualização gráfica das séries econômicas no intuito de fornecer suporte para a decisão quanto ao teste de raiz unitária a ser adotado.

A segunda seção apresenta os resultados dos testes de raiz unitária no qual são identificadas a ordem de integração das variáveis relacionadas no modelo. A identificação da ordem de integração permite determinar se a série possui raiz unitária ou se é estacionária, evitando um relacionamento espúrio entre as variáveis.

A terceira seção mostra os resultados do teste de sentido de causalidade de Granger no intuito de verificar se a relação entre a variável quantidade importada de leite e a variável-preço de importação de leite é bi-causal ou unidirecional. Para tanto, procedeu-se à análise da co-integração entre as variáveis tomadas duas a duas, adotando o procedimento de Engle e Granger. Segue o teste de Hausman com o objetivo de assegurar a causalidade entre as variáveis endógenas caso exista.

A quarta seção verifica, a partir do resultado do teste de raiz unitária, a existência de co-integração entre as variáveis. Esses resultados têm a finalidade de testar as relações entre as variáveis que estão envolvidas no modelo econômico, observando as pressuposições feitas neste modelo. Neste item usar-se-ão todas as variáveis com mesma ordem de integração indicadas no modelo econômico, por meio do teste de co-integração de Johansen. 
Na última seção apresenta-se as análises e os resultados do ajustamento da equação de importação de leite e de preço de importação pelo Brasil no período de janeiro de 1991 a dezembro de 2003.

\subsection{Análise gráfica}

A decisão quanto ao teste a ser adotado para avaliar a estacionariedade das séries econômicas é facilitada pela visualização gráfica individual, especialmente no que se refere à possibilidade de ocorrência de quebra estrutural.

Na Figura 21, observa-se que as importações de leite obedecem a um padrão cíclico, com maiores volumes em 1995, 1996 e 2000. No final do período analisado, provavelmente devido à desvalorização da moeda brasileira e à maior oferta de leite no mercado interno, as importações tenderam à redução.

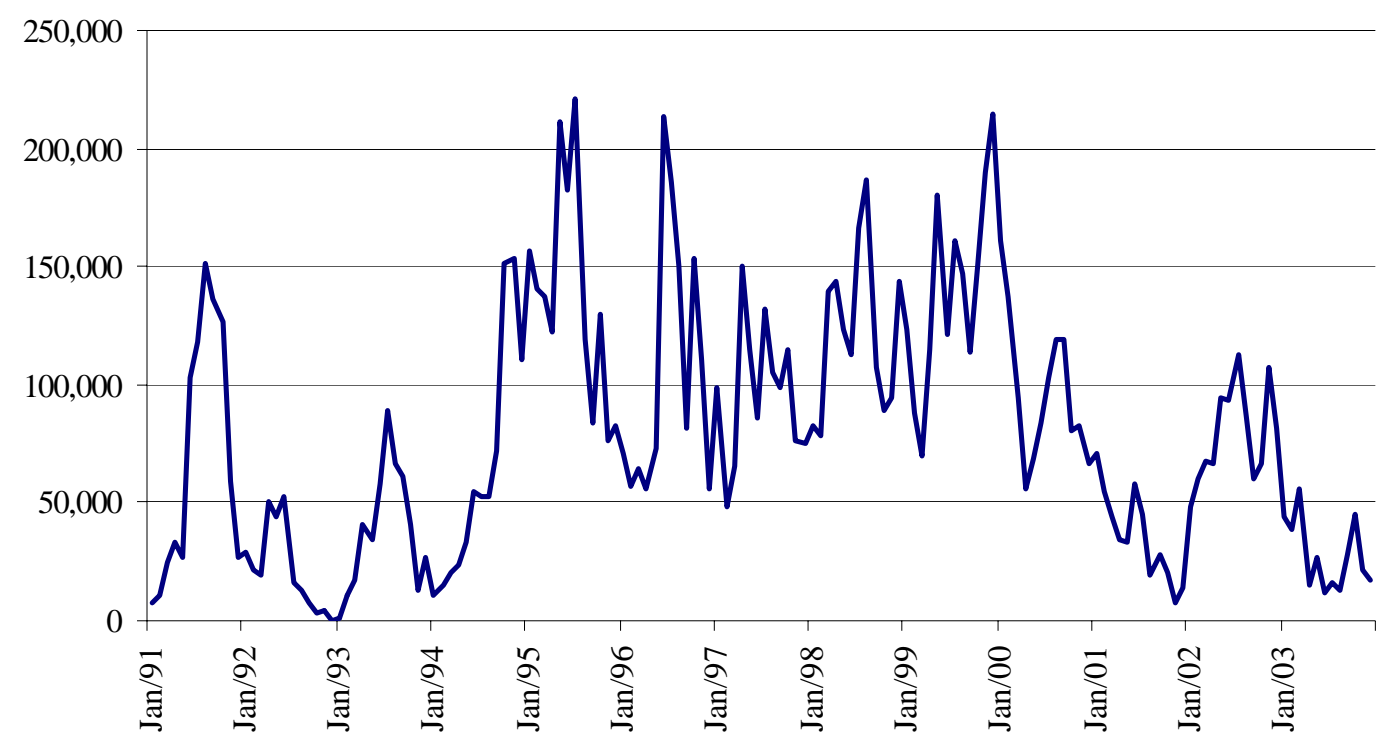

Figura 21 -Evolução da importação de leite (em mil litros), Brasil, janeiro de 1991 a dezembro de 2003

Fonte: Brasil (2003) 
As Figuras 22 e 23 apresentam padrões oscilatórios distintos, não sugerindo qualquer interação dos preços do leite importado e de preços domésticos. Observa-se uma tendência ascendente da série de preços nominais de importação e descendente da série de preços internos reais.

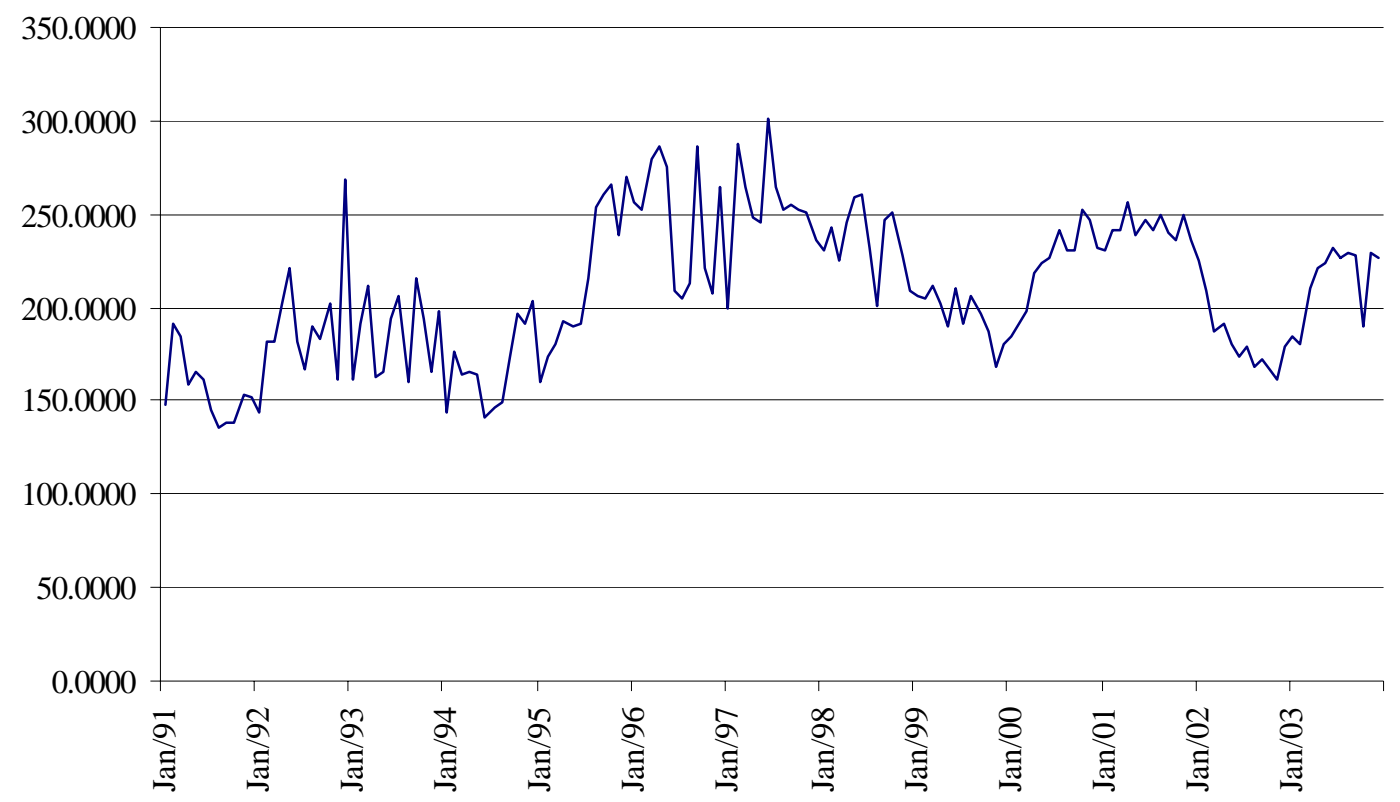

Figura 22 - Evolução dos preços nominais de importação de leite (US\$/mil litros) entre janeiro de 1991 a dezembro de 2003

Fonte: Brasil (2003) 


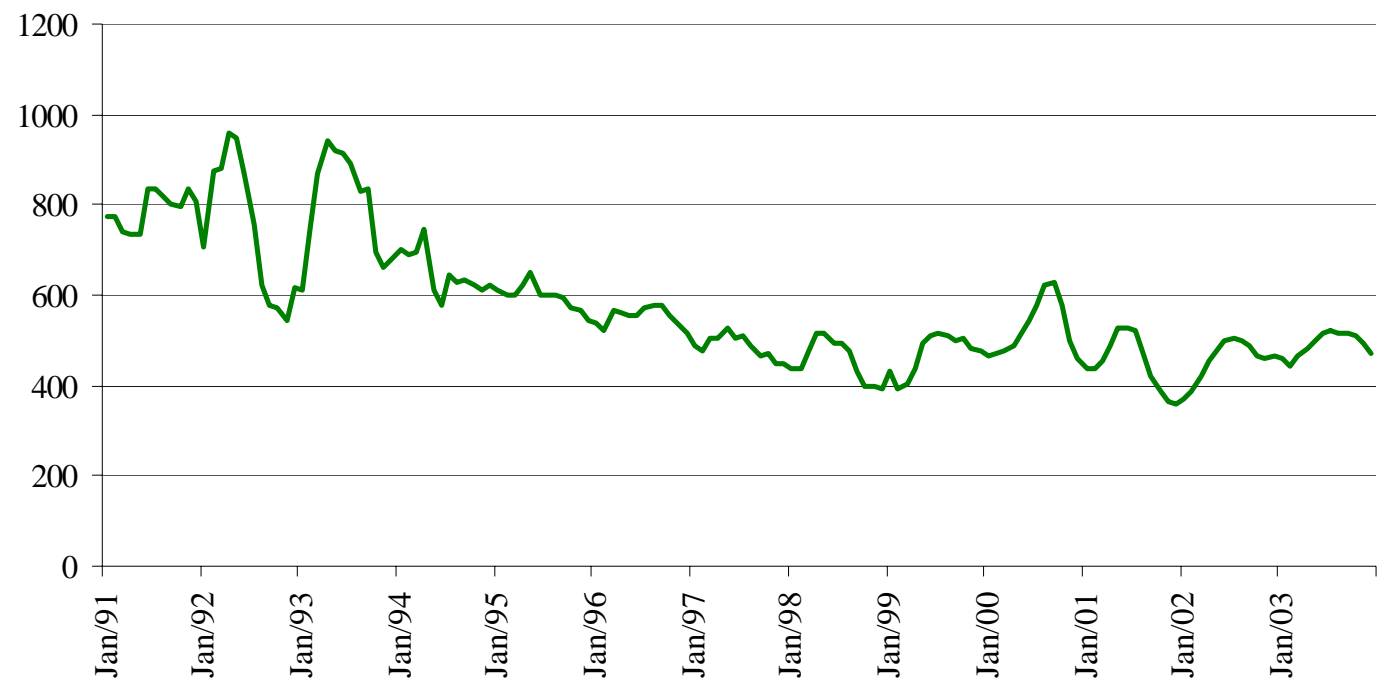

Figura 23 -Evolução dos preços internos reais de leite (R\$/mil litros) entre janeiro de 1991 a dezembro de 2003

Fonte: CEPEA (2003)

A Figura 24 mostra a evolução da taxa de câmbio mensal real em que se percebe uma tendência ascendente da taxa de câmbio em virtude das desvalorizações sucessivas e da própria extensão da série, relativamente longa. Observa-se pela visualização gráfica a existência de duas quebras estruturais da série considerada. Para tanto se pesquisou elementos que sustentassem sua existência e determinou-se a primeira quebra estrutural como aquela dada pela mudança de sistema cambial, de bandas cambiais para livremente administrado a partir de janeiro de 1999. A segunda quebra foi observada em maio de 2002 quando das repercussões das pesquisas eleitorais à presidência do Brasil que fizeram as taxas de câmbio subirem pelo efeito especulativo seguido pelo efeito "manada".

Destaca-se que outras pesquisas que analisam o efeito da variável taxa de câmbio real sobre alguma outra série econômica admitem que ela seja suscetível a quebras estruturais (Osaki, 2001; Bacchi e Alves, 2004). 


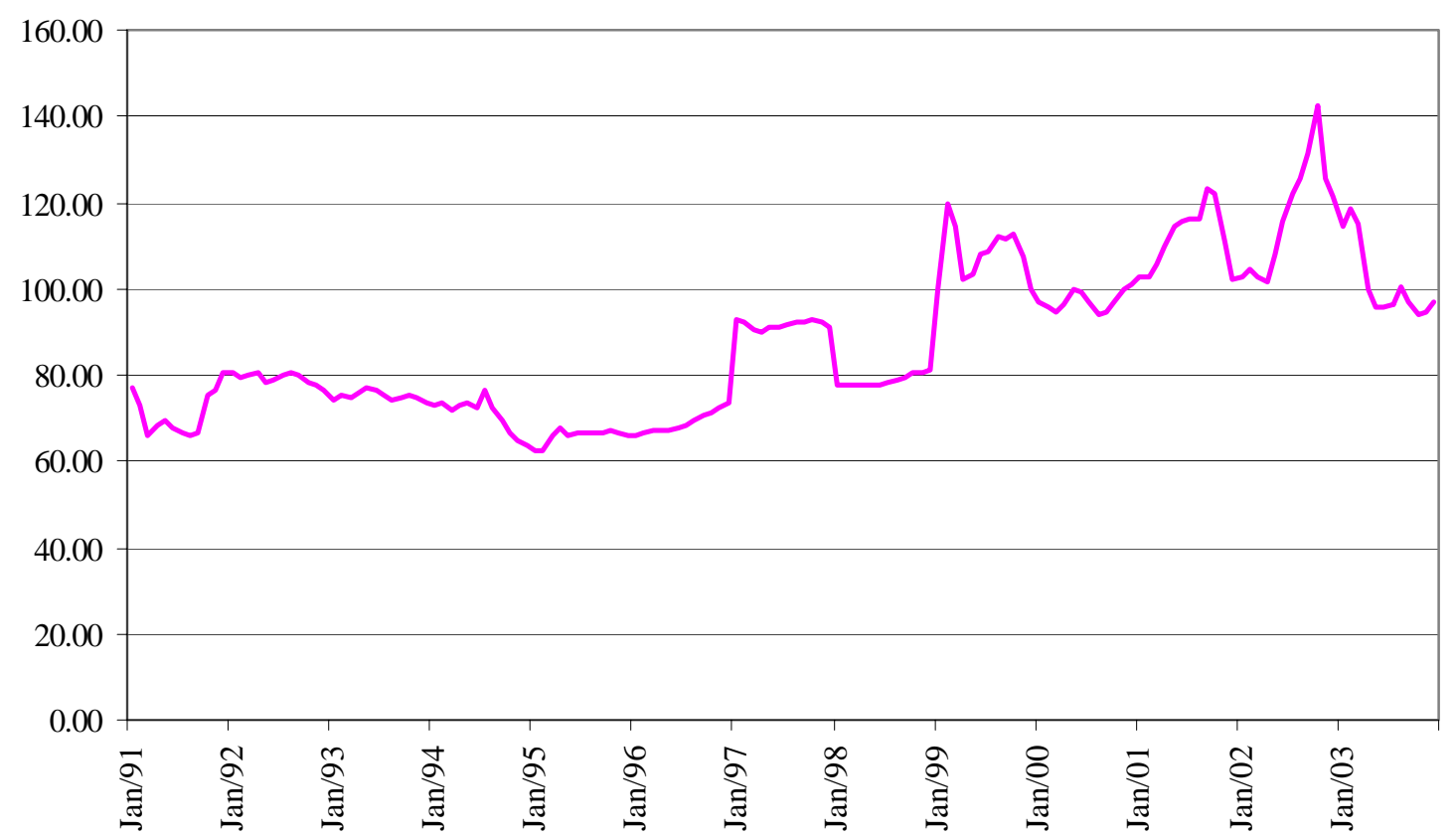

Figura 24 - Evolução da taxa de câmbio real mensal (US\$/R\$) entre janeiro de 1991 e dezembro de 2003, base 1999

Fonte: FGV (2004) e IPEA (2004)

A Figura 25 ilustra o desempenho da economia brasileira em que se observa um comportamento crescente sem quebra estrutural. 


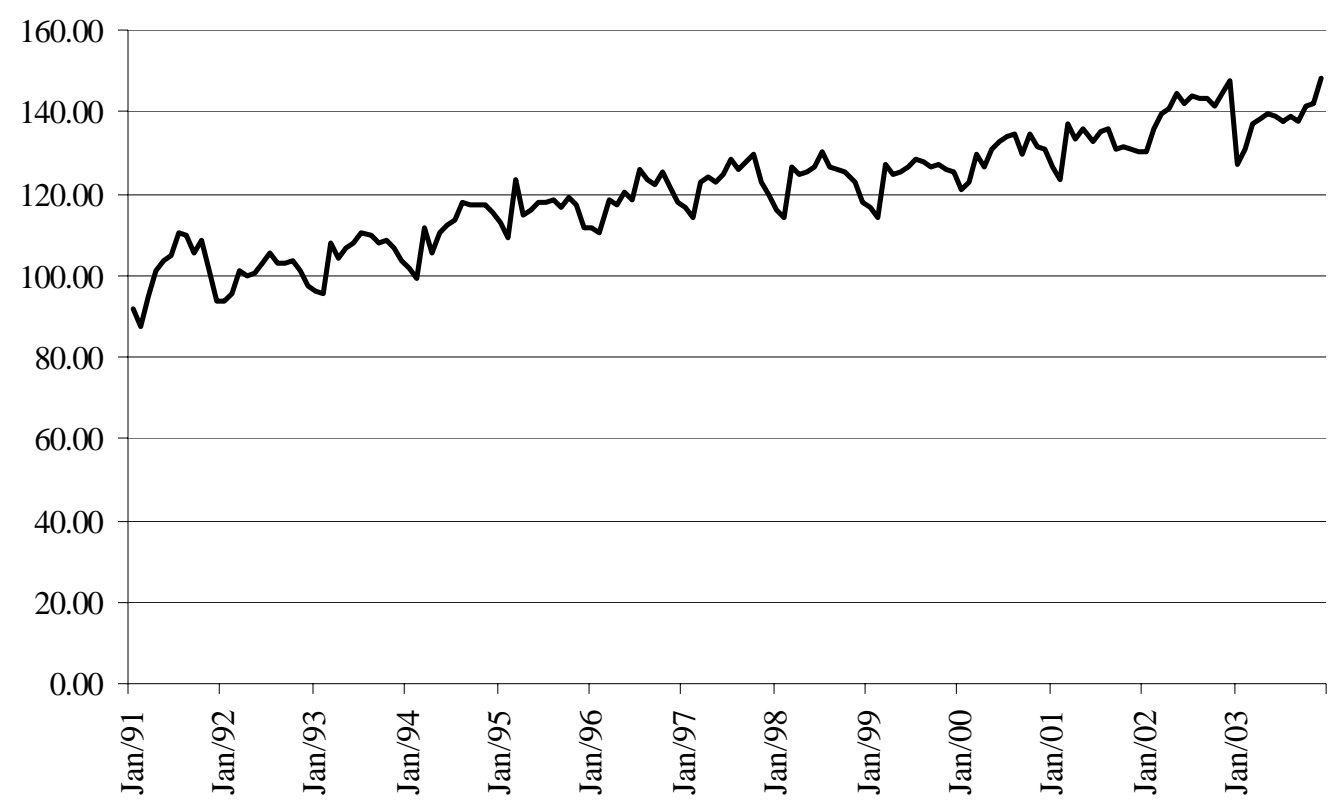

Figura 25 - Evolução do PIB real per capita (R\$/hab.), Brasil, entre janeiro de 1991 a dezembro de 2003, base 1990

Fonte: IPEA (2003) e FIPE (2003) 
A Figura 26 mostra a evolução das exportações mundiais de leite com tendência ascendente em todo o período, não apresentando nenhuma quebra estrutural.

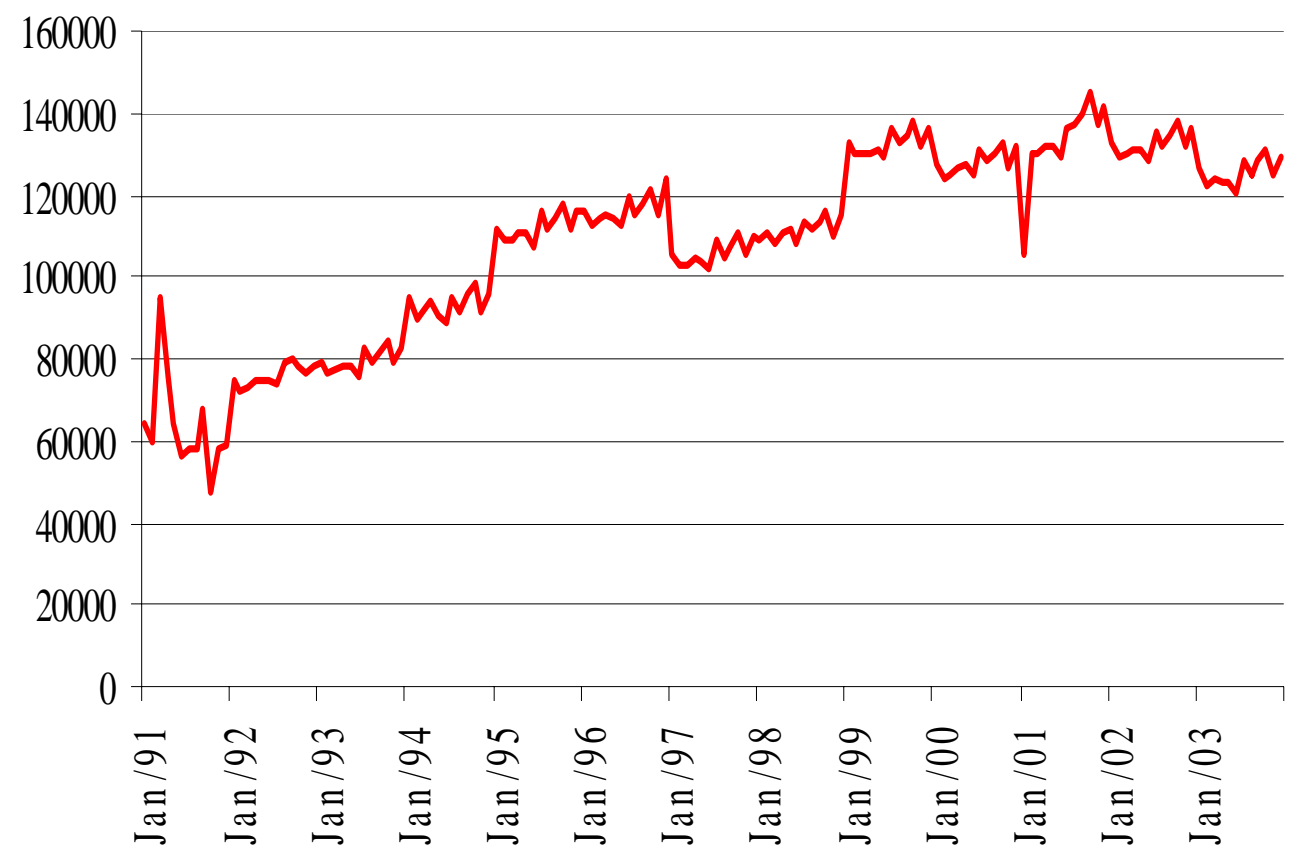

Figura 26 - Evolução das exportações mundiais de leite (em toneladas), período mensal, entre janeiro de 1991 a dezembro de 2003

Fonte: FAO (2004)

\subsection{Teste de raiz unitária}

Antes de proceder ao teste de raiz unitária, determina-se o número de defasagens (lags) a serem utilizadas na estimação de cada variável, visando eliminar a autocorrelação dos resíduos. Para a determinação do número de defasagens utilizou-se o critério de informação de Akaike (AIC) e Schwartz (SBC), processada em logaritmo no programa WinRats versão 3.2 (Regression Analysis of Time Series for Windows). 
Para a variável taxa de câmbio $\left(e_{t}\right)$ o critério de informação de AIC e SBC apresentou o menor valor na segunda defasagem, de modo que foi usado uma defasagem no teste de raiz unitária. As variáveis quantidade de leite importado, PIB per capita real e exportação mundial de leite apresentaram pelos critérios AIC e SBC seus menores valores na décima terceira defasagem, de modo que se utilizou doze lags no teste de raiz unitária. A variável preço de importação de leite obteve pelo critério de AIC e SBC o menor valor na nona defasagem, assim utilizou-se no teste de raiz unitária oito lags. A variável preço doméstico de leite apresentou o menor valor pelo critério AIC e SBC na sétima defasagem. Assim, o teste de raiz unitária foi feito com seis lags. Todas as variáveis estão sendo consideradas em nível.

As Tabelas 18 a 21 apresentam os resultados dos testes de raiz unitária para as séries tomadas nos logaritmos: importação mensal de leite (lm), preço mensal de leite no mercado interno (lpd), preço mensal de importação de leite (lpm), taxa mensal de câmbio real (le), PIB mensal per capita (ly) e exportação mensal mundial de leite (lw). Utilizou-se o procedimento proposto por Enders (2004) para identificar o modelo específico a ser considerado no teste, incluindo ou não termos deterministas.

A Tabela 18 apresenta a estatística $\tau_{\tau}$, que avaliou a significância das variáveis defasadas no modelo 1 , não foi significativa para as variáveis relacionadas. $\mathrm{O}$ mesmo acontecendo para a estatística $\tau_{\beta \tau}$, que avaliou a significância da tendência no modelo. 
Tabela 21. Teste de estacionariedade em modelo com constante $(\alpha)$ e tendência $(T)$, estatística $\tau_{\tau}^{1}$

\begin{tabular}{|c|c|c|c|c|}
\hline \multirow{2}{*}{$\begin{array}{r}\text { Modelo 1: } \\
\text { Variáveis }\end{array}$} & \multicolumn{3}{|c|}{$\Delta x_{t}=\alpha+\theta T+\gamma_{1} x_{t-1}+\sum_{j=1}^{n} \gamma_{j} \Delta x_{t-j}+\varepsilon_{t}$} & \multirow{2}{*}{$\begin{array}{l}\quad \mathrm{H}_{0:} \gamma_{1}=0 \\
\text { Nível de significância } \\
\text { da estatística “Q” }\end{array}$} \\
\hline & Valor de $p$ - 1 & $\begin{array}{l}\text { Valor da estatística t } \\
\qquad \mathrm{H}_{0}: \gamma_{1}=0\end{array}$ & $\begin{array}{l}\text { Valor da estatística t } \\
\qquad \mathrm{H}_{0}: \theta=0\end{array}$ & \\
\hline $\mathrm{l}_{\mathrm{m}}$ & 12 & $-2,43$ & 1,04 & 0,99 \\
\hline $\operatorname{lp}_{\mathrm{d}}$ & 6 & $-2,48$ & $-1,94$ & 0,75 \\
\hline $\mathrm{lp}_{\mathrm{m}}$ & 8 & $-2,24$ & 0,01 & 0,58 \\
\hline le ${ }^{(2)}$ & 1 & $-0,99$ & 0,71 & 0,99 \\
\hline ly & 12 & $-1,98$ & 1,87 & 0,70 \\
\hline$l_{\mathrm{w}}$ & 12 & $-1,71$ & 0,92 & 0,78 \\
\hline
\end{tabular}

1 Valores críticos de $\tau_{\tau}$ e $\tau_{\beta \tau}$ conforme descrito por Dickey e Fuller (1981) e correspondem, respectivamente, a -3,45 e 2,79 em nível de 5\% e -4,04 e 3,53 em nível de $1 \%$

2 Ajustado com duas quebras estruturais (1994, janeiro de 1999 e maio de 2002)

Na Tabela 19, a estatística $\tau_{\alpha \mu}$ foi utilizada para avaliar a significância do termo constante, sendo significativa a 5\% de probabilidade apenas para a variável preço mensal de importação de leite.

A estacionariedade dessas variáveis em nível deve também ser verificada no modelo sem constante e sem tendência pela estatística $\tau$ apresentada na Tabela 20. 
Tabela 22. Teste de estacionariedade em modelo com constante $(\alpha)$, estatística $\tau_{\mu}{ }^{1}$

\begin{tabular}{|c|c|c|c|c|}
\hline \multirow{2}{*}{$\begin{array}{l}\text { Modelo 2: } \\
\text { Variáveis }\end{array}$} & \multicolumn{3}{|c|}{$\Delta x_{t}=\alpha+\gamma_{1} x_{t-1}+\sum_{j=1}^{n} \gamma_{j} \Delta x_{t-j}+\varepsilon_{t}$} & \multirow{2}{*}{$\begin{array}{l}\quad \mathrm{H}_{0:} \gamma_{1}=0 \\
\text { Nível de significância } \\
\text { da estatística "Q" }\end{array}$} \\
\hline & Valor de $p-1$ & $\begin{array}{l}\text { Valor da estatística t } \\
\qquad \mathrm{H}_{0}: \gamma_{1}=0\end{array}$ & $\begin{array}{l}\text { Valor da estatística t } \\
\qquad \mathrm{H}_{0}: \alpha=0\end{array}$ & \\
\hline $\mathrm{l}_{\mathrm{m}}$ & 12 & $-2,21$ & 2,21 & 0,99 \\
\hline $\operatorname{lp}_{\mathrm{d}}$ & 6 & $-1,67$ & 1,93 & 0,59 \\
\hline $\mathrm{lp}_{\mathrm{m}}$ & 8 & $-2,72$ & $2,73^{*}$ & 0,58 \\
\hline $\mathrm{le}^{(2)}$ & 1 & $-1,05$ & 0,76 & 0,99 \\
\hline ly & 12 & $-0,68$ & 0,76 & 0,68 \\
\hline $\mathrm{ll}_{\mathrm{w}}$ & 12 & $-2,16$ & 2,19 & 0,70 \\
\hline
\end{tabular}

1 Valores críticos de $\tau_{\mu}$ e $\tau_{\alpha \mu}$ conforme descrito por Dickey e Fuller (1981) e correspondem, respectivamente, a -2,89 e 2,54 em nível de 5\% e -3,51 e 3,22 em nível de $1 \%$

2 Ajustado com duas quebras estruturais (janeiro de 1999 e maio de 2002)

* significativo ao nível de significância de 5\%

As demais variáveis relacionadas pelo modelo apresentaram no teste de raiz unitária ordem de integração igual a 1, [I(1)]. Isso significa que elas não rejeitaram a hipótese nula de raiz unitária, sendo necessário que na especificação do modelo elas sejam consideradas nas diferenças de primeira ordem. Ou seja, a estacionariedade das séries só foi configurada nas diferenças, quando os valores encontrados foram superiores ao valor crítico em nível de 1\% (Tabela 21).

Para todas as variáveis foram encontrados níveis de significância da estatística Q do teste de Ljung-Box maiores que 0,48, rejeitando a hipótese nula desse teste, que considera a existência de autocorrelação serial entre os resíduos. 
Tabela 23. Teste de estacionariedade em modelo sem constante e sem tendência, estatística $\tau^{1}$

\begin{tabular}{|c|c|c|c|}
\hline \multirow{2}{*}{$\begin{array}{r}\text { Modelo 3: } \\
\text { Variáveis }\end{array}$} & \multicolumn{2}{|c|}{$\Delta x_{t}=\gamma_{1} x_{t-1}+\sum_{j=1}^{n} \gamma_{j} \Delta x_{t-j}+\varepsilon_{t}$} & \multirow{2}{*}{$\begin{array}{l}\quad \mathrm{H}_{0:} \gamma_{1}=0 \\
\text { Nível de significância da } \\
\text { estatística "Q" }\end{array}$} \\
\hline & Valor de $p-1$ & $\begin{array}{l}\text { Valor da estatística } \mathrm{t} \\
\qquad \mathrm{H}_{0}: \gamma_{1}=0\end{array}$ & \\
\hline$l_{m}$ & 12 & $-0,02$ & 0,99 \\
\hline $\operatorname{lp}_{\mathrm{d}}$ & 6 & 0,37 & 0,57 \\
\hline lpm & 8 & 0,31 & 0,48 \\
\hline $\mathrm{le}^{(2)}$ & 1 & $-1,13$ & 0,99 \\
\hline ly & 12 & 2,09 & 0,71 \\
\hline $1 l_{\mathrm{w}}$ & 12 & 1,49 & 0,86 \\
\hline
\end{tabular}

1 Valores críticos de $\tau$ conforme descrito por Dickey e Fuller (1981) e corresponde a 1,95 em nível de 5\% e -2,60 em nível de 1\%

2 Ajustado com duas quebras estruturais (janeiro de 1999 e maio de 2002) 
Tabela 24. Teste de raiz unitária em modelo sem constante e sem tendência, estatística $\tau^{1}$

\begin{tabular}{lccc}
\hline Modelo 4: & $\Delta \Delta x_{t}=\sigma_{1} \Delta x_{t-1}+\sum_{j=1}^{n} \sigma_{j} \Delta \Delta x_{t-j}+\varepsilon_{t}$ & $\mathrm{H}_{0:} \sigma_{1}=0$ \\
\multicolumn{1}{c}{ Variáveis } & Valor de $p-1$ & $\mathrm{H}_{0}: \sigma_{1}=0$ & Nível de ignificância da estatística \\
\hline$\Delta \mathrm{l}_{\mathrm{m}}$ & 12 & $-3,69^{*}$ & “Q” \\
$\Delta \mathrm{l}_{\mathrm{d}}$ & 6 & $-7,29^{*}$ & 0,99 \\
$\Delta \mathrm{l}_{\mathrm{m}}$ & 8 & $-4,86^{*}$ & 0,62 \\
$\Delta \mathrm{le}^{(2)}$ & 1 & $-5,20^{*}$ & 0,48 \\
$\Delta \mathrm{ly}$ & 12 & $-3,35^{*}$ & 0,89 \\
$\Delta \mathrm{ll}_{\mathrm{w}}$ & 12 & $-3,18^{*}$ & 0,49 \\
\hline
\end{tabular}

1 Valores críticos de $\tau$ conforme descrito por Dickey e Fuller (1981) e corresponde a 1,95 em nível de 5\% e -2,60 em nível de 1\%

2 Ajustado com duas quebras estruturais (janeiro de 1999 e maio de 2002)

* significativo ao nível de significância de 1\%

\subsection{Teste de sentido de causalidade de Granger}

Os testes de co-integração foram realizados entre as variáveis duas a duas, para obter os termos de correção de erro para os testes de causalidade. Os resultados estão apresentados na Tabela 25.

O valor do teste “t” para o resíduo $(-3,83)$ no teste de co-integração é maior, em módulo, que o valor crítico (vc) de -3,55 em nível de significância de 10\%. Concluise que há um vetor de co-integração entre as variáveis da equação (i). Considerando a equação (ii), o valor do teste $t$ para o resíduo $(-3,85)$ no teste de co-integração é significativo ao nível de $10 \%$. Conclui-se que na equação (ii) existe um vetor de cointegração. 
Tabela 25. Resultados do teste de co-integração

Regressão estimada para testar a cointegração
Resultado do teste de estacionariedade aplicado no resíduo estimado

(i) $l_{m}=8,007548-0,5634245 l p_{m}$

$$
\mathrm{t}=-3,83
$$

$$
\mathrm{R}^{2}=0,99
$$

$\mathrm{Q}(\%)=0,969$

vc $(5 \%)=-3,89 *$

vc $(10 \%)=-3,55 *$

(ii) $l p_{m}=5,120586-0,0180994 l_{m}$

$$
\mathrm{t}=-3,85
$$

$$
\mathrm{R}^{2}=0,99
$$$$
\mathrm{Q}(\%)=0,847
$$

$\operatorname{vc}(5 \%)=-3,89 *$

$\mathrm{Vc}(10 \%)=-3,55^{*}$

* valor crítico para 100 observações e 1 variável (Harris, 1995)

No intuito de proceder à verificação do grau de associação linear entre a

\begin{tabular}{|c|c|c|c|c|c|c|}
\hline \multicolumn{3}{|c|}{ Defasagens } & \multicolumn{2}{|c|}{$\begin{array}{l}\text { Correlações cruzadas } \\
\Delta l_{m} \text { e } \Delta l p_{m}\end{array}$} & \multirow[b]{2}{*}{0.0096495} & \multirow[b]{2}{*}{0.0760867} \\
\hline-10 & -0.1226550 & -0.0114848 & 0.0007200 & $0.1827805^{*}$ & & \\
\hline-4 & 0.0944175 & $-0.1868382 *$ & 0.0469267 & -0.0473011 & -0.0139322 & 0.0919624 \\
\hline 2 & -0.0849551 & -0.0031836 & -0.1556921 & -0.0671414 & 0.0442662 & 0.1400722 \\
\hline 8 & 0.1093607 & -0.1538096 & -0.0759457 & & & \\
\hline
\end{tabular}
defasagem de uma variável em relação à outra, foram realizados testes de correlação cruzada. Os resultados dos testes de correlação estão apresentados na Tabela 26.

Tabela 26. Correlações cruzadas entre as variáveis utilizando 10 defasagens ${ }^{13}$

* Correlação significativa ( valor crítico para o teste de correlação segue a fórmula $\left.\frac{2}{\sqrt{n}}=\frac{2}{\sqrt{142}}=0,16783\right)$

\footnotetext{
${ }^{13}$ As defasagens negativas correspondem a defasagem da primeira variável descrita em relação à segunda, assim como as defasagens positivas referem-se à defasagem da segunda variável em relação à primeira.
} 
Os resultados da Tabela 26 fornecem algumas informações sobre o grau de correlação entre as variáveis. Assim, tem-se uma relação linear significativa no sentido quantidade mensal de importação de leite pelo Brasil defasada em relação ao preço mensal de importação. Utilizaram-se as defasagens de um a quatro para o teste de causalidade das variáveis, desde que os valores obtidos tenham sido significativos.

Os resultados da correlação cruzada fornecem indicação da existência da relação de causalidade entre as variáveis citadas. Porém, para referendar a existência de causalidade proceder-se-á ao teste de sentido de causalidade de Granger e ao teste de exogeneidade.

Os resultados das equações definidas no teste de causalidade são apresentados na Tabela 27. As relações de causalidade fornecem uma indicação mais precisa das relações comportamentais do mercado importador de leite no país.

Tabela 27. Resultados do teste de causalidade de Granger com termo de correção de erro

\begin{tabular}{llccc}
\hline Variável dependente & Variável explicativa & $p$ Teste $\mathrm{F}$ & $p$ Teste t & Teste Q \\
\hline$\Delta l_{m}$ & $\Delta l p_{m}$ & 0,001 & 0,003 & 0,16 \\
$\Delta l p_{m}$ & $\Delta l_{m}$ & 0,001 & 0,002 & 0,18 \\
\hline
\end{tabular}

Observa-se um sentido bi-causal no mercado importador de leite, em que a quantidade importada de leite $\left(\Delta l_{m}\right)$ causa o preço de importação de leite $\left(\Delta l p_{m}\right)$ e, também, que o preço de importação de leite $\left(\Delta l p_{m}\right)$ causa a quantidade de leite importado $\left(\Delta l_{m}\right)$. Portanto, será estimado o modelo pelo método de Mínimos Quadrados de Dois Estágios, uma vez que existe uma relação endógena no sistema de equações. Além disso, as equações (2) e (3) são sobre-identificadas indicando a utilização do método de MQ2E. 


\subsection{Teste de exogeneidade e de Hausman}

Tabela 28. Resultados do teste de Hausman

\begin{tabular}{|c|c|c|c|c|}
\hline \multirow[b]{2}{*}{ Variáveis } & \multicolumn{2}{|c|}{$\Delta l_{m}$} & \multicolumn{2}{|c|}{$\Delta l p_{m}$} \\
\hline & Coeficiente & Valor $\mathrm{p}$ de $\mathrm{t}$ & Coeficiente & Valor p de $\mathrm{t}$ \\
\hline Constante & 9,045811 & 14,96971 & 4,342549 & 24,73361 \\
\hline$\Delta \mathrm{l}_{\mathrm{m}}$ & - & - & $-0,652837$ & $-40,32745$ \\
\hline$\Delta \operatorname{lp}_{\mathrm{d}}{ }^{1}$ & 2,488259 & 7,84625 & - & - \\
\hline$\Delta \mathrm{lp}_{\mathrm{m}}$ & $-6,350305$ & $-31,97191$ & - & - \\
\hline$\Delta \mathrm{le}^{1,2}$ & $-1,358041$ & $-5,70965$ & $-0,858267$ & $-13,43305$ \\
\hline$\Delta \mathrm{ly}^{1}$ & 6,410267 & 9,46624 & 1,823598 & 11,91541 \\
\hline$\Delta \mathrm{ll}_{\mathrm{w}}{ }^{1}$ & 1,328282 & 3,40598 & $-0,611759$ & $-7,17624$ \\
\hline$\hat{\varpi}_{t}$ & $6,331356^{*}$ & 27,72871 & - & - \\
\hline$\hat{\delta}_{t}$ & - & - & $0,652837^{*}$ & 35,75900 \\
\hline$r 1^{(1)}$ & $-0,024938$ & $-15,31705$ & $-0,006616$ & $-18,19791$ \\
\hline$r 2^{(1)}$ & $-0,184431$ & $-14,06500$ & $-0,093189$ & $-24,29216$ \\
\hline $\mathrm{d}_{1}$ & $-0,195657$ & $-5,28205$ & 0,001113 & 0,12177 \\
\hline \multirow[t]{2}{*}{$\mathrm{d}_{2}$} & $-0,004756$ & $-0,20205$ & 0,054068 & 8,88968 \\
\hline & \multicolumn{2}{|c|}{$\mathrm{F}=56,12^{*}$} & \multicolumn{2}{|c|}{$\mathrm{F}=89,47^{*}$} \\
\hline
\end{tabular}

* significativo ao nível de significância de 1\%

${ }^{1}$ variável defasada

1, 2 variável defasada com duas quebras estruturais

Conclui-se que há exogeneidade fraca, pois os resíduos são significativos pelo teste $t$. Assim, pode-se afirmar que existe causalidade entre $\Delta l m$ e $\Delta p m$, sendo condição necessária à exogeneidade forte. A fraca, referendada pelo teste de Hausman é 
condição suficiente para confirmar a causalidade no sentido de Granger, uma vez que o objetivo é a estimação de variáveis endógenas.

\subsection{Teste de co-integração de Johansen}

Nos resultados da análise de co-integração para as séries de mesma ordem, os testes do máximo autovalor e do traço indicam que há dois vetores de co-integração (Tabela 29). Dessa maneira, os resultados mostram que existem relações de equilíbrio de longo prazo entre as variáveis.

Tabela 29. Resultados do teste de co-integração de Johansen

\begin{tabular}{cccc}
\hline Hipótese Nula & Hipótese Alternativa & $\boldsymbol{\lambda}_{\max }$ & $\boldsymbol{\lambda}_{\text {trace }}$ \\
\hline $\mathrm{r} \leq 5$ & $\mathrm{r}=6$ & 3,628 & 3,628 \\
$\mathrm{r} \leq 4$ & $\mathrm{r}=5$ & 10,814 & 14,441 \\
$\mathrm{r} \leq 3$ & $\mathrm{r}=4$ & 15,053 & 29,494 \\
$\mathrm{r} \leq 2$ & $\mathrm{r}=3$ & 26,845 & 56,339 \\
$\mathrm{r} \leq 1$ & $\mathrm{r}=2$ & $44,088^{*}$ & $100,427^{*}$ \\
$\mathrm{r} \leq 0$ & $\mathrm{r}=1$ & $86,955^{*}$ & $187,382^{*}$ \\
\hline
\end{tabular}

Fonte: dados da pesquisa

* significativo a 1\% de significância [valores críticos em Osterwald-Lenum (1992)] 


\subsection{Estimação das funções de demanda e preço de leite importado}

Na Tabela 29, observa-se o resultado da estimação da função demanda de leite importado (eq. 3). Vale ressaltar que as séries utilizadas possuem raiz unitária, sendo utilizadas na primeira diferença ${ }^{14}$.

Tabela 29. Estimativa do ajustamento em dois estágios da demanda por leite importado $\left(\mathrm{M}^{\mathrm{d}}\right)$

\begin{tabular}{lcc}
\hline \multicolumn{1}{c}{ Variáveis } & \multicolumn{2}{c}{ Coeficientes } \\
\hline Constante & $6,185614^{*}$ & Estatística $\boldsymbol{t}$ \\
$\Delta l p_{m}$ & $-1,562731^{*}$ & $-5,96051$ \\
$\Delta l m_{d}$ & - & - \\
$\Delta l l_{w}$ & - & - \\
$\Delta l e\{1\}^{1}$ & $-1,183131^{*}$ & $-1,86461$ \\
$\Delta l e\{2\}$ & $-0,715673$ & $-1,07018$ \\
$\Delta l e\{3\}$ & $-0,405317$ & $-0,59596$ \\
$\Delta l e\{4\}$ & 0,545874 & 0,79684 \\
$\Delta l e\{5\}$ & $-0,696495$ & $-1,04448$ \\
$\Delta l y\{1\}$ & 2,356858 & 1,37965 \\
$\Delta l y\{2\}$ & 0,554008 & 0,37965 \\
$\Delta l y\{3\}$ & $2,982639 *$ & 1,74637 \\
$\Delta l y\{4\}$ & 0,531644 & 0,34129 \\
$\Delta l y\{5\}$ & $-1,275972$ & $-0,84996$ \\
\hline$\Delta l y\{6\}$ & $-0,509354$ & $-0,35155$ \\
$\Delta l y\{7\}$ & 0,894439 & 0,61366
\end{tabular}

\footnotetext{
${ }^{14}$ Estando as variáveis dependente e independente (com exceção das dummies) expressas em logaritmos, os coeficientes das regressões representam relações entre variações percentuais nas taxas de crescimento entre essas variáveis. Se definir a variação percentual na taxa de crescimento como aceleração na variável, então os coeficientes podem ser encarados como relação entre acelerações das variáveis.
} 
Tabela 29. Estimativa do ajustamento em dois estágios da demanda por leite importado $\left(\mathrm{M}^{\mathrm{d}}\right)$

\begin{tabular}{lcc}
\hline & Variáveis & Coeficientes \\
$\Delta l y\{8\}$ & $-1,214613$ & Estatística $\boldsymbol{t}$ \\
$\Delta l y\{9\}$ & 1,949891 & $-0,84876$ \\
$\Delta l p_{d}$ & $1,643824^{* *}$ & 1,36933 \\
$r 1^{1}$ & $-0,009389^{*}$ & 1,46999 \\
$r 2^{1}$ & $-0,132842^{*}$ & \\
$d 1$ & 0,001714 & \\
$d 2$ & 0,074887 & \\
$R^{2}$ & 0,3432 & \\
\hline
\end{tabular}

* significativo a $1 \%$

** significativo a $10 \%$

${ }^{1}$ variável defasada e com duas quebras estruturais

Na estimação das referidas equações, todas as variáveis apresentaram sinais coerentes com a teoria econômica e nível de significância a pelo menos $10 \%$ à exceção das variáveis dummies que indicavam estabilidade econômica (d1) e política antidumping (d2) relacionada na equação de demanda por leite importado $\left(M^{d}\right)$.

Na estimação de $M^{d}$, a variável preço de importação de leite, cujo coeficiente é significativo a $1 \%{ }^{15}$, apresentou uma flexibilidade preço de $-1,562$, significando que um aumento de $10 \%$ na taxa de crescimento desse preço diminuiria a taxa de crescimento da quantidade importada em 15,62\%, no mês seguinte à variação.

A variável taxa de câmbio possui uma flexibilidade câmbio de -1,183 e apresentou-se significativa a 1\%. A taxa de câmbio foi defasada em dois meses, indicando que um aumento de $10 \%$ na desvalorização diminuiria a taxa de crescimento 
das importações em 11,83\% a partir do segundo mês após a desvalorização. Vale destacar, que nos períodos de estabilidade cambial houve uma maior propensão ao aumento de importações de leite; ao se proceder à flexibilização em 1999, permitiu-se que a taxa de câmbio real impedisse um maior aumento dos níveis de importação de leite no país.

O coeficiente da variável PIB per capita real foi significativo a $1 \%$ apresentando sinal coerente ao esperado. O coeficiente da variável PIB per capita real foi significativo a $1 \%$ e apresentou uma flexibilidade renda de 2,982 com nove meses de defasagem. Assim, um aumento de $10 \%$ na taxa de crescimento do PIB per capita brasileiro eleva em 29,82\% a taxa de importações de leite a partir do nono mês posterior ao aumento do PIB per capita. Essa defasagem de nove meses já era esperada em virtude da impossibilidade de alteração dos níveis de importação num curto espaço de tempo dado um aumento da renda per capita.

A variável preço doméstico de leite possui uma flexibilidade preço interno de 1,644, que é significativa a 10\%. Uma elevação na taxa de crescimento dos preços domésticos do leite em torno de $10 \%$ aumenta a taxa de crescimento das importações em 16,44\% após o segundo mês de elevação do preço interno. Percebe-se que as importações de leite são sensíveis às variações de preço no mercado doméstico.

O coeficiente da dummy que incorporou a estabilidade econômica não foi significativo. O que se apreende é que as importações diminuíram em virtude da melhoria das condições macroeconômicas. Ou seja, a estabilização de preços teria proporcionado melhores condições à cadeia produtiva de lácteos e à população que incorpora em sua alimentação diária o consumo de leite.

A dummy anti-dumping não foi significativa, indicando que a definição de ajustes de preços para que determinadas importações fossem feitas não impediu um maior aumento das importações de leite, porém apresentou sinal esperado.

\footnotetext{
${ }^{15} \mathrm{O}$ método de mínimos quadrados de dois estágios produzem apenas aproximações das estatísticas $t$.
} 
As duas variáveis de correção de erro que traduzem as elasticidades de longo prazo foram significativas em $1 \%$ e se apresentaram negativamente relacionadas com as importações.

As variáveis relacionadas pela pesquisa do comportamento da demanda por leite importado explicaram 34\% das importações de leite conforme sugere o coeficiente de determinação.

As variáveis relacionadas para a estimação do preço de importação são mostradas na Tabela 30. Na equação do preço de leite importado $\left(\Delta \operatorname{lp}_{m}\right)$, o sinal do coeficiente da quantidade importada apresenta-se negativo, contrário ao esperado. Embora tal efeito possa ocorrer sinalizando redução de preço para compras mais volumosas, permanece a possibilidade de que a equação não tenha sido bem estimada.

A flexibilidade de demanda do leite importado foi de -0,1246; assim, para ocorrer um aumento de $10 \%$ na taxa de crescimento da quantidade importada é necessária uma redução de $1,25 \%$ na taxa de crescimento do preço de importação. O coeficiente foi significativo a $1 \%$.

A flexibilidade de oferta (exportação) mundial de leite em relação ao preço pago pelo Brasil foi de -0,4391, significando que um aumento de $10 \%$ na taxa de crescimento da oferta mundial reduz a taxa de crescimento dos preços de importação em 4,39\%. O coeficiente apresentou nível de significância de 10\%. 
Tabela 30. Estimativa do ajustamento em dois estágios da função preço de importação $\left(\mathrm{P}_{\mathrm{m}}\right)$

\begin{tabular}{lcc}
\hline \multicolumn{1}{c}{ Variáveis } & $\Delta l p_{m}$ & Estatística $t$ \\
\hline Constante & $0,645634^{*}$ & 2,33833 \\
$\Delta l m_{d}$ & $-0,124643^{* *}$ & $-5,35339$ \\
$\Delta l l_{w}\{1\}$ & $-0,439108^{* *}$ & $-1,59144$ \\
$\Delta l l_{w}\{2\}$ & 0,099479 & 0,32199 \\
$\Delta l l_{w}\{3\}$ & $-0,250912$ & $-0,86180$ \\
$\Delta l l_{w}\{4\}$ & 0,338293 & $-1,26965$ \\
$\Delta l l_{w}\{5\}$ & $-0,285272$ & $-1,06826$ \\
$\Delta l l_{w}\{6\}$ & $-0,291853$ & $-1,36950$ \\
$r 1^{1}$ & $-0,002861^{*}$ & 3,03168 \\
$r 2^{1}$ & $-0,012235^{*}$ & $-2,09053$ \\
$R^{2}$ & 0,2225 & \\
\hline
\end{tabular}

As variáveis, quantidade demandada de leite pelo país e produção mundial de leite explicaram 22\% dos preços de importação pagos pelo Brasil como sugere o coeficiente de determinação.

Os resultados retratam a dinâmica do mercado de importação de leite no Brasil. Por exemplo, um aumento no PIB brasileiro tende a aumentar o volume importado que, por sua vez eleva o preço de importação, contendo parcialmente o efeito de crescimento das importações. Da mesma forma, uma expansão da produção mundial reduz o preço de importação que provoca um aumento nas importações, que atenua a queda original de preço.

Tratando-se de um sistema de duas equações simultâneas, a interpretação dos efeitos de choques nas variáveis exógenas sobre as endógenas $\left(\Delta l m_{d} e \Delta l p_{m}\right)$ fica facilitada a partir de sua forma reduzida. Esta pode ser obtida resolvendo-se o sistema 
para as variáveis endógenas em termos de todas as exógenas. Por exemplo, pode-se substituir $\Delta l m_{d}$ na equação de $\Delta l p_{m} ;$ o resultado é então substituído em $\Delta l m_{d}$. Os resultados estão na Tabela 31.

As equações em sua forma reduzida e estimada pelo ajustamento de dois estágios são apresentadas abaixo:

$$
\begin{aligned}
& \Delta l m_{d}= 6,185-1,563 \Delta l p_{m}-1,183 \Delta l e+2,983 \Delta l y+1,644 \Delta l p_{d} \\
&-0,009 r 1-0,133 r 2+0,002 d 1+0,075 d 2 \\
& \Delta l p_{m}=0,646-0,125 \Delta l m_{d}-0,439 \Delta l l_{w}-0,003 r 1-0,012 r 2
\end{aligned}
$$

Substituindo (19) em (18) tem-se:

$$
\begin{aligned}
& \Delta l m_{d}=6,185-1,563\left(0,646-0,125 \Delta l m_{d}-0,439 \Delta l l_{w}-0,003 r 1-0,012 r 2\right)-1,183 \Delta l e+ \\
& +2,983 \Delta l y+1,644 \Delta l p_{d}-0,009 r 1-0,133 r 2+0,002 d 1+0,075 d 2 \\
& 0,805 \Delta l m_{d}=5,175+0,686 \Delta l l_{w}+0,005 r 1+0,188 r 2-1,183 \Delta l e+2,983 \Delta l y+1,644 \Delta l p_{d}- \\
& -0,009 r 1-0,133 r 2+0,002 d 1+0,075 d 2 \\
& \Delta l m_{d}=6,429+0,852 \Delta l l_{w}-1,469 \Delta l e+3,706 \Delta l y+2,042 \Delta l p_{d}-0,004 r 1-0,055 r 2+ \\
& +0,002 d 1+0,075 d 2
\end{aligned}
$$

Substituindo (20) em (19) tem-se: 


$$
\begin{aligned}
\Delta l p_{m}= & 0,646-0,125\left(6,429+0,852 \Delta l l_{w}-1,469 \Delta l e+3,706 \Delta l y+2,042 \Delta l p_{d}-0,004 r 1-\right. \\
& -0,055 r 2+0,002 d 1+0,075 d 2)-0,439 \Delta l l_{w}-0,003 r 1-0,012 r 2 \\
\Delta l p_{m}= & 0,646-0,804-0,107 \Delta l l_{w}+0,184 \Delta l e-0,463 \Delta l y-0,255 \Delta l p_{d}+0,007 r 1+0,043 r 2+ \\
& +0,002 d 1-0,075 d 2-0,439 \Delta l l_{w} \\
\Delta l p_{m}= & -0,158-0,546 \Delta l l_{w}+0,184 \Delta l e-0,463 \Delta l y-0,255 \Delta l p_{d}-0,007 r 1-0,043 r 2+ \\
& +0,002 d 1-0,075 d 2
\end{aligned}
$$

Tabela 31. Resultados das substituições do sistema simultâneo

$\Delta l m_{d} \Delta l p_{m}$

Variáveis

Coeficientes

\begin{tabular}{lcc}
\hline Constante & 6,429 & $-0,158$ \\
$\Delta l e$ & $-1,469$ & 0,184 \\
$\Delta l y$ & 3,706 & $-0,463$ \\
$\Delta l p_{d}$ & 2,042 & $-0,255$ \\
$\Delta l l_{w}$ & 0,852 & $-0,546$ \\
$r 1$ & $-0,004$ & 0,007 \\
$r 2$ & $-0,055$ & 0,043 \\
$d 1$ & 0,002 & 0,002 \\
$d 2$ & 0,075 & 0,075
\end{tabular}

Assim, supondo um aumento de $10 \%$ na taxa de crescimento da renda per capita real brasileira, o impacto a partir do sétimo mês sobre a importação de leite seria 
um aumento 6,43\% na taxa de importação. Em contrapartida, esse aumento de renda geraria uma redução de 4,63\% no preço do leite importado.

Uma valorização de $10 \%$ na taxa de crescimento do câmbio real aumentaria a taxa de crescimento do preço importado em $1,84 \%$ e a taxa de crescimento da quantidade de leite importado reduziria em 1,47\%.

O impacto no mesmo mês de um aumento de $10 \%$ na taxa de crescimento da oferta (exportação) mundial de leite refletiu-se em um aumento de 5,46\% na taxa de crescimento do preço de importação e em uma redução de 8,52\% na taxa de crescimento das importações pelo Brasil. 


\section{CONCLUSÕES}

O sistema agroindustrial do leite no país passou por importantes alterações desde o início da década de 1990. Houve reorganização intensa na pecuária leiteira que refletiram no aumento de competitividade para enfrentar a concorrência externa. O segmento de leite fluido experimentou a desregulamentação do setor após 46 anos de controle governamental no estabelecimento de preço do leite tipo C. Concomitantemente, houve lançamentos de novos produtos e derivados, a abertura econômica do país e a formação do Mercosul.

A abertura econômica e a formação do Mercosul levaram as empresas à competição com empresas de grande porte e a enfrentar os preços praticados no resto do mundo. No mercado interno houve um processo de concentração das empresas de laticínios e a entrada de empresas multinacionais no mercado. Em paralelo, houve um aumento da participação relativa do leite UHT no mercado nacional de leite fluido durante a década de 1990.

Com esta pesquisa pretendeu-se analisar os fatores que têm influenciado as importações de lácteos pelo Brasil no período de 1991 a 2003. O objetivos específicos foram analisar o comportamento das quantidades importadas de leite frente ao comportamento dos preços de importação, taxa de câmbio, renda per capita, preço doméstico de leite, estabilização econômica e política anti-dumping; enfocar o comércio internacional de leite e destacar medidas implementadas pelo Brasil para impedir políticas comerciais que penalizem o produtor nacional. 
As importações totais de leite que incluem leite em pó integral, leite em pó desnatado, leite UHT e creme de leite foram mais significativas nos períodos 1995, 1996 e 1999. Como já foi observado anteriormente, esse quadro reflete a política de sobrevalorização cambial, uma maior integração com os parceiros dos Mercosul e um maior consumo de leite da população brasileira frente à produção nacional.

Os resultados obtidos pelas estimações das equações de demanda e de oferta de importações permitiram caracterizar a dinâmica do mercado importador de leite no país. As variáveis que foram selecionadas para explicar esse mercado foram: preço de importação de leite, taxa de câmbio real, PIB per capita real, preço interno de leite e quantidade de exportação mundial.

Vale destacar, na equação da demanda por leite importado, as variáveis preço de importação de leite, taxa de câmbio real, PIB per capita real e preço interno de leite por serem significativas e apresentarem sinais coerentes com a teoria econômica. As elasticidades estimadas foram todas próximas ou superiores à unidade, revelando um mercado bastante dinâmico com ajustes rápidos no curto prazo. A demanda por importação mostrou-se bastante elástica tanto em relação ao preço de importação como ao preço doméstico. As elasticidades foram de magnitudes bem parecidas, sugerindo uma boa integração do segmento leiteiro ao mercado internacional: variações iguais nos dois preços mantida a taxa de câmbio, não alterariam o volume importado de leite. O crescimento da renda tende a resultar em incremento importante das importações, indicando que o setor nacional tem dificuldade de atender a um crescimento mais rápido do consumo interno. O câmbio real tem sido um fator relevante para as importações de lácteos na medida que é determinante do preço relativo dos produtos nacional e importado.

No tocante à oferta de leite importado, nota-se que as importações brasileiras se apresentam como se o país fizesse volumosas compras do produto, diante do sinal incoerente com a teoria econômica. Embora o volume de comércio internacional de lácteos seja expressivo - próximo a $1 / 7$ da produção mundial, parecem prevalecer 
condicionantes de mercados regionais, sendo o Brasil um comprador importante no âmbito da América do Sul. Nota-se, todavia, igualmente uma integração do mercado internacional de lácteos, posto que o preço pago pelo Brasil é influenciado pelas exportações mundiais. Ou seja, havendo uma expansão da oferta os preços tendem a cair significativamente de sorte que a produção seja escoada para os diversos mercados regionais.

É importante também reconhecer que, as dummies incluídas para captar as variações de políticas econômicas, como a estabilização monetária e as políticas antidumping não apresentaram efeitos significativos. É possível que seus efeitos tenham sido captados por outras variáveis presentes no modelo. Por exemplo, os efeitos da estabilização monetária podem ter sido captados pela variável câmbio real, que se manteve fortemente valorizado no período que seguiu o Plano Real. O mesmo papel pode ter cumprido a variável representativa do PIB brasileiro. Quanto ao papel das medidas anti-dumping, seus efeitos podem ter repercutido sobre os preços domésticos e externos, ambos também incluídos no modelo. 


\section{REFERÊNCIAS BIBLIOGRÁFICAS}

ALVES, D.; FAVA, V.L.; SILBER, S.D. Current account balance and the real exchange rate: the brazilian case in the last two decades. Economia Aplicada, v.3, p. 15-33, mar. 1999. Número especial.

ASSOCIAÇÃO BRASILEIRA DE LEITE LONGA VIDA (ABLV). Consumo de leite longa vida. http://www.ablv.org.br (20 set. 2004)

BACCHI, M.R.P.; ALVES, L.R.A. Formação de preço do açúcar cristal empacotado ao varejo da região centro-sul do Brasil. Agricultura em São Paulo, v.51, n.1, p.5-22, jan-jun 2004..

BAILEY, K.W. Marketing and pricing of milk and dairy products in the United State. Ames: Iowa University Press, 1997. 281p.

BANCO INTERAMERICANO DE DESENVOLVIMENTO (BID). Mercosul e Comunidade Andina. http://www.iadb.org (04 ago. 2003)

BARROS, G.S.C. Economia da Comercialização Agrícola. Piracicaba: FESALQ/USP, 1987. 360p.

BARROS, G.S.C.; GALAN, V.B.; GUIMARÃES, V.A.; BACCHI, M.R.P. Sistema agroindustrial do leite no Brasil. Brasília: Embrapa Informação Tecnológica, 2001. 170p. 
BRANDÃO, A.S.P; LEITE, J.L.B. Características principais do comércio internacional de leite. In: GOMES, A.T.; LEITE, J.L.B.; CARNEIRO, A.V. (Ed.). O agronegócio do leite no Brasil. Juiz de Fora: Embrapa Gado de Leite, 2001.p.167180.

BRASIL. Secretaria de Comércio Exterior. Sistema Alice. http://aliceweb.desenvolvimento.gov.br (10 jun. 2003)

BRASIL. Ministério do Desenvolvimento, Indústria e Comércio. Aliceweb e estatísticas. http//mdic.gov.br (12 ago. 2003 e 25 set. 2004)

BRID, J.C.M. Liberalización comercial y la demanda de importaciones en México. Investigación Económica, n.24, p.13-50, abr-jun, 2002.

CAMPOS, B.R. Fatores externos condicionantes da competitividade da produção de leite no Brasil. Viçosa, 2001. 60p. Tese (M.S.) - Universidade Federal de Viçosa.

CARVALHO, A.; SILVA, M.A. Economia internacional. 2.ed. São Paulo: Saraiva, 2002. 300p.

CASTRO, A.S.; CAVALCANTI, M.A.F.H. Estimação de equações de exportação e importação para o Brasil: 1955/95. Rio de Janeiro: IPEA, 1997. 61p. (Texto para a discussão, 469).

CENTRO DE ESTUDOS ESPECIAIS EM ECONOMIA APLICADA (CEPEA). http:// www.cepea.esalq.usp.br (14 ago. 2002 e 20 set. 2004)

COLLINS, D.; MAYDEW, E.; WEISS, I. Changes in the value-relevance of earnings and book values over the past forty years. Journal of Accounting and Economics, v.26, n 9-10, p.143-81, Nov. 1997.

DIB, M.F.S.P. Importações brasileiras: políticas de controle e determinantes da demanda. Rio de Janeiro, 1985. Dissertação (M.S.) 146p. - Pontifícia Universidade Católica.

DICKEY, D.A.; FULLER, W.A. Likelihood ratio statistics for auto-regressive time series with a unit root. Econometrica, v.49, n.4, p.1057-1072, 1981. 
ENDERS, W. Applied econometric time series. New York: John Wiley \& Sons, 2004. 460p.

ENGLE, R.F.; GRANGER, C.W.J. Co-integration and error correction representation, estimation and testing. Econometrica, v.55, n.2, p.251-276, 1987.

ENGLE, R.F.; HENDRY, D.F.; RICHARD, J.F. Exogeneity, causality and structural invariance in econometric modelling. Louvain-la-Neuve: Université Catholique de Louvain, 1980. Core Discussion Paper 8038)

ESTADOS UNIDOS. Departamento de Agricultura dos Estados Unidos da América. Working papers. http://www.usda.gov/wps/portal/usdahome (25 Oct. 2004)

FACHADA, J.P. Um estudo econométrico da balança comercial brasileira: 1975-1988. Rio de Janeiro, 1990. 98p. Dissertação (M.S.) - Pontifícia Universidade Católica.

FAO. Estatísticas agropecuárias. http://www.fao.org (05 May 2003 e 01 Sep. 2004)

FRANSES, P.H.; HALDRUP, N. The effects of additive outliers on tests for unit roots and cointegration. Florence: European University Institute, 1993. 24p. (EUI working paper ECO, 93/16)

FUNDAÇÃO GETÚlIO VARGAS (FGV). Dados IGP-DI. http://www.fgvdados.com.br. (15 out. 2001 e 03 set. 2004)

FUNDAÇÃO INSTITUTO DE PESQUISA ECONÔMICA (FIPE). Índice nacional de atividade. http://www.fipe.com.br/Home/Index.asp (01 nov. 2003)

GRANGER, C.W.J. Investigating causal relations by econometric models and cross espectral methods. Econometrica, v.37 n.3, p.434-38, 1969.

GREENE, E. Econometrics Analysis. New York: Prentice-Hall, 2001. 856p.

GREENSHIELDS, B.F. Changes in exchange rates: impact on US grain and soybean exports to Japan. Washington: US Department of Agriculture, Economic Reseach Service, July 1974. (FAER 364)

GUJARATI, D.N. Econometria básica. 3ª Ed. São Paulo: Makron Books, 2000. 846p. 
HARRIS, R. Using cointegration analysis in econometric modelling. London: Prentice Hall-Harvest Wheatsheaf, 1995. 234 p.

HAUSMAN, J.A. Specification and estimation of simultaneous equations models. In: GRILICHES, Z.; INTRILIGATOR, M. (Ed.). Handbook of econometrics, Amsterdam: North Holland, 1983. p 1234-1244.

HAUSMAN, J.A. Specification tests in econometrics. Econometrica, v.46, n.6, 1978. p.1251-1271.

HEMPHILL, W.L. The effect of foreign exchange receipts on imports of less developed countries, 1974, p.637-677. (IMF Staff Papers, 21)

HITIRIS, T.; PETOUSSIS, E. Price and tariff effects in a dynamic specification of the demand for imports. Applied Economics, 16, p.15-24, 1984.

INSTITUTO BRASILEIRO DE GEOGRAFIA E ESTATÍSTICA (IBGE). Dados do PIB trimestral. http//www.igbe.gov.br. (22 Out. 2001)

INSTITUTO BRASILEIRO DE GEOGRAFIA E ESTATÍSTICA (IBGE). Sidra. http://www.sidra.ibge.gov.br. (03 maio 2003)

INSTITUTO DE PESQUISA ECONÔMICA APLICADA (IPEA). Dados macroeconômicos. http://www.ipeadata.gov.br. (02 ago. 2003)

JANK, M.S. Contratos entre indústrias de produtores de leite. In: CONGRESSO NACIONAL DE LATICÍNIOS, 15, 1999, Juiz de Fora. Organização da produção primária: um desafio para a indústria de laticínios. Juiz de Fora: EPAMIG/Centro Tecnológico - ILTC, 1999. 283p.

JANK, M.S.; GALAN, V.B. Competitividade do sistema agroindustrial do leite no Brasil. In: JANK, M.S.; FARINA, E.M.Q. (Eds.). O agribusiness do leite no Brasil. São Paulo: Milkbizz, 1999. p.41-104.

JOHANSEN, S.; JUSELIUS, K. Maximum likelihood estimation and inference on cointegration - with aplications to the demand for money. Oxford Bulletin of Economics and Statistics, v.52, n. 2, p.169-219, 1990. 
JUDGE, G.G.; GRIFFITHS, W.E.; HILL, R.C.; LÜTKEPOHL, H.; LEE, T.C. The theory and practice of econometrics. New York: John Wiley \& Sons, 1985. 1200p.

KOOPMANS, T. C. Statistical inference in dynamic economic models. New York: John Wiley \& Sons, 1950. p.1-12: When is an equation system complete for statistical purpose?

LIRIO, V.S.; CAMPOS, A.C. Do Mercosul à Alca: impactos sobre as cadeias do agronegócio brasileiro. Viçosa: UFV, 2003. 203p.

LÜTKEPOHL, H. Introduction to multiple time series. Berlin: Springer-Verlag, 1991. $478 \mathrm{p}$.

MACHADO, J.B.; RIBEIRO, F.J. A crise do Mercosul: mudança cambial e conflitos comerciais. Revista Brasileira de Comércio Exterior, n.61, p.23-27, out./dez. 1999.

MARTINS, P.C. Políticas públicas e mercados deprimem o resultado do sistema agroindustrial do leite. Piracicaba, 2002. 217p. Tese (Doutorado) - Escola Superior de Agricultura “Luiz de Queiroz”, Universidade de São Paulo.

MARTINS, P.C.; GUILHOTO, J.J.M. Leite e derivados e a geração de emprego, renda e ICMS no contexto da economia brasileira. In: GOMES, A.T.; LEITE, J.L.B.; CARNEIRO, A.V. (Ed.). O agronegócio do leite no Brasil. Juiz de Fora: Embrapa Gado de Leite, 2001. p.179-205.

MARTINS, R.S.; SANTOS, C.V.; TEIXEIRA, S.R. Alterações da rede logística e expansão do mercado de leite longa vida no Brasil. http://www.dae.ufla.br/cedoc/artigo05299.doc (11 jun. 2001)

NAKANE, M.I. Testes de exogeneidade fraca e de superexogeneidade para a demanda por moeda no Brasil. Rio de Janeiro: BNDES, dez. 1994. 213p. (18º Prêmio BNDES de Economia) 
NEVES, B.S. Índices para conversão de produtos em equivalente leite de origem. Juiz de Fora: EPAMIG - Instituto Cândido Tostes, 2p.

ORDEN, D. A critique of exchange rate treatment in agricultural trade models: comment. American Journal of Agricultural Economics,v. 68, n.2, p.1234-1245, 1986.

ORGANIZAÇÃO DE COOPERAÇÃO E DESENVOLVIMENTO ECONÔMICO (OCDE). Subsídio equivalente ao produtor de leite. http://www.oecd.org (20 set. 2004)

OSAKI, M. Determinantes da oferta e da demanda por cebola Argentina no Brasil nos anos 90. Piracicaba, 2003. 101p. Dissertação (M.S.) - Escola de Agricultura "Luiz de Queiroz”, Universidade de São Paulo.

OSAKI, M.; BARROS, G.S.C. Determinação da demanda por importação da batata semente. In: CONGRESSO BRASILEIRO DE ECONOMIA E SOCIOLOGIA RURAL, 41 ${ }^{\mathrm{O}}$, Juiz de Fora. Anais. Juiz de Fora: SOBER, 2003.

PAIVA, C. Trade elasticities and market expectations in Brazil. Washington: IMF, July 2003. 22p. (Working Paper 140)

PERRON, P. The great crash, the oil price shock and the unit root hypothesis. Econometrica, v.57, n 6, p.1361-1401, Nov. 1989.

PERRON, P. The great crash, the oil price shock and the unit roots hypothesis. Econometrica, v.61, n.1, Jan. 1993. p.248-249.

PERRON, P. Trend, unit root and structural change in macroeconomic time series. In: RAO, B.B. Cointegration for the applied economist. New York: ST. Martin's Press, 1994. p.113-146.

PORTUGAL, L. Methodology for the measurement of support and use in policy evaluation. http://www.oecd.org (10 Sep. 2004)

PORTUGAL, M.S. Um modelo de correção de erros para a demanda de importações brasileira. Pesquisa e Planejamento Econômico, v.22, n.3, p 234-156. dez. 1992. 
REZENDE, M.F.C. Crescimento econômico, disponibilidade de divisas e importações totais e por categoria de uso no Brasil: um modelo de correção de erros. Rio de Janeiro: IPEA, 2000. 36p. ( Texto para Discussão, 714)

SCHMITZ, T.G.; SEALE JUNIOR, J.L. Import demand for disaggregated fresh fruits in Japan. Journal of Agricultural and Applied Economics, n.3, v.39, p.585-602, Dec. 2002.

SCHUH, G. E. The exchange rate and U.S. agriculture. American Journal of Agriculture Economics, v.56, n.1, p. 1-13, Feb. 1974.

SILVA, F.S.; BARROS, G.S.C. O saldo comercial do agronegócio brasileiro e seus determinantes. http://cepea.esalq.usp.br (10 out. 2003)

TANNÚS, S.P. Estabilização, abertura econômica e as importações brasileiras de leite, 1980-1998 (compact disc) n.17. In: CONGRESSO BRASILEIRO DE ECONOMIA E SOCIOLOGIA RURAL, Rio de Janeiro. Anais. Brasília: SOBER, 2000.

THORSTEnSEN, V. Organização Mundial do Comércio: as regras do comércio internacional e a rodada do milênio. São Paulo: Aduaneiras, 1999. 406p.

TURNBULL, A.D. Indústrias leiteiras da Nova Zelândia e o mercado global de laticínio. In: CASTRO, M.C. D. O agronegócio do leite e os alimentos funcionais. Juiz de Fora: EPAMIG/ILCT, 2001. p.17-34.

ZAGURY, S. Um modelo para o balanço de pagamentos: estimativas econométricas e projeções. Rio de Janeiro, 1994. 203 p.Dissertação (M.S.) - Universidade Pontifícia Católica.

ZINI JÚNIOR, A.A. Funções de exportação e de importação para o Brasil. Pesquisa e Planejamento Econômico, v.18, n.3, p.615-662, 1988. 